\title{
Numerical modeling of carbon dioxide injection at a pilot sequestration site
}

\author{
Benjamin David Bowes \\ West Virginia University
}

Follow this and additional works at: https://researchrepository.wvu.edu/etd

\section{Recommended Citation}

Bowes, Benjamin David, "Numerical modeling of carbon dioxide injection at a pilot sequestration site" (2013). Graduate Theses, Dissertations, and Problem Reports. 4953.

https://researchrepository.wvu.edu/etd/4953

This Thesis is protected by copyright and/or related rights. It has been brought to you by the The Research Repository @ WVU with permission from the rights-holder(s). You are free to use this Thesis in any way that is permitted by the copyright and related rights legislation that applies to your use. For other uses you must obtain permission from the rights-holder(s) directly, unless additional rights are indicated by a Creative Commons license in the record and/ or on the work itself. This Thesis has been accepted for inclusion in WVU Graduate Theses, Dissertations, and Problem Reports collection by an authorized administrator of The Research Repository @ WVU. For more information, please contact researchrepository@mail.wvu.edu. 


\title{
NUMERICAL MODELING OF CARBON DIOXIDE INJECTION AT A PILOT SEQUESTRATION SITE
}

\author{
Benjamin David Bowes
}

Thesis submitted to the

Benjamin M. Statler

College of Engineering and Mineral Resources

at West Virginia University

in partial fulfillment of the requirements

for the degree of

Master of Science

in

Civil \& Environmental Engineering

\author{
Hema J. Siriwardane, Ph.D., Chair \\ John D. Quaranta, Ph.D. \\ Thomas H. Wilson, Ph.D.
}

Morgantown, West Virginia

2013

Keywords: Coalbed Methane; $\mathrm{CO}_{2}$ Injection; Sequestration; Tracer; Modeling 


\section{ABSTRACT \\ Numerical Modeling of Carbon Dioxide Injection at a Pilot Sequestration Site}

\section{Benjamin David Bowes}

Over the past several years, lessons learned from various sequestration sites have identified deep, unmineable coal seams as favorable and profitable reservoirs for commercial carbon dioxide $\left(\mathrm{CO}_{2}\right)$ sequestration and long-term $\mathrm{CO}_{2}$ storage. Long-term consequences, however, have not been completely identified and understood. In order to assess the aptitude of such deep unmineable coal seams for a possible commercial sequestration site, a reservoir modeling study was performed at an ongoing Pump Canyon, NM sequestration site located in the coalbed methane (CBM) fairway region of the well-established San Juan basin. The demonstration at the Pump Canyon pilot area is a part of the Southwest Regional Partnership on $\mathrm{CO}_{2}$ sequestration sponsored by the U.S. Department of Energy to evaluate available technologies and practices to capture and store greenhouse gases such as $\mathrm{CO}_{2}$.

The present paper includes three objectives - (1) to study the history of CBM production in the region and construct an appropriate reservoir model based on the cleat geometry and available geological information, (2) to identify any unknown reservoir and geologic properties at the site through a history matching process, and (3) to model $\mathrm{CO}_{2}$ and tracer injections to aid in understanding fluid flow through the system.. CBM production data over past two decades demonstrates an adequate facility for deploying the first commercial sequestration in the San Juan basin. A reservoir model was constructed using a modified existing simulator and based on available reservoir and geologic data. Several simulations were performed to obtain a historymatch and analyze the $\mathrm{CBM}$ production history before and after $\mathrm{CO}_{2}$ injection. During $\mathrm{CO}_{2}$ injection a tracer was injected into the reservoir for tracking purposes. The tracer's movement through the reservoir system was tracked using data from nearby producing wells. Tracer breakthrough occurred when nearby wells began to produce significant quantities of the injected tracer. Several simulations were performed to obtain matches with breakthrough data and tracer properties and further refine the model. The successful performance of this reservoir identifies the San Juan basin as a promising site for commercial sequestration of carbon dioxide. 


\title{
This thesis is dedicated to
}

\author{
my Cate grandmother,
}

\section{Venita Bowes}

It was her greatest belief that learning was a lifelong process and she always urged me to learn as much as I could and reach for the stars. Through her actions she taught me that no amount of trial and tribulation can stop a person with iron will, and in tough times it is her memory that keeps me going. It is my most sincere wish that when my time here has passed someone may compare me to my grandmother, for in my eyes there could be no greater honor. 


\section{ACKNOWLEDGEMENTS}

I am very thankful for Dr. Hema Siriwardane, my research advisor and graduate committee chairman. His guidance and encouragement throughout the many stages of this project have been instrumental. I also wish to sincerely thank Dr. Thomas Wilson and Dr. John Quaranta for serving as members of my graduate committee and for reviewing this report.

I would like to express my gratitude to the United States Department of Energy for funding this project through a graduate research assistantship at West Virginia University. I would also like to thank my friends and coworkers at West Virginia University: Raj Gondle, Rupesh Gondle, Sai Bharath Varre, Sumanth Gundagatti, Andrew Dietz, Laura Sesack, Rajesh Tolikonda, and Jeremi Stawovy among countless others. Their support and influence has been very much appreciated.

Finally I would like to thank my family and friends for all the love and support I have received over the years. Words cannot express the gratitude I have for my family; without them I would never have been in the position to write this report, and for that I am forever grateful. I would also like to offer my deepest thanks to each and every one of my friends. I could write a book about all the wonderful things they have done for me, but suffice it to say that this work would not have been without their support. Finally a big thank you to my loving girlfriend Loran Thistlethwaite; she never got tired of hearing me say "it won't be like this for long" and for that I am blessed. 


\section{TABLE OF CONTENTS}

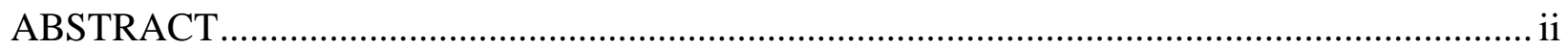

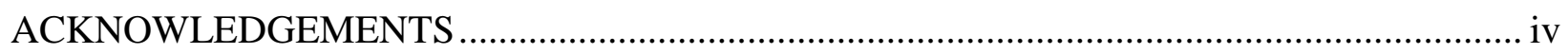

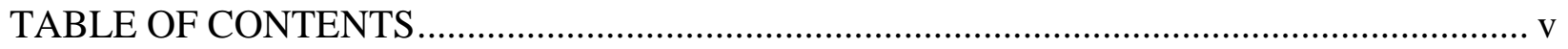

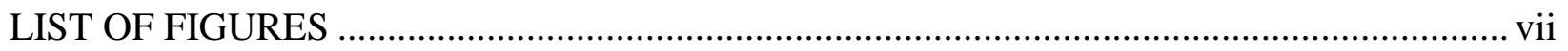

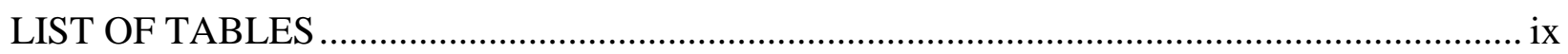

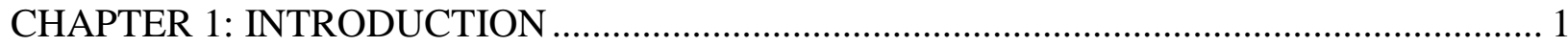

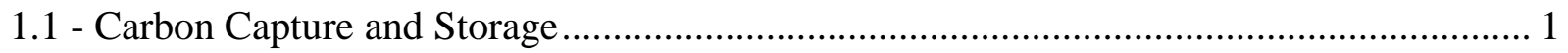

1.2 - Carbon Sequestration into Coal Seams ....................................................................... 2

1.3 - Scope of Work

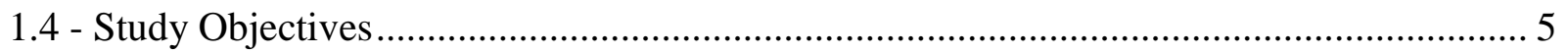

CHAPTER 2: COALBED METHANE RECOVERY AND CARBON SEQUESTRATION

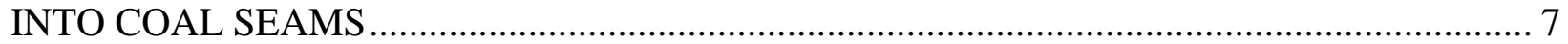

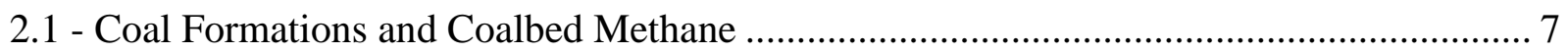

2.2 - Fluid Storage and Transport in Coal Seams ……….......................................................... 9

2.3 - Coalbed Methane Production ................................................................................. 12

2.4 - Carbon Sequestration and Enhanced Coalbed Methane Recovery in Coals .................... 13

2.5 - Storage Capacity of Coal Formations.......................................................................... 14

2.6 - Swelling and Shrinkage of Coals............................................................................ 16

CHAPTER 3: DESCRIPTION OF THE PUMP CANYON SEQUESTRATION SITE .............. 18

3.1 - Location of the Pump Canyon Field Site....................................................................... 18

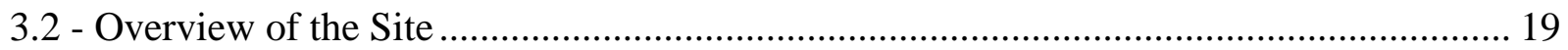

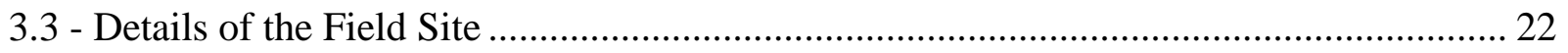

3.4 - Production History of the Pump Canyon Reservoir ........................................................ 23

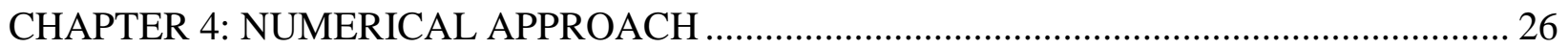

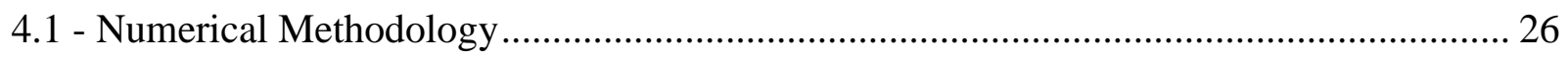

4.2 - Modified PSU-COALCOMP Reservoir Simulator …………………………………........ 29

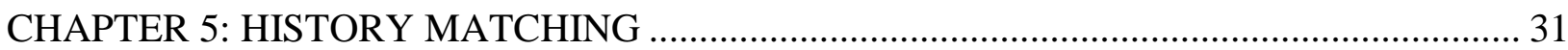

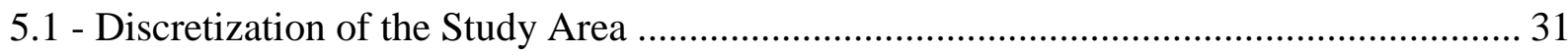

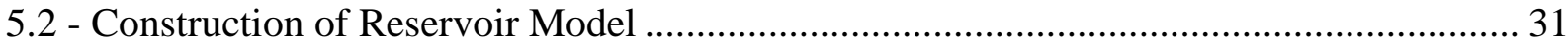

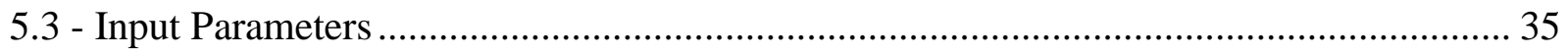


CHAPTER 6: MODELING CARBON DIOXIDE INJECTION …………………….................. 46

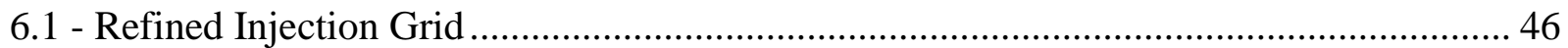

6.2 - Overview of Field Injection........................................................................................ 47

6.3 - Simulating Injection of Carbon Dioxide ....................................................................... 52

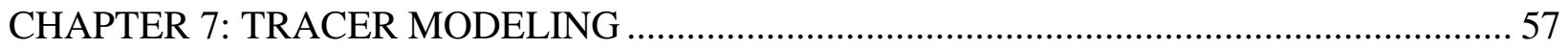

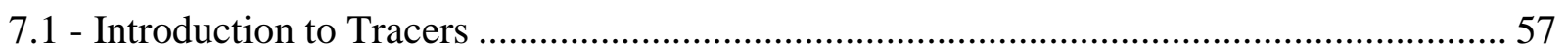

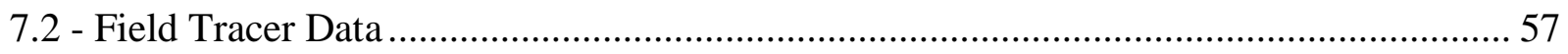

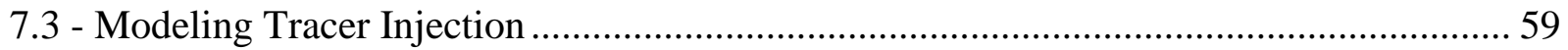

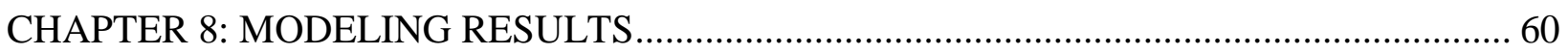

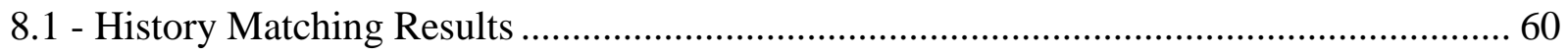



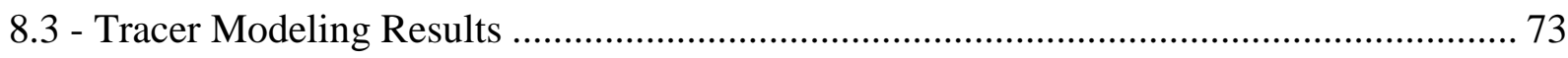

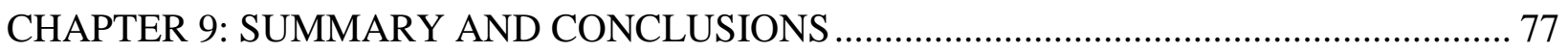

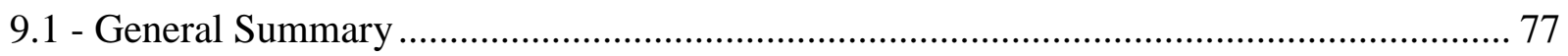

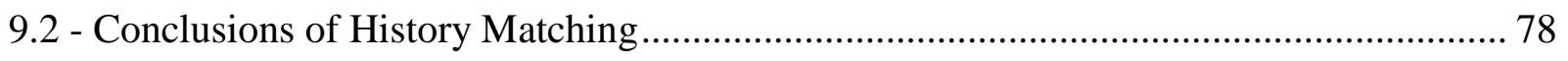

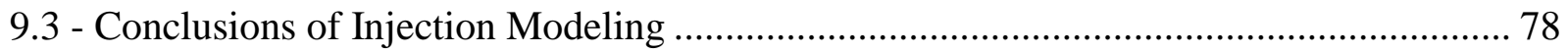

9.4 - Conclusions of Tracer Modeling ……………………............................................... 79

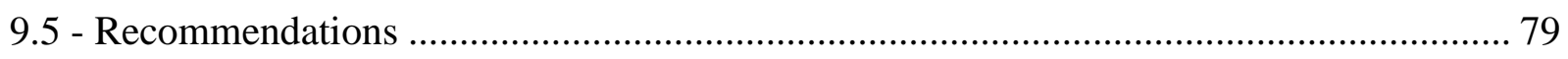

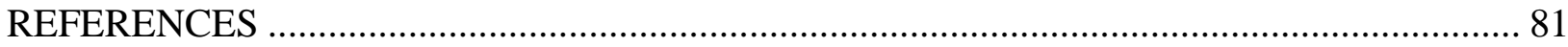




\section{LIST OF FIGURES}

Figure 1.1: Conceptual Diagram of a Sequestration Project....................................................... 4

Figure 2.1: Coal reserves in the Unites States of America (www.eia.doe.gov) ………................. 8

Figure 2.2: Schematic Diagram of a Coal Formation .............................................................. 10

Figure 2.3: Schematic Diagram of CBM Movement Through a Coal Formation ......................... 12

Figure 2.4: A typical Langmuir Isotherm for a Coalbed Methane Reservoir ............................... 16

Figure 2.5: The Effects of Swelling and Shrinkage on Coal Formations ..................................... 17

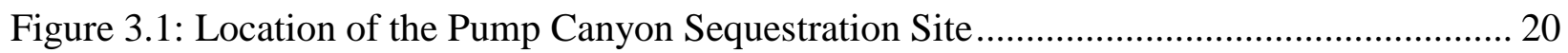

Figure 3.2: Proximity of Pump Canyon to Existing Pipelines..................................................... 21

Figure 3.3: Geologic Formation in the Pump Canyon Region (Stone et al, 1983) ....................... 22

Figure 3.4: Gantt Chart Showing the Production Timeline of the Study Area ............................ 25

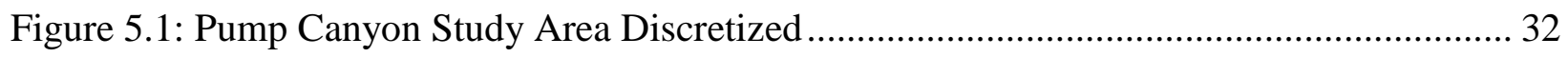

Figure 5.2: The Pump Canyon Finite Difference Grid .......................................................... 33

Figure 5.3: Pump Canyon Grid Rotated to Account for Cleat Orientation .................................. 35

Figure 5.4: Estimated Initial Coal Porosity of the Pump Canyon Reservoir ................................ 39

Figure 5.5: Estimated Initial Face Cleat Coal Permeability of the Pump Canyon Reservoir ....... 40

Figure 5.6: Bottomhole Pressure Data from Wells in the Study Area.......................................... 41

Figure 6.1: Location of the Refined Grid Relative to the History Matching Grid......................... 47

Figure 6.2: Refined Grid used for Injection Modeling ............................................................ 48

Figure 6.3: Refined Grid Rotated to Account for Cleat Orientation............................................... 49

Figure 6.4: Refined Finite Difference Grids for Injection Modeling........................................... 50

Figure 6.5: Field Measured Injection Pressures and Rates ......................................................... 51

Figure 6.6: Initial Reservoir Porosity for the Refined Grid ....................................................... 52

Figure 6.7: Initial Reservoir Face Cleat Permeability for the Refined Grid .............................. 53

Figure 6.8: Initial Reservoir Pressure for the Refined Grid...................................................... 54

Figure 6.9: Initial Reservoir Water Saturation for the Refined Grid ........................................... 55

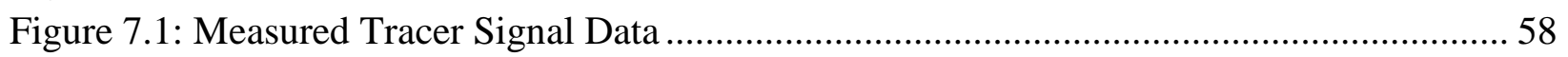

Figure 8.1: Finite Difference Grid Used for History Matching .................................................... 62

Figure 8.2: Influence of Reservoir Anisotropy on Cumulative CBM Production ......................... 63

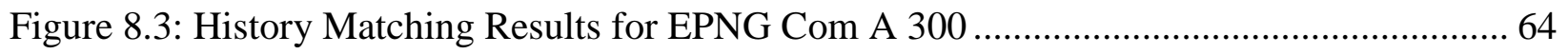

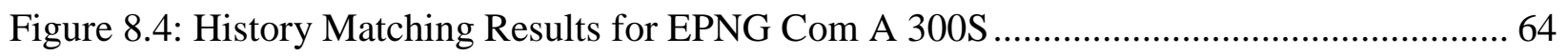

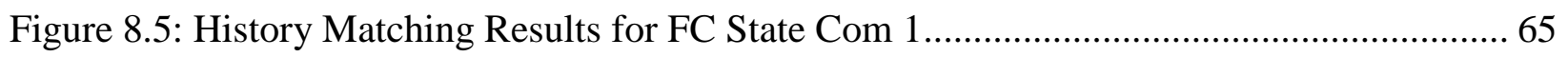

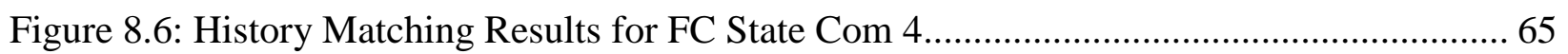

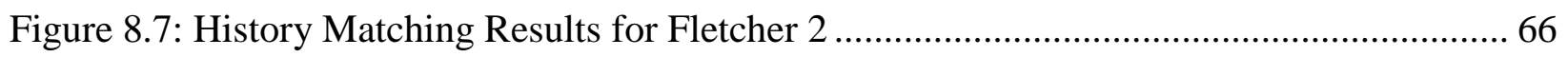

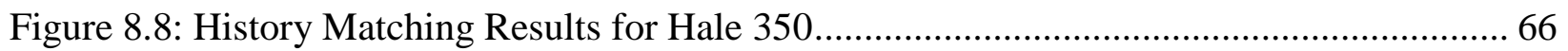

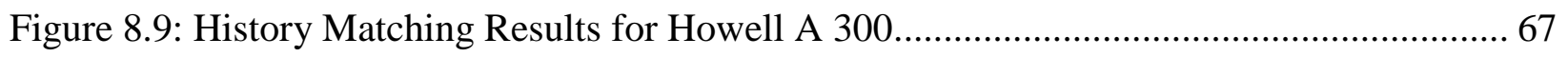

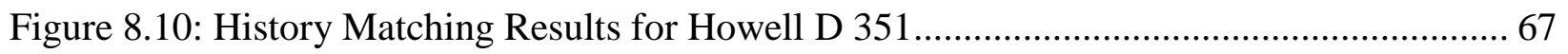

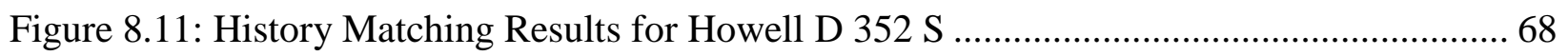

Figure 8.12: History Matching Results for Total CBM Production .......................................... 68 
Figure 8.13: Comparison of Measured and Simulated Reservoir Pressures............................. 71

Figure 8.14: Comparison of Measured and Simulated Injection Pressures .............................. 72

Figure 8.15: Pressure Distribution During Injection of Carbon Dioxide.................................. 73

Figure 8.16: Simulated and Measured Tracer Production at FC State Com 1 ......................... 74

Figure 8.17: Simulated and Measured Tracer Production at EPNG Com A 300 ...................... 75

Figure 8.18: Influence of Volume of Injected Tracer on Relative Tracer Production at FC State

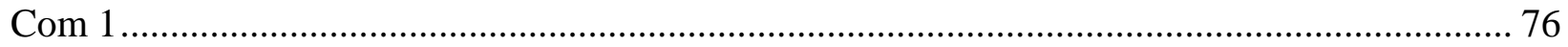




\section{LIST OF TABLES}

Table 3.1: Gas Content, Formation Thickness, and Coal Density data for the Fruitland Coals ... 19

Table 5.1: Index of Production Wells in the Study Area .......................................................... 34

Table 5.2: Properties used for History Matching ................................................................. 37

Table 5.3: Gas Content, Thickness, and Density Data for the Fruitland Coals ......................... 43

Table 5.4: Gas Properties of Carbon Dioxide and Methane ................................................... 44

Table 6.1: Index of Wells in the Refined Injection Grid .................................................... 51

Table 6.2: Input Parameters used for Injection Modeling ..................................................... 56

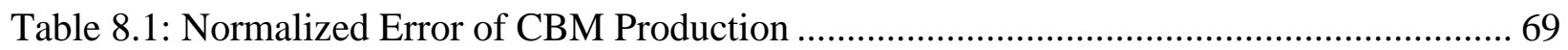

Table 8.2: Square of the Normalized Error of CBM Production ............................................. 69

Table 8.3: Coefficient of Correlation of CBM Production ..................................................... 70

Table 8.4: Summary of Statistics of CBM Production ....................................................... 70 


\section{CHAPTER 1: INTRODUCTION}

\section{1 - Carbon Capture and Storage}

The earth's atmosphere keeps temperatures on our planet stable by a delicate balance of receiving and emitting infrared radiation from the sun. Sunlight passes through our atmosphere and reflects off of the earth and back out into space. The balance of transferred radiation is what keeps the earth's temperature roughly constant. With the rise of industrialization, however, came increasing concentrations of greenhouse gases. Greenhouse gases are chemical compounds that settle in our atmosphere and allow infrared radiation to enter via sunlight and then absorb the reflected radiation and trap the heat inside. In recent years there has been a steady rise in global temperatures due to emissions of greenhouse gases. Carbon dioxide is considered the single largest contributor to greenhouse gas emissions. In the United States, carbon dioxide accounts for over $80 \%$ of all greenhouse gas emissions (U.S. DOE Atlas, 2007).

Carbon dioxide in the earth's atmosphere comes from both manmade and natural sources. Volcanic eruptions, atmospheric exchanges with the ocean, and flora and fauna respiration all naturally produce carbon dioxide. Emissions containing carbon dioxide are also the direct result of many common industrial, commercial, and agricultural applications. Combustion of fossil fuels, mass power production, and various manufacturing processes all produce carbon dioxide as a byproduct.

Earth is kept at an inhabitable temperature by an atmospheric layer of greenhouse gases. This layer allows radiation from the sun to enter the atmosphere and traps it inside. In recent years there has been a steady rise in global temperatures due to emissions of greenhouse gases. Atmospheric levels of carbon dioxide have been increased in due to worldwide industrialization. Carbon dioxide concentration in the atmosphere has risen to over $375 \mathrm{ppm}$ today, much higher than the concentration recorded in 1750 of $280 \mathrm{ppm}$ (www.CO ${ }_{2}$ NOW.org; IPCC, 2007). Such evidence suggests that reducing carbon dioxide emissions into the atmosphere is an urgent and worldwide problem. 
Options for reducing greenhouse emissions are hindered by the world's reliance on fossil fuels. Ultimately, clean energy sources are the only option for greenhouse gas abatement. It will be years, however, before fossil fuels are overtaken as the primary energy producer worldwide. Current options focus on the capture and storage of carbon dioxide from emissions. Geologic sequestration is one option for long term carbon dioxide storage. Carbon dioxide has previously been sequestered in depleted oil and gas reservoirs, deep saline aquifers, and deep unmineable coal seams. Another option is deep ocean storage. Carbon dioxide is heavier than water and as a result will sink to the bottom when large amounts are introduced to the ocean. There are several uncertainties with deep ocean storage and currently such operations are not widely practiced. Options for long term storage of carbon dioxide exist, however many of these options are still being developed and perfected.

With carbon dioxide making up such a large percentage of greenhouse gas emissions, worldwide efforts have been increased to find a way to safely capture and permanently store carbon dioxide. Carbon capture can vary in difficulty depending on the nature of the emissions. There are a number of capture techniques available and several new and promising technologies in the development stage. The fundamental concept is to separate the carbon dioxide from other emissions. The pure carbon dioxide gathered in the capture stage must be compressed to a supercritical state. From there the carbon dioxide is stored and piped to wherever its permanent storage location will be. Finding permanent storage for the massive amounts of carbon dioxide is a tougher task than carbon capture, and is discussed further in subsequent sections.

\section{2 - Carbon Sequestration into Coal Seams}

Carbon sequestration is the storage of carbon dioxide in undergrounds reservoirs. Compressed carbon dioxide is pumped into the ground through an injection well into a geologic formation for long term and potentially permanent storage. Carbon sequestration would allow our society to continue the use of existing technologies that are dependent on fossil fuels while newer clean energy sources are being explored and developed. Sequestering carbon into coal formations is a promising option for long term and permanent carbon dioxide storage needs. 
Carbon sequestration into coals focuses on deep unmineable coal seams. These formations may be unmineable due to extreme depths, poor quality of coal, and a number of other factors. Such coals, however, are often used for methane production. The pore spaces in coals initially contain water and methane. After removing these fluids, the remaining coal matrix offers an excellent storage opportunity. After the drilling and production processes have run their course plenty of data on the geology of the area and the reservoir is available. The current study focuses on carbon sequestration into a deep unmineable coal seam.

Carbon sequestration into coal formations is a relatively new and promising technique. Deep unmineable coal seams are an ideal target for sequestration projects. Such formations initially contain water and methane gas. After enough water is removed from the formation, methane gas can be produced from wells drilled into the coal. After methane production reaches a peak, a drop in gas production from the coal seam is observed. As the reservoir pressure depletes, the storage potential of the formation increases due to more unoccupied pore space in the coal seam. Injection of carbon dioxide into a depleted reservoir not only provides a storage option for carbon dioxide, but produced enhanced coalbed methane recovery as a result. A conceptual diagram showing a hypothetical carbon sequestration project is shown in Figure 1.1. More information on coalbed methane and enhanced coalbed methane recovery is available in subsequent sections.

Sequestration into coal formations also entails some challenges and uncertainties. Coal is a heterogeneous material and one formation can have properties that differ spatially. In addition, swelling and shrinkage of the coal matrix due to injection of carbon dioxide can have a profound effect on reservoir behavior during sequestration activities. Swelling and shrinkage of coal formations is covered more in depth in subsequent sections. 




Figure 1.1: Conceptual Diagram of a Sequestration Project

\section{3 - Scope of Work}

In this report, an attempt has been made to model the past and future behavior of the Pump Canyon coalbed methane reservoir with an overall goal of assessing the suitability of the site for a large scale injection project. Available geologic data and historical production data was incorporated into a reservoir model and several simulations were run to determine unknown reservoir properties and their influence on reservoir behavior. After an accepTable history match was obtained, the injection of carbon dioxide and injected tracers was modeled as well. Special attention was paid to the influence of swelling and shrinkage of the coal matrix on injectivity of the reservoir. Reservoir modeling work at the Pump Canyon site is vital to a successful operation. While data for the study area is plentiful, there are always uncertainties when it 
comes to dealing with a geologic formation a few thousand feet underground. While the field operations are the ultimate goal of the project, having a reliable reservoir model can help investigate discrepancies noticed in the field. Having a foothold in both the theoretical side and the field side of a sequestration project will result in a more efficient operation, and reservoir modeling is a vital part of that puzzle.

\section{4 - Study Objectives}

The Pump Canyon Sequestration site was selected to assess the suitability of deep unmineable coal seams for possible commercial scale sequestration operations and long term storage of carbon dioxide. This site is a part of the southwest regional partnership. The southwest regional partnership is one of seven regional partnerships that is working in conjunction with, and sponsored by, the United Stated Department of Energy. The Pump Canyon sequestration demonstration site is located in the San Juan basin in Northern New Mexico.

Understanding the behavior of the Pump Canyon reservoir during sequestration activities could prove to be invaluable. The present study focuses on the numerical modeling of the Pump Canyon sequestration site. Reservoir modeling is an integral part in piecing together the puzzle. It is vital to supplement field operations with a theoretical investigation to gain a thorough understanding of the complicated reservoir system and to try and predict future behavior under different conditions. Objectives for this project include:

- Study the history of coalbed methane production in the study area

- Construct an appropriate reservoir model based on available geologic data

- Perform history matching to obtain estimates of unknown properties

- Model the injection of carbon dioxide into the reservoir to and the behavior of the reservoir system 
- Monitor the movement of tracers injected into the reservoir to better understand the response of the reservoir system

- Investigate the swelling and shrinkage of coals and the impact of swelling and shrinkage on sequestration practices 


\section{CHAPTER 2: COALBED METHANE RECOVERY AND CARBON SEQUESTRATION INTO COAL SEAMS}

\section{1 - Coal Formations and Coalbed Methane}

Coal formations are a major contributor to energy needs both on a national and global level. Currently about one quarter of the energy used in the United States comes from coal and roughly half of the electricity used in the United States comes from coal sources (www.teachcoal.org). The Unites States alone produces approximately one fifth of the world's coal which ranks second only to China (www.teachcoal.org). Energy from coal is a vital part of not only the American financial and industrial sectors, but for the world's as well.

Natural gas, usually methane, is also a commonly used source of energy. Methane is a molecule consisting of one carbon atom surrounded by four hydrogen atoms. Due to its simple chemical formula it produces few byproducts when burned, mainly water and carbon dioxide. Natural gas is another large producer of energy in the United States. Natural gas accounts for slightly less than one quarter of energy consumption in the Unites States (www.pge.com). The United States accounts for nearly one quarter of the world's natural gas consumption as well (www.pge.com).

Coal is a sedimentary formation that is formed by the preservation of organic material. Coal formations were created long ago when organic material was gathered in a swampy environment. The oxygen deprived environment of swampy water kept the organic material from decaying and over time as the low lying areas flooded, sediments washed in and covered it up. As time went on and resulting overburden pressures increased, the organic material evolved into coal, oil, and natural gas. This process is known as coalification (Cervik, 1969). The result of the coalification process is a geologic layer rich in organic material and full of internal energy. Such energy sources are known as fossil fuels, and are vital to everyday life in modern society.

Coal formations and natural gas deposits can be found all over the world. Figure 1 shows the significant coal deposits in the United States of America. Coal mining operations extract coal reserves from the ground in cases where the coal quality, depth, and quantity make such endeavors profitable. Underground mining is a vital part of our nation's energy supply. Due to 
the way they are formed, coal formations generally contain methane, known as coalbed methane when taken from coals. Due to its volatile nature, coalbed methane is a major source of concern in the underground mining industry; however methane is a valuable gas and in coals that cannot be mined methane is often produced from the formation.

Coal is used in a variety of applications, but first and foremost is as an energy source. Electricity and heat are the primary uses of coal energy. Although electricity generation is the primary consumer of coal reserves, many other processes and systems require coal to work properly. Steel production requires significant quantities of coal. Coal is also used in the manufacturing of cement which is the binding material present in concrete. Fly ash, a byproduct of coal combustion, is also commonly added to concrete mixtures used in various construction practices.

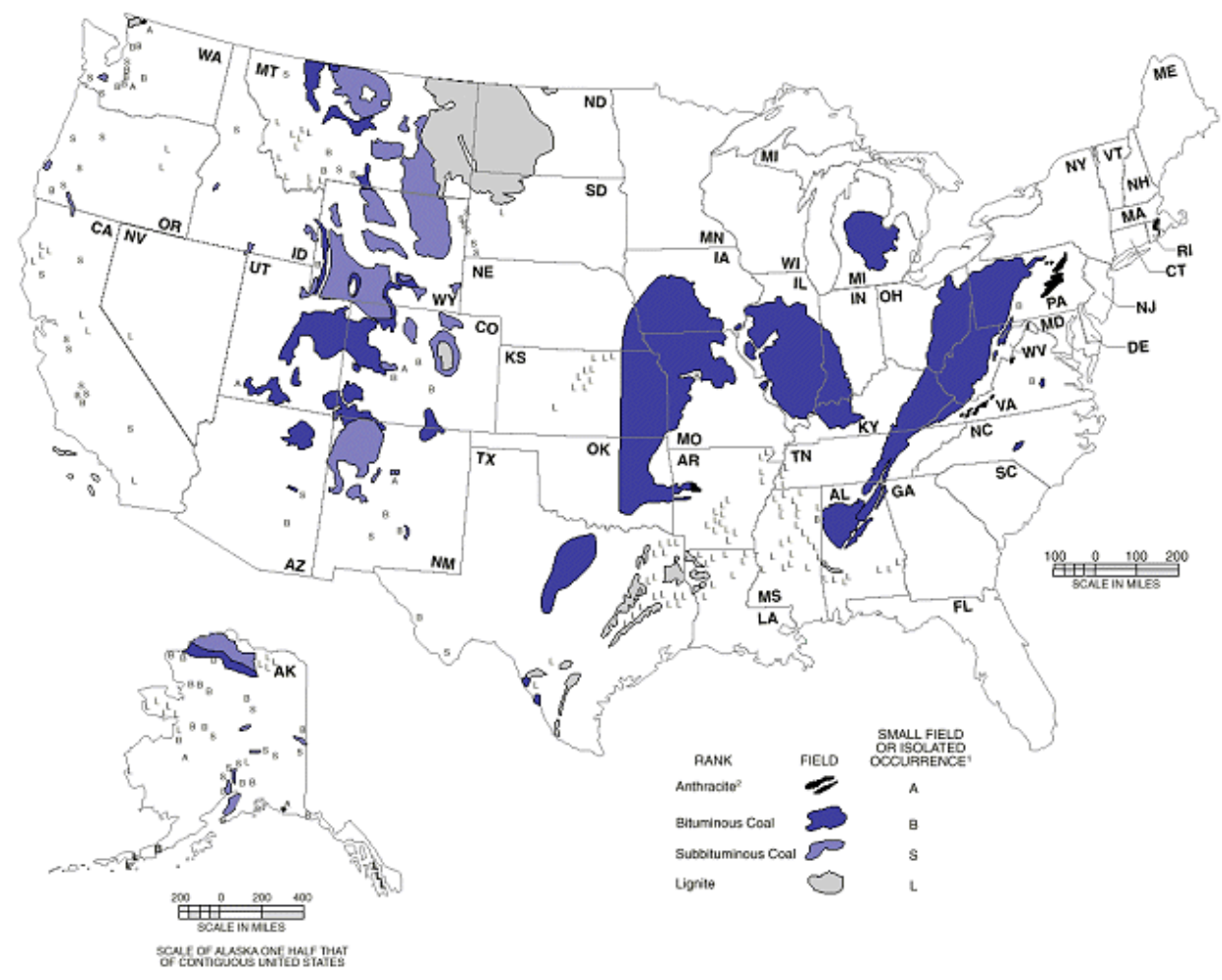

Figure 2.1: Coal reserves in the Unites States of America (www.eia.doe.gov) 
Natural gas is also a widely used source of energy. Coalbed methane can be used to produce power in gas turbine plant. The residential sector accounts for a significant portion of natural gas usage as well; natural gas can be used to heat a home, run a kitchen appliance, or fuel a hot water heater. Due to its relatively clean combustion, natural gas is delving into non traditional industries as well. Auto and aircraft makers have begun to experiment with vehicles powered by natural gas and the development of such technologies is ever growing.

Some coals are unmineable due to extreme depths, poor quality, or any number of factors that could combine to make a mining operation unfeasible (Winschel and Scandrol, 2007). In such cases, it is a common practice to produce coalbed methane from the coal formation. Production wells are drilled into the coal layer and methane trapped in the formation is pumped up to the ground surface where it is captured and stored. Natural gas production from deep unmineable coal seams in covered more in depth in subsequent sections.

\section{2 - Fluid Storage and Transport in Coal Seams}

Coal is a naturally fractured, dual porosity geologic formation (Rogers, 1994). Coal formations consist of system of coal blocks separated by a network of fractures known as cleats (Rogers, 1994). Face cleats generally have a wider aperture opening and are continuous while butt cleats have slightly smaller and non-continuous aperture sizes and are oriented orthogonally to face cleats. There are two distinct entities in a coal formation, the micropore space of the coal where coalbed methane is stored and the macropore space where fluid transport takes place. Figure 2.2 shows a schematic diagram of coal structure and the corresponding cleat network

Coalbed methane is stored in coal formations by two processes: compression and adsorption. Initially, some free gas may be present in the macropore space of a coalbed methane reservoir. Since the reservoir is under pressure and water initially fills the cleat network, however, any methane in the cleats is unable to move through the formation and is trapped. The trapped gas will remain held in the macropores of the coal seam until the reservoir experiences a reduction in pressure, removal of water from the cleat network, or a combination of both. 


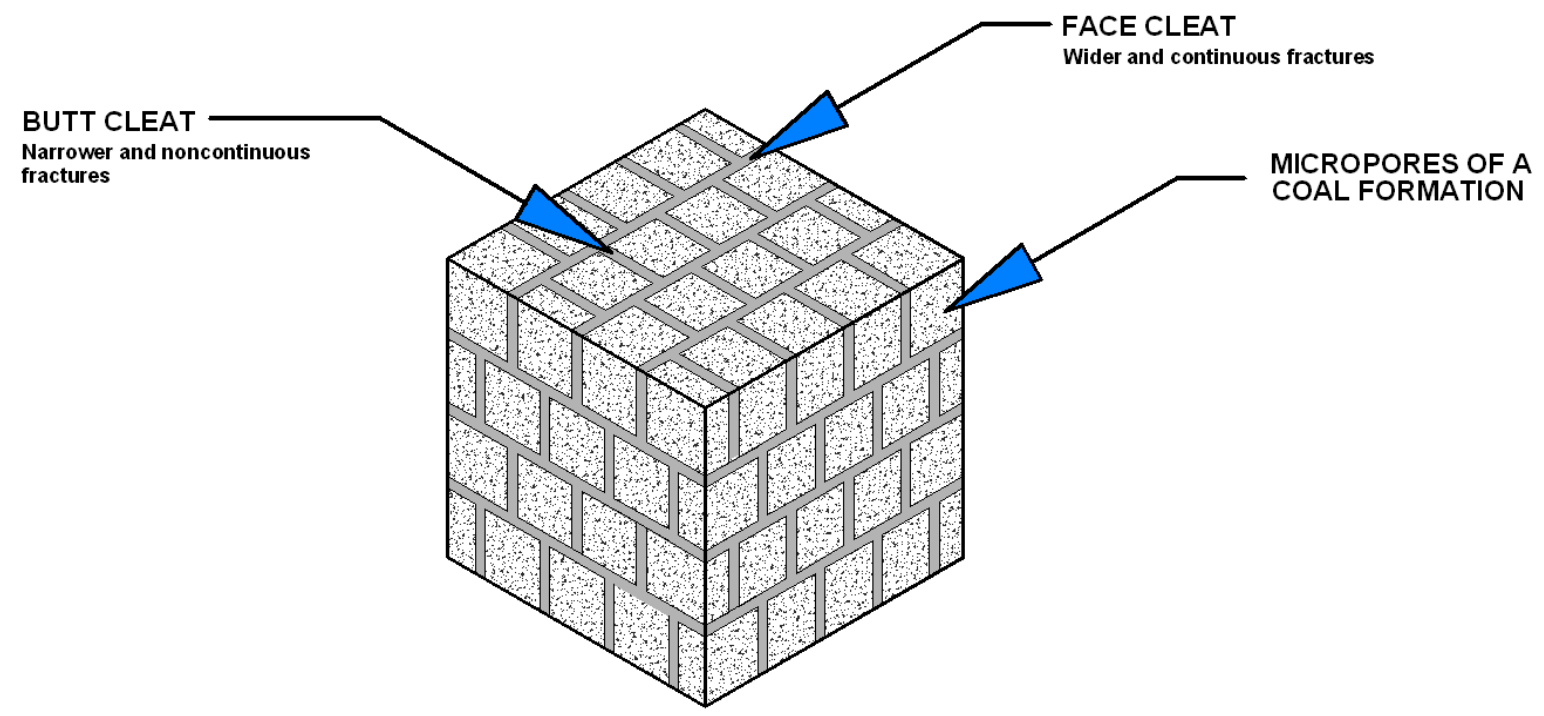

Figure 2.2: Schematic Diagram of a Coal Formation

The majority of natural gas stored in a coal seam is found in the micropores of the coal formation. The coal adsorbs the coalbed methane and stores it internally. Coalbed methane is held on the internal surface area of the micorpores in the coal structure by adsorption (McElhiney et al, 1989). Coals can have a very high internal surface area and can hold a significant quantity of natural gas within its structure.

Coalbed methane is transported through the cleat network in a coal formation. When the reservoir is initially saturated, no transport can take place due to the presence of water in the cleats. With the dewatering complete, coalbed methane can begin to diffuse into the cleat network. The diffusion process is governed by Frick's Law (Cervik, 1969). In accordance with Frick's Law, flow of the diffused gas is controlled by the difference in methane concentrations between the micropores and the macropores in the coal structure. Frick's Law is shown below in Equation 2.1. After the coalbed methane has been desorbed and diffused into the cleat network, the gas can flow to the wellbore. Transport in the cleat network obeys Darcy's Law of flow through porous media (Cervik, 1969). Once coalbed methane enters the cleat network, fluid flow is controlled by pressure gradient per Darcy's Law. The difference in reservoir pressure and the pressure in the wellbore determines the direction of flow and the rate at which gas moves through the reservoir. Darcy's Law is presented in Equation 2.2. Figure 2.3 shows a schematic 
diagram of coalbed methane desorbing from the coal matrix and travelling through the cleat network towards the wellbore.

$$
q^{\prime}=-D A \frac{d C}{d L}
$$

where,

$$
\begin{aligned}
& q^{\prime}=\text { Rate of gas flow through coal micropores } \\
& D=\text { Diffusion coefficient } \\
& A=\text { Cross-sectional area } \\
& C=\mathrm{CH}_{4} \text { concentration in the coal } \\
& \mathrm{L}=\text { Length }
\end{aligned}
$$

$$
q=-\frac{k A}{\mu} \frac{d P}{d L}
$$

where,

$$
\begin{aligned}
& \mathrm{q}=\text { Rate of gas flow through the cleat network } \\
& \mathrm{k}=\text { Fracture permeability of the coal } \\
& \mathrm{A}=\text { Cross-sectional area }
\end{aligned}
$$




$$
\begin{aligned}
& \mu=\text { Viscosity of the gas } \\
& \mathrm{P}=\mathrm{CH}_{4} \text { Pressure } \\
& \mathrm{L}=\text { Length }
\end{aligned}
$$

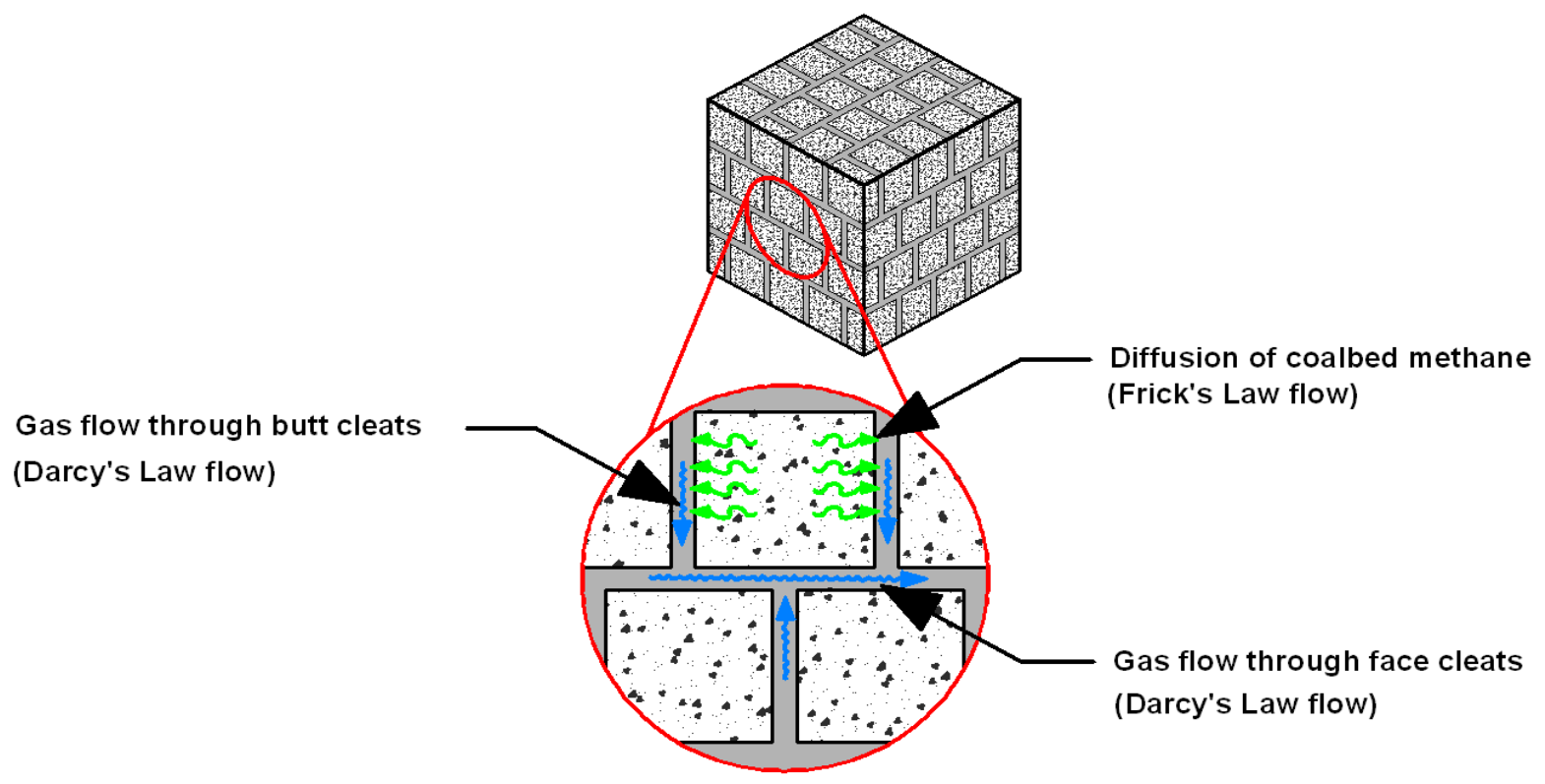

Figure 2.3: Schematic Diagram of CBM Movement Through a Coal Formation

\section{3 - Coalbed Methane Production}

After a coalbed methane reservoir has been identified and selected for use, a production well must be drilled into the target formation. Required drilling depth, well complexity, and subsurface composition vary from well to well; therefore each drilling project is unique. After the well is drilled and secured, production operations can begin.

After successful completion of a production well, dewatering is the next critical step. Initially, most coal formations are saturated with water. This water fills the fractures and prevents any coalbed methane from moving through the cleat network. To open the apertures 
and allow coalbed methane to flow through to the well, some water must be removed first. After sufficient water removal, production of coalbed methane follows.

After dewatering is complete and coalbed methane production begins, a rise in gas production rate is observed. Differing pressures in the well and the reservoir below will cause coalbed methane to flow through the cleat network and into the production well. After an initial rise in gas production, a maximum production rate is reached and rates thereafter follow a steady decline due to reduction of reservoir pressure in the coal formation.

Some significant changes in the reservoir take place while the production life cycle runs its course. Pressure in the reservoir was initially due to a combination off stresses from the weight of overburden material and a good reservoir seal which prevents any passageways for pressure relief. As production begins, however, reservoir pressure steadily drops until it reaches depletion and coalbed methane production rates fall off.

\section{4 - Carbon Sequestration and Enhanced Coalbed Methane Recovery in Coals}

Carbon sequestration into a depleted coalbed methane reservoir is a promising option for long term carbon dioxide storage. After a production well has been run its course and reservoir pressures begin to decrease with methane production rates, a considerable amount of pore space in the coal is available for storage. This space was initially filled with water and/or coalbed methane. Available pore space in conjunction with coal's high affinity for the adsorption of coalbed methane combine to offer a great sequestration opportunity for carbon dioxide. Carbon dioxide that has been captured and compressed can be injected into such depleted reservoirs for permanent storage.

Enhanced coalbed methane recovery is a techniques used to stimulate methane production from a well that has reached its maximum production rate and is nearing depletion. In an enhanced coalbed methane recovery project, carbon dioxide is pumped into a depleting reservoir to flush the methane out of the formation. Coal has been shown to have a higher affinity for adsorption of carbon dioxide than methane (Burruss, 2003). As a result, when carbon dioxide is introduced into a coalbed methane reservoir the micropores of the coal desorb the 
methane initially contained in the coal and adsorb the carbon dioxide. This released methane can then move through the cleat network and up the production well. Enhanced coalbed methane recovery is a common practice in older reservoirs that are nearing the end of their life cycle.

Enhanced coalbed methane recovery is an advantage to sequestering carbon dioxide into deep, unmineable coal seams. After production tails off and sequestration begins, the remaining coalbed methane present in the reservoir is released as a result of the coal adsorbing the carbon dioxide. This can lead to increased methane production levels at production wells in the region. This additional coalbed methane production can help offset costs associated with sequestration projects of this nature. More information on enhanced coalbed methane recovery in sequestration projects can be found elsewhere (Gale and Freund, 2001; Smith et al, 2004).

\section{5 - Storage Capacity of Coal Formations}

In order to adequately characterize any coalbed methane reservoir, an estimate of storage capacity is necessary. Several reservoir properties and characteristics must be taken into consideration when determining initial estimates of gas in a reservoir including geometry of the target coal formation, previous production on the region, and configuration of existing wells among others. Two quantities commonly used to describe the potential of coalbed methane in coal seams are estimates of initial gas in place (IGIP) and producible gas in place (PGIP); Equations for these quantities are shown in Equations 2.3 and 2.4, respectively. More on storage capacity calculations can be found elsewhere (Bachuet al 2007) .

The volume of gas contained in a coalbed methane reservoir changes with the pressure in the formation. The relationship between gas stored and pressure is given by the Langmuir isotherm (Langmuir, 1918). Figure 2.4 shows a typical Langmuir isotherm. Two key parameters in determining potential storage of a reservoir are given by this curve, the Langmuir volume $\left(\mathrm{V}_{\mathrm{L}}\right)$ and Langmuir pressure $\left(\mathrm{P}_{\mathrm{L}}\right)$. Langmuir volume is the maximum amount of gas that can be stored in a given coal at infinite pressures and Langmuir pressure is defined as the pressure at which half of that Langmuir volume is stored. The Langmuir isotherm can be produced for a given coal formation by analyzing core samples gathered from the coal seam of interest. More on isotherms can be found elsewhere (Bromhal et al, 2005). 
where,

$$
\begin{aligned}
& \text { IGIP = Initial gas in place } \\
& A=\text { Area of the coal } \\
& h=\text { Effective thickness of the coal } \\
& \rho=\text { Bulk density of the coal } \\
& G_{c}=\text { Gas content of the coal basin } \\
& \mathrm{f}_{\mathrm{a}}, \mathrm{f}_{\mathrm{m}}=\text { Fractions of ash and moisture content }
\end{aligned}
$$

where,

$$
\begin{aligned}
& \text { IGIP = Producible gas in place } \\
& \mathrm{R}_{\mathrm{f}}=\text { Recovery factor } \\
& \mathrm{C}=\text { Completion factor } \\
& \text { IGIP = Initial gas in place }
\end{aligned}
$$




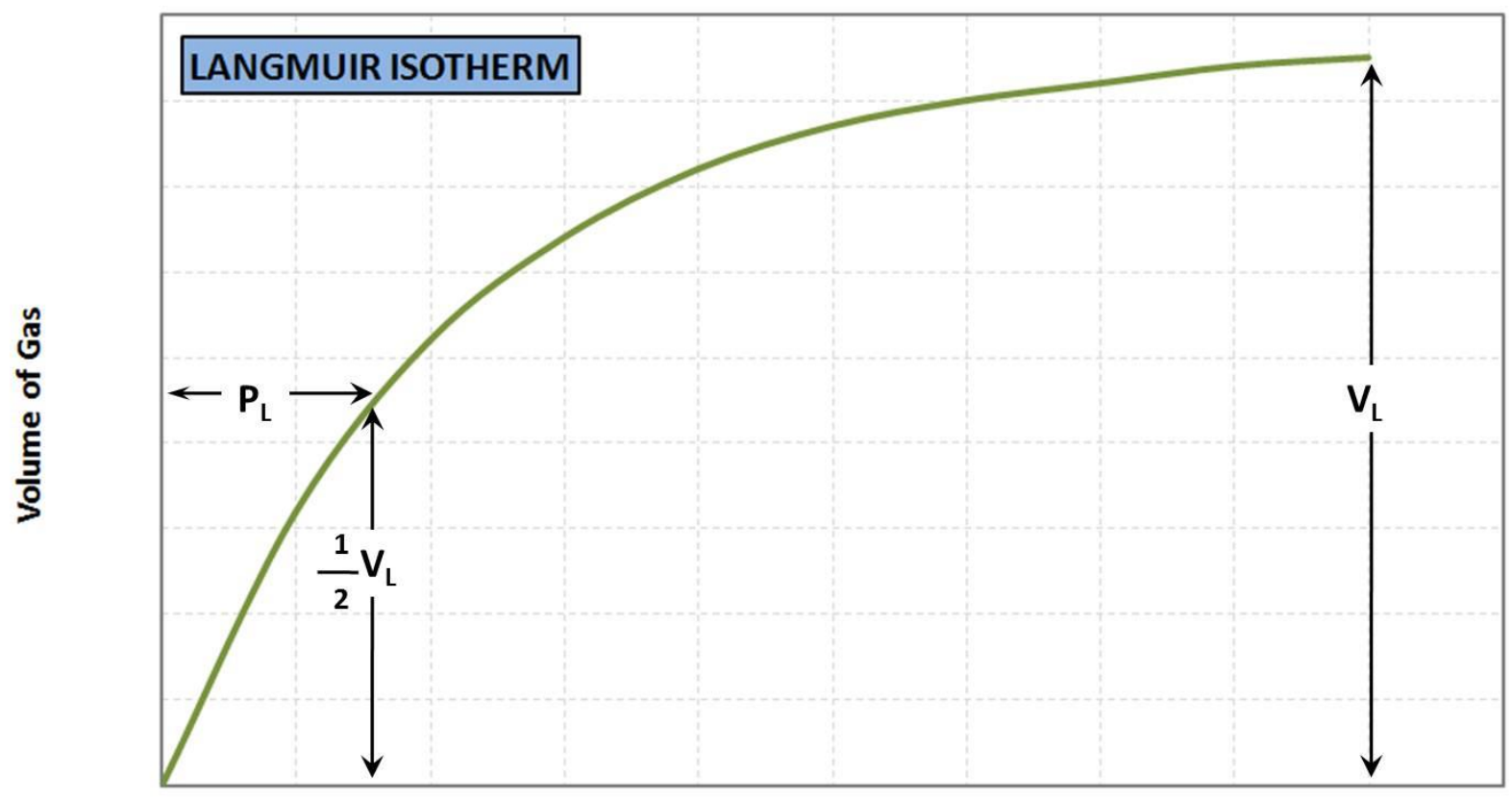

Gas Pressure

Figure 2.4: A typical Langmuir Isotherm for a Coalbed Methane Reservoir

\section{6 - Swelling and Shrinkage of Coals}

Coals are known to swell and shrink with changes in internal storage of the formation (Chikatamarla and Bustin 2004; Palmer and Mansoori 1996). As the internal storage pores of coal fill up with a fluid, the coal itself swells to include the additional material. In the same fashion, coal can shrink with the extraction of gases contained in the formation. As the pore spaces in the coal release methane, the coal shrinks due to less internal matter to store. Swelling and shrinkage of coals can have a significant impact on the performance of injection into or production from coal formations.

During injection, carbon dioxide adsorbed by the coal formation can cause coal swelling. Swelling occurs when the internal pore spaces of the coal absorb carbon dioxide. As the 
micropores of the coal fill up with carbon dioxide, the coal swells to account for the additional contents. This swelling reduces the size of the aperture openings that make up the cleat network and constricts fluid movement in the coal. The reduced macropore volume effectively reduces the permeability of the coal formation and injection becomes a more difficult task. In the same fashion, coals that are depleted or nearing depletion experience shrinkage. As the micropores of the coal shrink due to the absence of coalbed methane in the formation, the aperture openings of the macropores widen and the effective permeability of the coal formation is increased (Siriwardane et al, 2009; Clarkson et al, 2008; Mitra and Harpalani, 2007; Karacan, 2007; Mazumder and Wolf, 2006 ${ }^{\mathrm{c}}$; Shi and Durucan, 2003). Figure 2.5 shows a conceptual diagram of the effects of swelling and shrinkage on a coal formation.
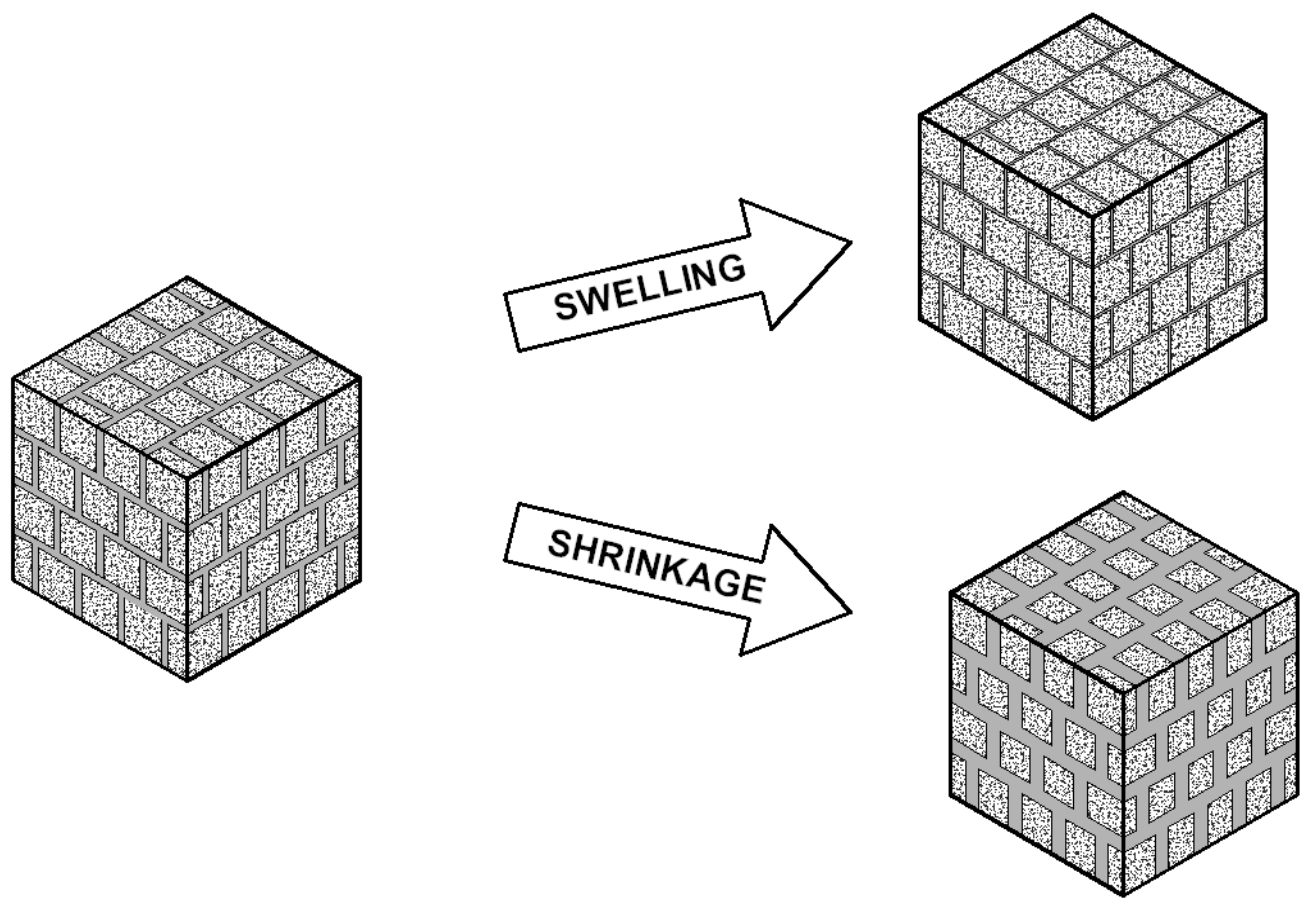

Figure 2.5: The Effects of Swelling and Shrinkage on Coal Formations 


\section{CHAPTER 3: DESCRIPTION OF THE PUMP CANYON SEQUESTRATION SITE}

\section{1 - Location of the Pump Canyon Field Site}

The Pump Canyon CBM reservoir is located in the San Juan basin in northern New Mexico. The Pump Canyon sequestration demonstration site is a part of the Southwest Regional Partnership sponsored by the United States Department of Energy. The goal of the Pump Canyon project is to assess the suitability deep, unmineable coal formations for potentially large scale sequestration operations. The Pump Canyon site is located just south of the Allison Unit which was the world's first carbon sequestration/enhanced CBM recovery field project dealing with deep unmineable coal seams. Figure 3.1 shows the location of the Pump Canyon sequestration field site.

Pump Canyon was selected as a demonstration site for a variety of reasons. One of the primary factors is the large storage potential of the reservoir. The Pump Canyon reservoir has an estimated storage capacity of $12 \mathrm{Gt}$ of carbon dioxide. This value covers at least $12 \%$ of the current storage capacity in the entire United States of America (www.southwestcarbonpartnership.org). In addition to its storage capabilities, an estimated 16 TCF of natural gas could be extracted by enhanced coalbed methane recovery. Enhanced coalbed methane recovery is a positive consequence of sequestering carbon dioxide into coal formations and can help offset the cost of injection.

Another reason Pump Canyon was selected is its favorable geology. The fairway region of the San Juan basin is a known area of high permeability coal (Oudinot, 2008). Hopes are that the high permeability of the underlying coal formation will assist in maintaining high injection pressures and rates. Swelling and shrinkage of the coal matrix is believed to be one of the primary factors affecting injectivity of coal seam and high permeability in this area may help offset the losses due to coal swelling.

Proximity of available carbon dioxide sources was also a factor in deciding where to locate this demonstration site. The Cortez pipeline was constructed to supply carbon dioxide to the Allison unit - an enhanced coalbed methane recovery project further to the north. By 
locating the site on the southern boundary of the fairway region, the project was able to maintain the advantages of the high permeability fairway and also minimize the distance required to connect to the Cortez pipeline. Figure 3.2 shows the location of the Cortez pipeline as well as the Pump Canyon and Allison Unit field sites.

\section{2 - Overview of the Site}

The target formation for carbon sequestration at the Pump Canyon demonstration site is the Fruitland coal. A geologic overview of the region and the target formation is shown in Figure 3.3. The Fruitland coal lies at a depth of approximately 3000 feet. This formation is split up into three separate coal seams totaling about 75 feet spread out over a 175 foot interval (Oudinot et al 2008; Koperna et al, 2009). Data on gas content, formation thickness, and coal density for all three coal seams is presented in Table 3.1.

Table 3.1: Gas Content, Formation Thickness, and Coal Density data for the Fruitland Coals

\begin{tabular}{|c|c|c|c|c|c|c|}
\hline \multirow{2}{*}{$\begin{array}{c}\text { Coal } \\
\text { Formation }\end{array}$} & \multirow{2}{*}{$\begin{array}{c}\text { Thickness } \\
\text { (ft) }\end{array}$} & \multirow{2}{*}{$\begin{array}{l}\text { Density } \\
\text { (g/cc) }\end{array}$} & \multicolumn{2}{|c|}{ Methane } & \multicolumn{2}{|c|}{ Carbon Dioxide } \\
\hline & & & $\begin{array}{c}\mathrm{V}_{\mathrm{L}} \\
\text { (SCF/ton) }\end{array}$ & $\begin{array}{c}P_{L} \\
\text { (psia) }\end{array}$ & $\begin{array}{c}\mathrm{V}_{\mathrm{L}} \\
\text { (SCF/ton) }\end{array}$ & $\begin{array}{c}P_{L} \\
\text { (psia) }\end{array}$ \\
\hline Upper Seam & 26 & 1.51 & 446.5 & 546 & 809 & 317 \\
\hline Middle Seam & 15 & 1.54 & 435.5 & 605.5 & 766 & 260 \\
\hline Lower Seam & 29 & 1.44 & 541.5 & 519.5 & 1038 & 371.5 \\
\hline Average & 60 & 1.48 & 490 & 548 & 909 & 329 \\
\hline
\end{tabular}




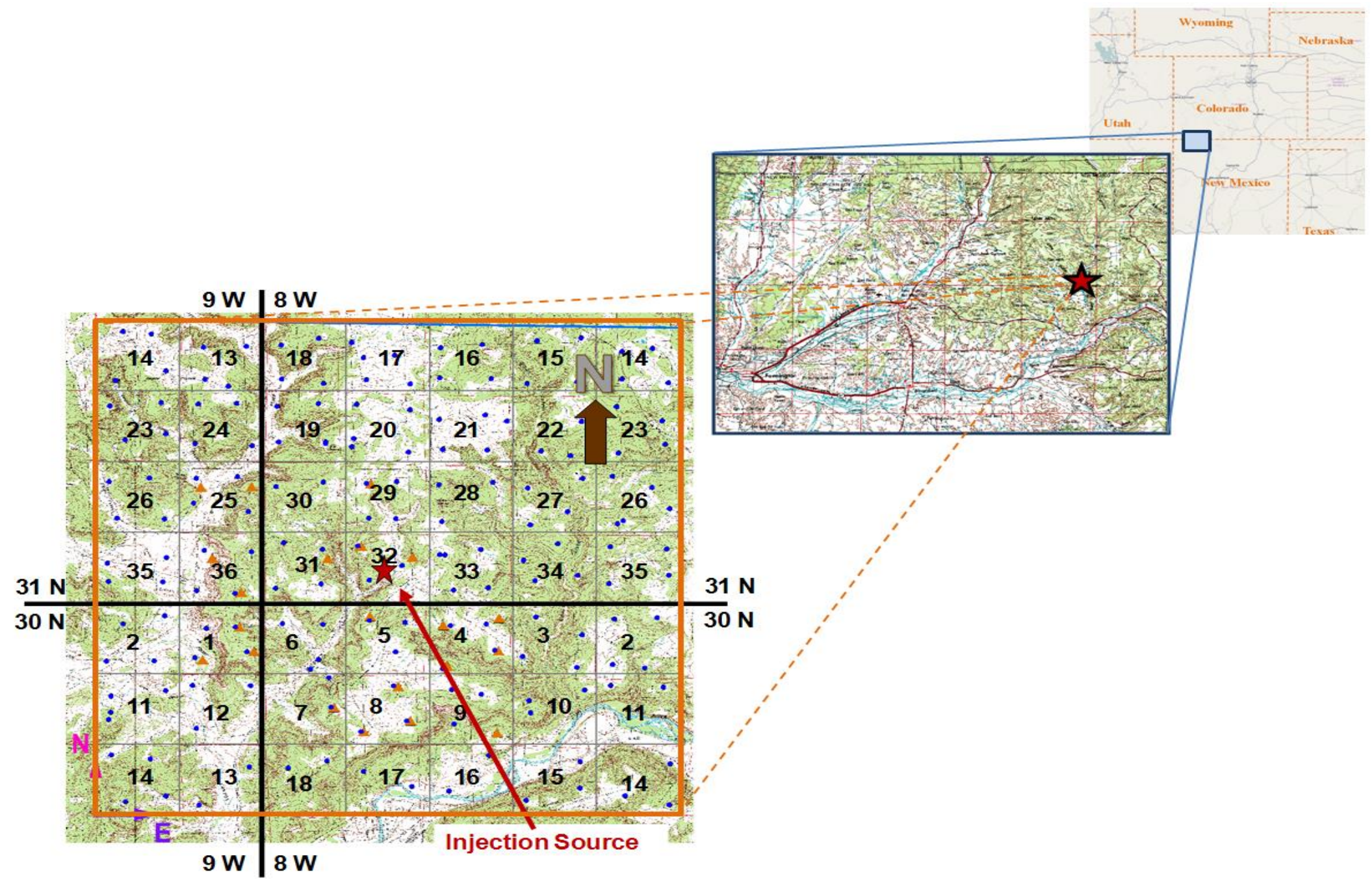

Figure 3.1: Location of the Pump Canyon Sequestration Site 


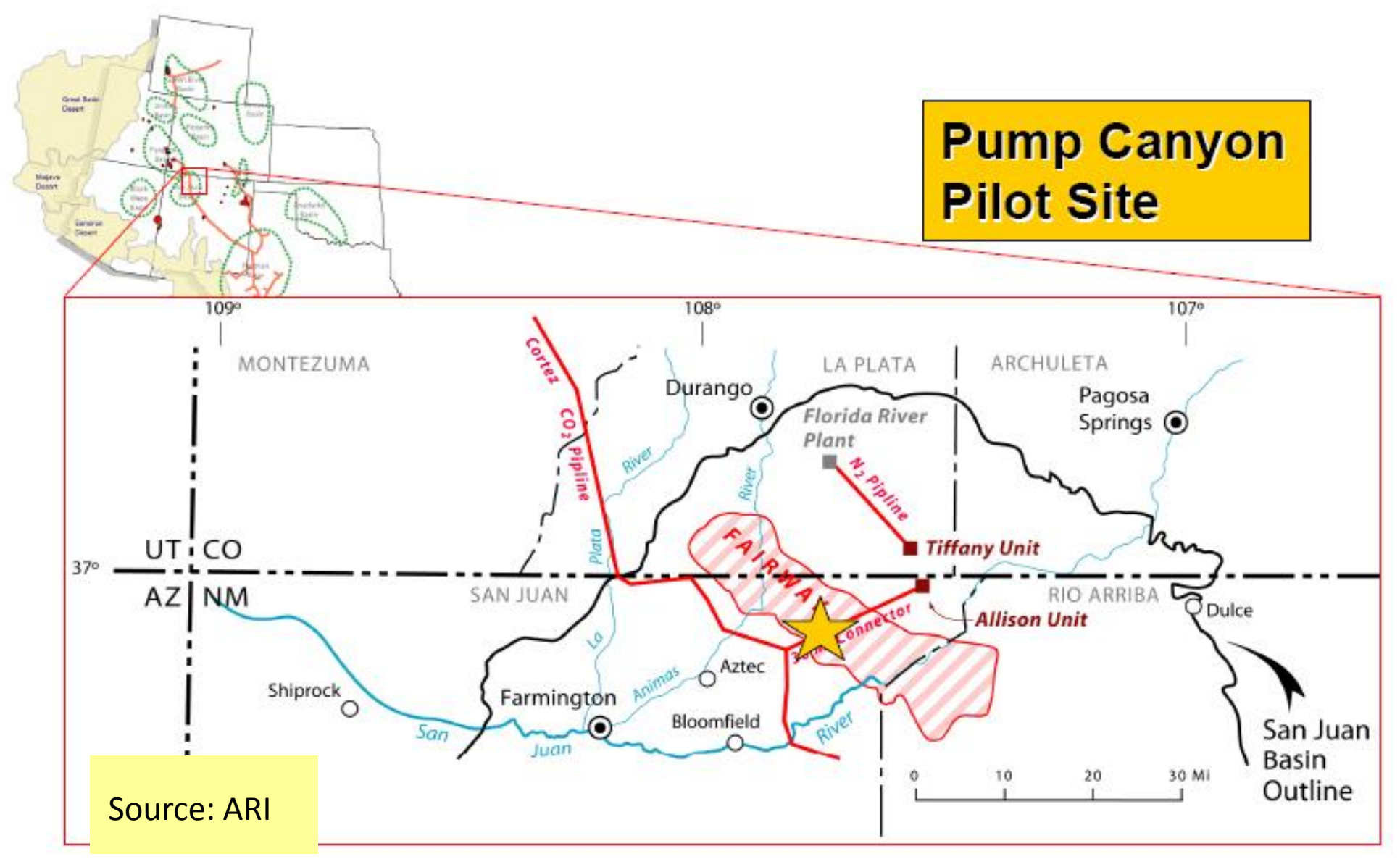

Figure 3.2: Proximity of Pump Canyon to Existing Pipelines 


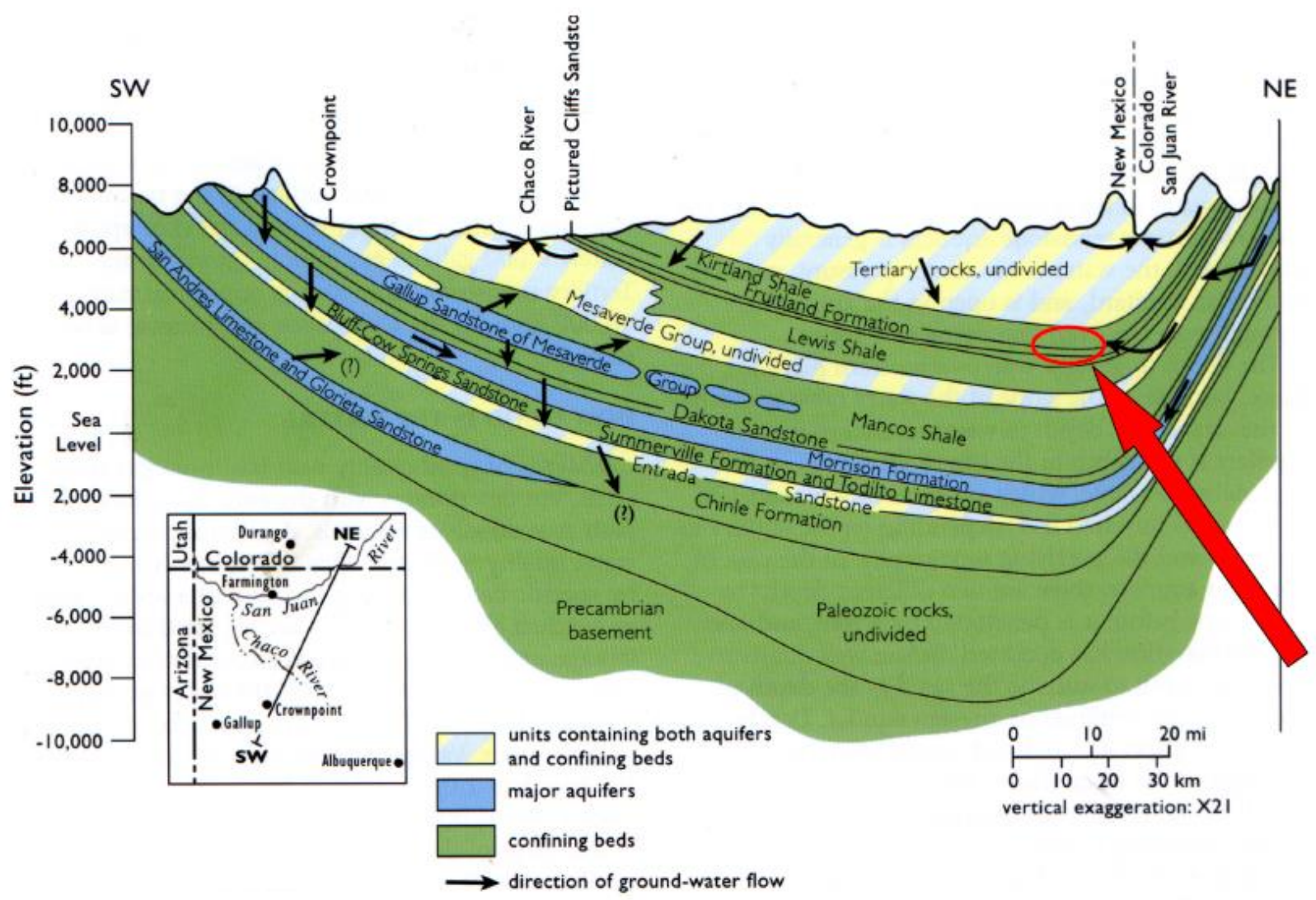

Figure 3.3: Geologic Formation in the Pump Canyon Region (Stone et al, 1983)

\section{3 - Details of the Field Site}

The study area covers an aerial extent of just over 18 square miles and contains 61 production wells, 2 pressure observation wells (POW's), and one injection well. The production wells and POW's were drill at various time ranging from as far back as 1982 to as recent as 2007. Most production wells were still actively producing at the time of this writing. The injection well was drilled in July 2008 and its exact location is T 31N, R 8W, Section 32 (Oudinot et al, 2008; Koperna et al, 2009). Cleat orientation of the Fruitland Coal formation has been reported as $\mathrm{N} \mathrm{35}^{\circ} \mathrm{E}$ at a nearby well, NBU \# 403 (Mavor and Close, 1989; Koperna et al, 2009; Oudinot et al, 2008); cleat orientation and reservoir anisotropy are covered in greater detail in Chapter 2. The locations of wells in the study area and cleat orientation of the reservoir geometry can be found elsewhere (Siriwardane et al, 2012). 
Carbon dioxide injection was planned for the deepest of the three coal seams. In the event of early breakthrough of carbon dioxide, the backup plan was to reroute the carbon dioxide into the middle coal seam and then the upper coal seam. No significant breakthrough has been observed and injection was focused on the lower coal seam. The injection rates were determined on site and the maximum allowable rate of injection was $2 \mathrm{MMcfd}$.

To study the reservoir's behavior during and after injection of carbon dioxide, a variety of measurement, monitoring, and verification (MMV) techniques have been employed at the site. Among these techniques are continuous measurement of injection volumes, pressures, and temperatures, tracers injected into the reservoir with carbon dioxide for tracking purposes, monitoring of produced gas at production wells, time-lapse vertical seismic profiling, an array of surface tiltmeters, and a series of shallow monitoring wells combined with a fluid sampling program. Tracer injection is discussed in more detail in later sections, and more information of other MMV techniques can be found elsewhere (Oudinot et al 2008).

\section{4 - Production History of the Pump Canyon Reservoir}

The Pump Canyon area has been utilized as a source of natural gas since the early 1980's. Over time, a series of production wells have been placed in the study area to extract coalbed methane. Figure 3.4 shows the production timeline for all production wells in the study area. The first active producer in the study area was drilled in 1982 and coalbed methane production has been continuous in the Pump canyon reservoir since that date. In the late 1980's and early 1990 's, several wells were drilled to produce methane from the Pump Canyon coalbed methane

reservoir. In the mid 2000's, several more production wells were added to those already operating in Pump Canyon. The majority of these wells remain in operation at present time.

The production wells in the study area are operated by Conoco Phillips. Gas production rates for all wells in the study area have been recorded monthly since their inception and were made available online at the Go-Tech website (www.octane.nmt.edu). Bubble maps showing 
coalbed methane production in the study area over time can be found elsewhere (Siriwardane et al, 2012).

Water production rates were available in some cases as well, however water production data was not available for all wells and the data is inconsistent. Overall water production data was considered to be unreliable, and as a result water production rates were not used in this reservoir modeling study. 


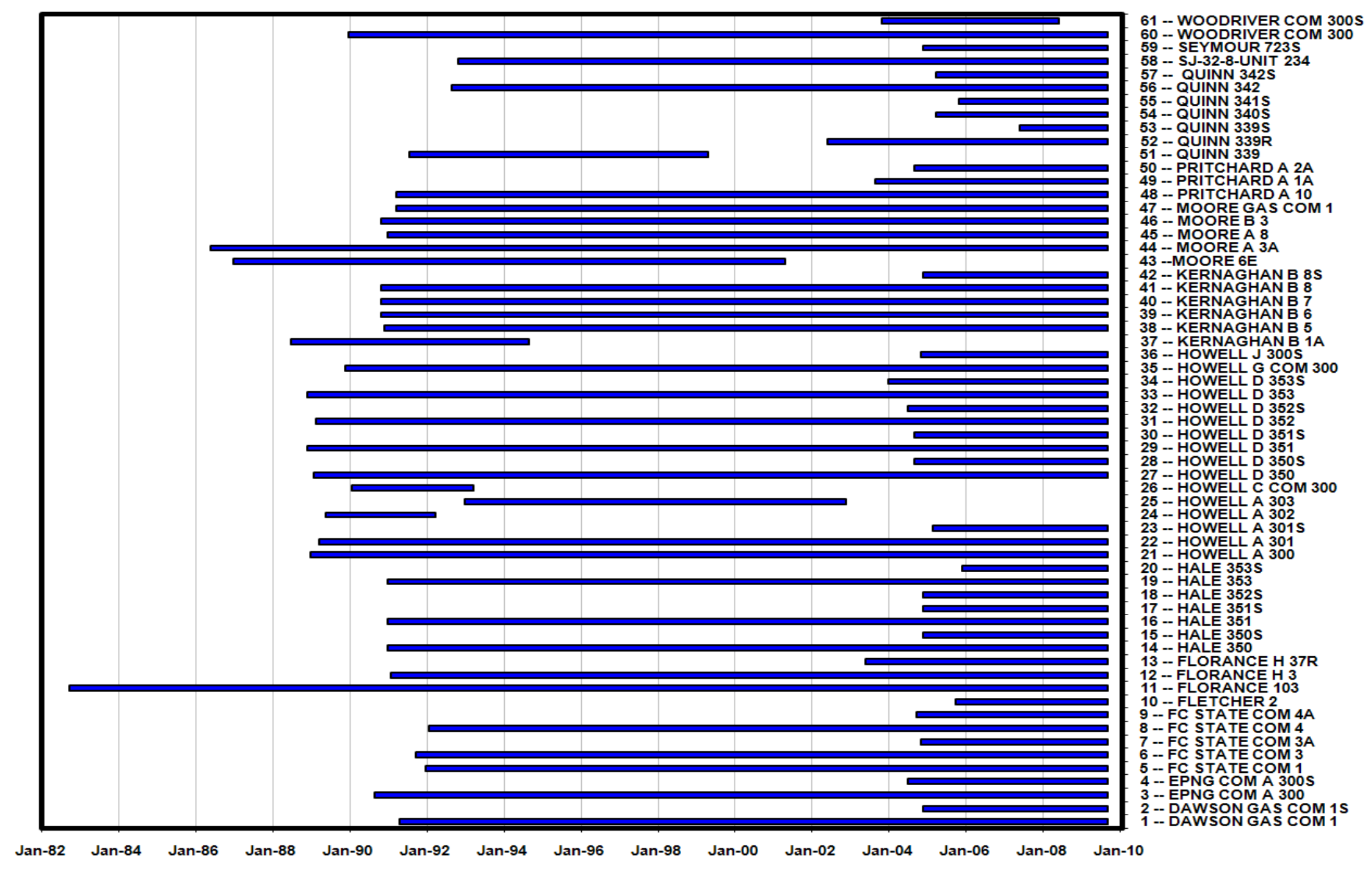

Figure 3.4: Gantt Chart Showing the Production Timeline of the Study Area 


\section{CHAPTER 4: NUMERICAL APPROACH}

\section{1 - Numerical Methodology}

The coal matrix swells when it adsorbs carbon dioxide causing a reduction in permeability. In the same fashion an increase in permeability is noticed when methane gas is released from the matrix causing an increase in permeability as discussed in Chapter 2 and illustrated in Figure 2.5. The strains associated with coal swelling and shrinkage are computed based amount of adsorbed carbon dioxide and desorbed methane in the coal matrix. In the SS model, strains due to coal swelling and shrinkage are calculated as shown below in Equations 4.1 and 4.2 .

Strain due to coal swelling:

$$
d \varepsilon_{v}^{s w}=C^{s w} d V_{a}
$$

where;

$$
\begin{aligned}
& \varepsilon_{v}^{s w}=\text { volumetric swelling strain } \\
& C^{s w}=\text { swelling constant } \\
& V_{a}=\text { adsorbed volume of the gas that causes swelling of the coal matrix }
\end{aligned}
$$

Strain due to coal shrinkage:

$$
\begin{aligned}
& d \varepsilon_{v}^{s h}=C^{s h} d V_{d} \\
& \text { where; } \\
& \varepsilon_{v}^{s h}=\text { volumetric shrinkage strain }
\end{aligned}
$$




$$
\begin{aligned}
& C^{s h}=\text { shrinkage constant } \\
& V_{d}=\text { desorbed volume of the gas that causes shrinkage of the coal matrix }
\end{aligned}
$$

The swelling of the coal matrix is observed when carbon dioxide is injected and the shrinkage of the coal matrix is observed when methane is depleted. The previous Equations allow for the possibility of "swelling or shrinkage" to occur along different paths during the process of sorption and desorption. The sorption may not be reversible and the constants for shrinkage and swelling may have different absolute values. Details on the mathematical formulation of coal swelling and shrinkage can be found elsewhere (Siriwardane et al, 2006). The amount of swelling and shrinkage depends on the adsorbed or desorbed volumes of each gas into the coal matrix, and can therefore be expressed as functions of gas pressures as shown below in Equations 4.3 and 4.4:

$$
\begin{gathered}
V_{a}=f_{1}(p) \\
V_{d}=f_{2}(p)
\end{gathered}
$$

Changes in stress acting on the reservoir, such as effective stresses and pore pressure, result in strains on the coal matrix. A constitutive equation for the calculation of incremental stress in a coal seam can be expressed as shown in Equation 4.5:

$$
d \sigma_{i j}=2 G d \varepsilon_{i j}+\left(K-\frac{2 G}{3}\right) d \varepsilon_{k k} \delta_{i j}+\alpha d p \delta_{i j}-C^{s w} f_{1}^{\prime}(p) d p K \delta_{i j}+C^{S H} f_{2}^{\prime}(p) d p K \delta_{i j}
$$

where;

$$
C^{s h}=\text { shrinkage constant }
$$




$$
\begin{aligned}
& C^{s w}=\text { swelling constant } \\
& \sigma_{i j}=\text { stress tensor } \\
& \varepsilon_{i j}=\text { strain tensor } \\
& \mathrm{p}=\text { pore pressure } \\
& \mathrm{G}=\text { shear modulus } \\
& \mathrm{K}=\text { bulk modulus } \\
& \alpha=\text { poroelastic constant }
\end{aligned}
$$

Bulk and shear moduli for a coal matrix can be written as shown in Equations 4.6 and 4.7 below, respectively:

$$
\begin{aligned}
& K=\frac{E}{3(1-2 v)} \\
& G=\frac{E}{2(1+v)}
\end{aligned}
$$

where;

$$
\begin{aligned}
& E=\text { Young's Modulus } \\
& v=\text { Poisson's Ratio }
\end{aligned}
$$

The change in the cleat porosity can be calculated on the basis of volumetric strains of the coal matrix. The constitutive relationship expressed in Equation5.5 can be inverted to determine the volumetric strain in the coal matrix. The volumetric strain, $\varepsilon_{v}$ can be expressed as shown in Equation 4.8: 
$\varepsilon_{v}=\varepsilon_{x x}+\varepsilon_{y y}+\varepsilon_{z z}$

where;

$\varepsilon_{x x}=$ linear strain in the x-direction

$\varepsilon_{y y}=$ linear strain in the y-direction

$\varepsilon_{z z}=$ linear strain in the z-direction

The permeability of the material was assumed to vary according to the cubic Equation (as shown in Equation 4.9) presented by Palmer and Mansoori (Palmer and Mansoori, 1996). In this study $\mathrm{k}_{0}$ is the reference state permeability and $\phi_{0}$ is the reference state porosity.

$$
k=k_{0}\left(\frac{\phi}{\phi_{0}}\right)^{3}
$$

\section{2 - Modified PSU-COALCOMP Reservoir Simulator}

A generalized swelling and shrinkage (SS) model was developed and has been integrated into an existing coalbed methane reservoir simulator, PSU-COALCOMP. The SS model is based on constitutive Equations that account for the coupled fluid pressure deformation behavior of a porous medium that undergoes swelling and shrinkage. In many earlier investigations, a number of reservoir simulators were developed, but not many attempts were made to include the influence of swelling and shrinkage of the coal. It is suspected that swelling will have a large influence on the permeability of the coal. This reduction may have major implications on 
sequestration into coal seams; consequences could include reduced injection volumes and longer than expected injection periods on large scale sequestration projects. 


\section{CHAPTER 5: HISTORY MATCHING}

\section{1 - Discretization of the Study Area}

The study area was discretized into a finite difference grid to create a reservoir model. The outer boundaries of this model are centered around the position of the injection well, reported as 31N, R8W, Section 32 (Oudinot et al, 2008; Koperna et al, 2009). The boundary is represented by a square with the length of each side being 22,600 feet. The total area enclosed by the boundary is over 18 square miles. The finite difference grid created for history matching of the Pump Canyon reservoir is a 40 x 40 grid with 1600 blocks. Figure 5.1 shows the Pump Canyon study area discretized. The grid has a refined center region for increased accuracy in reservoir calculations around the area planned for injection. Grid block sizes within this center region are 365 feet per side. In the corner reaches of the grid the block dimensions are 765 feet per side, and there are also several blocks that have sides of both lengths as shown in the aforementioned Figure. Figure 5.2 shows the finite difference grid used for reservoir simulation. A value of "1" in a cell indicates an active cell that does not contain a well, a "0" indicates an inactive cell, and a value of "-n" represents a cell containing well number $n$. An index of well numbers is shown in Table 5.1.

\section{2 - Construction of Reservoir Model}

There are 61 production wells and 2 pressure observation wells present in the history matching finite difference grid. These wells were placed by superimposing a copy of the finite difference grid over a map of the area and recording the coordinates of the wells.

Cleat orientation in the study area has been reported as $\mathrm{N} 35^{\circ} \mathrm{E}$ (Koperna et al, 2009; Oudinot et al, 2008). The modified PSU CoalComp reservoir simulator does not have the capability to take cleat orientation into account during simulations, therefore the finite difference grid was rotated until the $\mathrm{X}$ and $\mathrm{Y}$ axes defined by the grid were in alignment with the reported cleat orientation. Figure 5.3 shows the rotation of the grid to account for cleat orientation. 


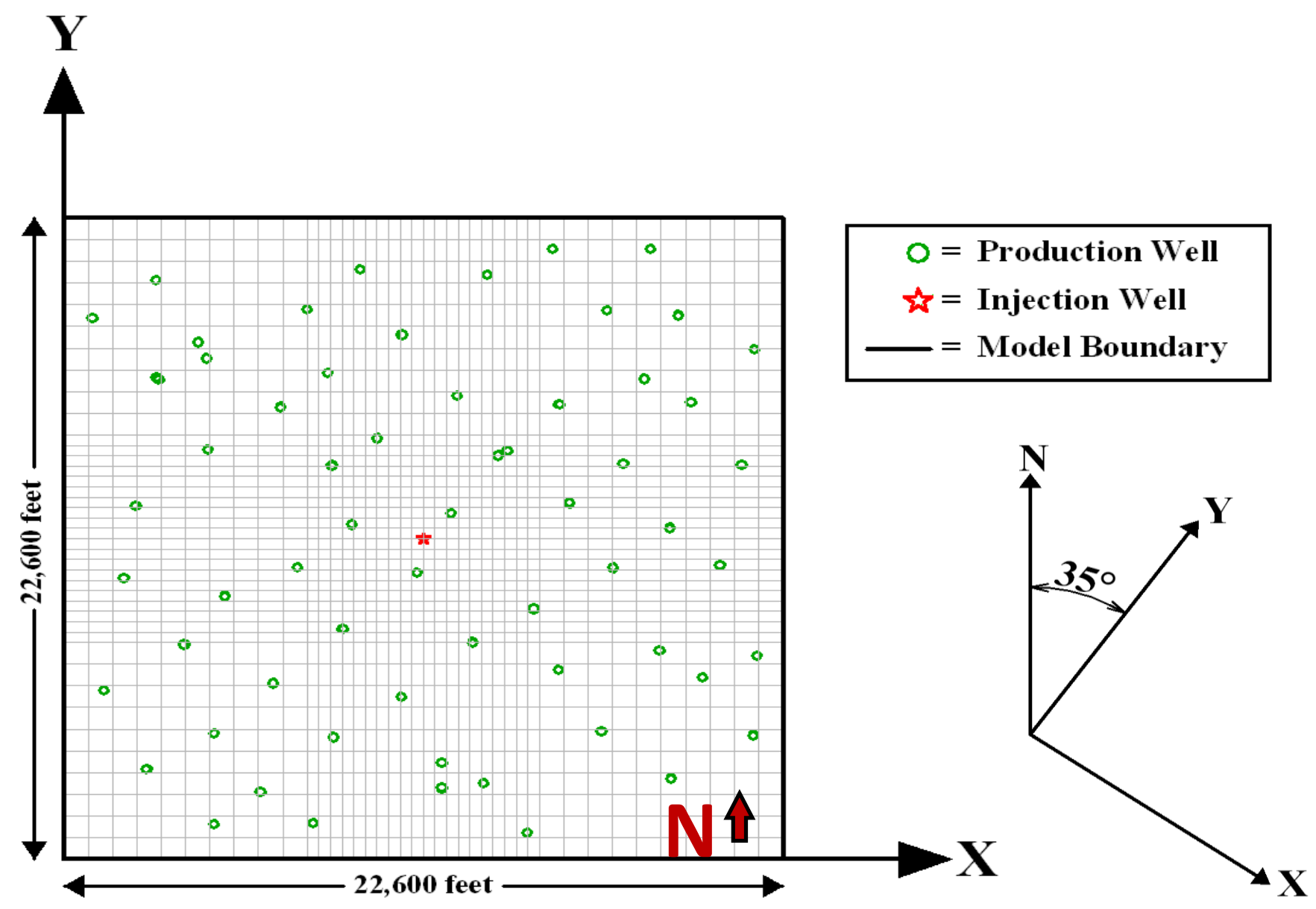

Figure 5.1: Pump Canyon Study Area Discretized

The three smaller coal seams that make up the Fruitland coal formation were idealized as one coal seam with composite properties. More detail on how those properties were determined is covered in subsequent sections. A uniform thickness and depth of the reservoir was assumed during simulations. The wellhead production pressures that accompany the available methane production rates were unavailable and were assumed to be the same for all wells. 


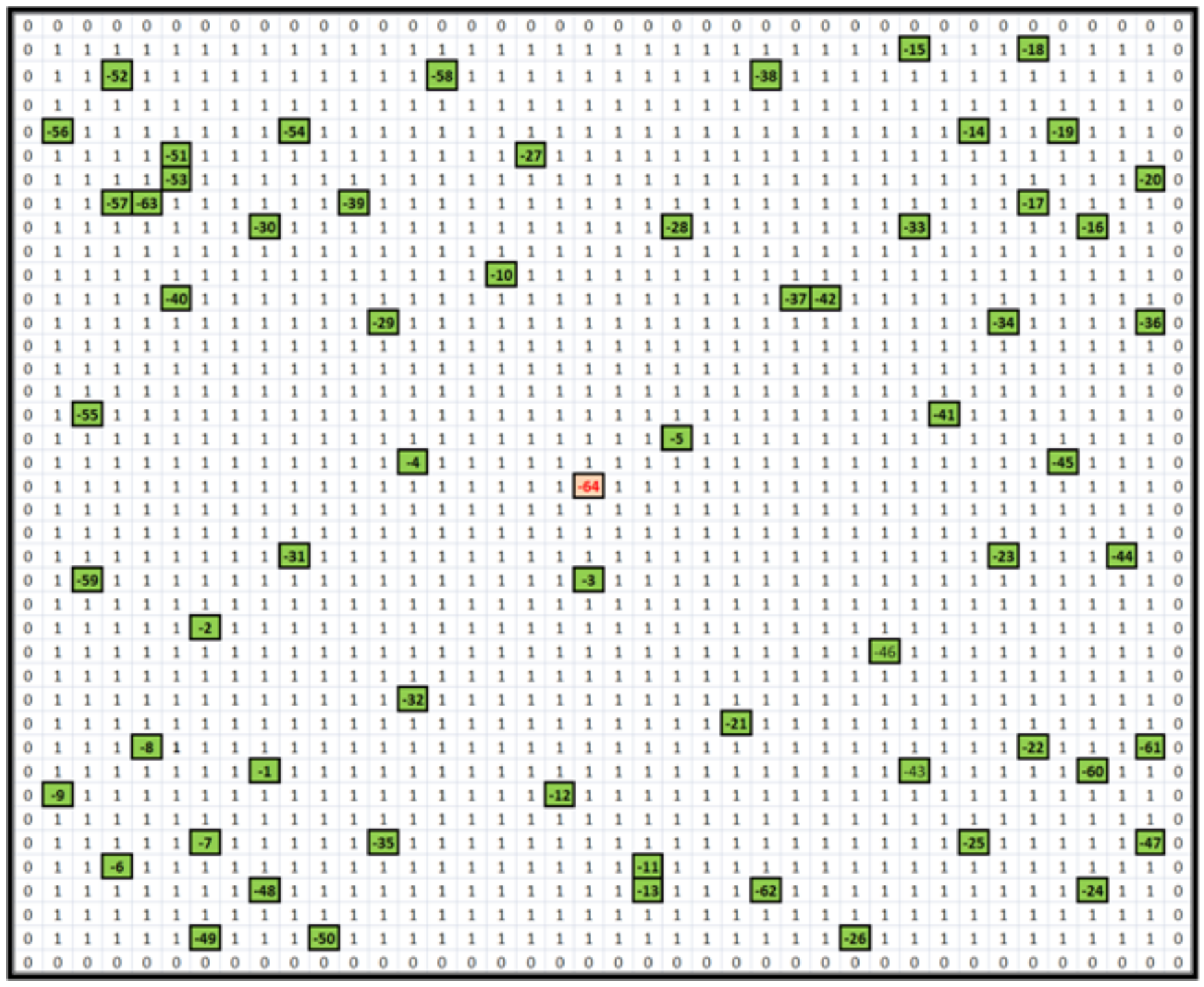

$\#$ = PRODUCTION WELL

$\# \quad=$ INJECTION WELL

1 = ACTIVE GRID BLOCK

Figure 5.2: The Pump Canyon Finite Difference Grid 
Table 5.1: Index of Production Wells in the Study Area

\section{INDEX OF PRODUCTION WELLS}

\begin{tabular}{|c|c|}
\hline Well \# & Well Name \\
\hline 1 & DAWSON GAS COM 1 \\
\hline 2 & DAWSON GAS COM $1 S$ \\
\hline 3 & EPNG COM A 300 \\
\hline 4 & EPNG COM A $300 S$ \\
\hline 5 & FC STATE COM 1 \\
\hline 6 & FC STATE COM 3 \\
\hline 7 & FC STATE COM 3A \\
\hline 8 & FC STATE COM 4 \\
\hline 9 & FC STATE COM 4A \\
\hline 10 & FLETCHER 2 \\
\hline 11 & FLORANCE 103 \\
\hline 12 & FLORANCE H 3 \\
\hline 13 & FLORANCE H 37R \\
\hline 14 & HALE 350 \\
\hline 15 & HALE 350S \\
\hline 16 & HALE 351 \\
\hline 17 & HALE 351S \\
\hline 18 & HALE 352S \\
\hline 19 & HALE 353 \\
\hline 20 & HALE 353S \\
\hline 21 & HOWELL A 300 \\
\hline 22 & HOWELL A 301 \\
\hline 23 & HOWELL A 301S \\
\hline 24 & HOWELL A 302 \\
\hline 25 & HOWELL A 303 \\
\hline 26 & HOWELL C COM 300 \\
\hline 27 & HOWELL D 350 \\
\hline 28 & HOWELL D 350S \\
\hline 29 & HOWELL D 351 \\
\hline 30 & HOWELL D 351S \\
\hline 31 & HOWELL D 352 \\
\hline 32 & HOWELL D 352S \\
\hline
\end{tabular}

$\begin{array}{cl}\text { Well \# } & \text { Well Name } \\ 33 & \text { HOWELL D 353 } \\ 34 & \text { HOWELL D 353S } \\ 35 & \text { HOWELL G COM 300 } \\ 36 & \text { HOWELL J 300S } \\ 37 & \text { KERNAGHAN B 1A } \\ 38 & \text { KERNAGHAN B 5 } \\ 39 & \text { KERNAGHAN B 6 } \\ 40 & \text { KERNAGHAN B 7 } \\ 41 & \text { KERNAGHAN B 8 } \\ 42 & \text { KERNAGHAN B 8S } \\ 43 & \text { MOORE 6E } \\ 44 & \text { MOORE A 3A } \\ 45 & \text { MOORE A 8 } \\ 46 & \text { MOORE B 3 } \\ 47 & \text { MOORE GAS COM 1 } \\ 48 & \text { PRITCHARD A 10 } \\ 49 & \text { PRITCHARD A 1A } \\ 50 & \text { PRITCHARD A 2A } \\ 51 & \text { QUINN 339 } \\ 52 & \text { QUINN 339R } \\ 53 & \text { QUINN 339S } \\ 54 & \text { QUINN 340S } \\ 55 & \text { QUINN 341S } \\ 56 & \text { QUINN 342 } \\ 57 & \text { QUINN 342S } \\ 58 & \text { SJ-32-8-UNIT 234 } \\ 59 & \text { SEYMOUR 723S } \\ 60 & \text { WOODRIVER COM 300 } \\ 61 & \text { WOODRIVER COM 300S } \\ 62 & \text { HOWELL C COM POW 300R } \\ 63 & \text { QUINN POW 2 } \\ & \end{array}$




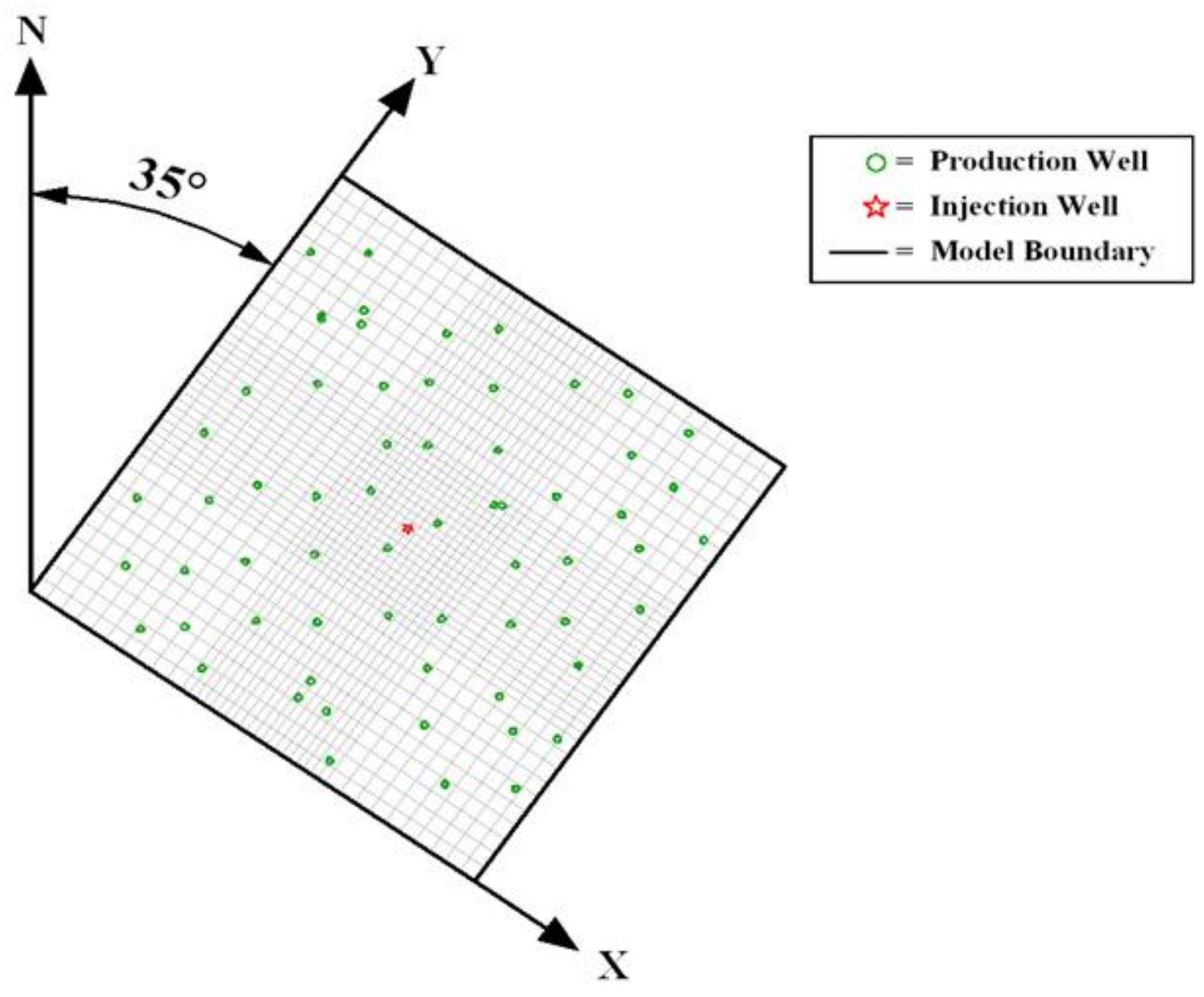

Figure 5.3: Pump Canyon Grid Rotated to Account for Cleat Orientation

\section{3 - Input Parameters}

A coalbed methane reservoir is a complex system, and as a result a plethora of data is required for reservoir simulation. Some information on the Pump Canyon site was available through previous work; however some of the data used in the model had to be estimated. Estimates parameters were varied during the history matching process until accepTable reservoir performance was observed. Table 5.2 shows the input parameter required by the PSU CoalComp reservoir simulator. Each parameter is discussed further detail in the forthcoming pages. 

(a) Reservoir Porosity
(b) Reservoir Permeability
(c) Reservoir Pressure
(d) Reservoir Temperature
(e) Formation Depth
(f) Water Saturation
(g) Langmuir Parameters, Thickness Data, and Coal Density
(h) Sorption Time Constant
(i) Initial Gas Composition
(j) Gas Properties
(k) Production Data
(I) Reservoir Anisotropy 
Table 5.2: Properties used for History Matching

\begin{tabular}{|c|c|}
\hline Reservoir Property & Input \\
\hline Reservoir Grid (I, J, K) & $40,40,1$ \\
\hline Individual Grid Block Size, I -Direction (feet) & $10 \times 765,20 \times 365,10 \times 765$ \\
\hline Individual Grid Block Size, J -Direction (feet) & $10 \times 765,20 \times 365,10 \times 765$ \\
\hline Reservoir Depth (feet) & 3,012 \\
\hline Reservoir Thickness (feet) & 60 (Average) \\
\hline Cleat Permeability (mD) & Figure 5.5 (based on the production index) \\
\hline Cleat Porosity $(\%)$ & Figure 5.6 (based on the permeability and 'a' factor) \\
\hline Permeability Anisotropy & $1.5-2$ \\
\hline Coal Density (pcf) & 99.88 \\
\hline Poisson's Ratio & 0.32 \\
\hline Elastic Modulus (psi) & 521,000 \\
\hline Palmer and Mansoori exponent & 3 \\
\hline $\mathrm{CH}_{4}$ Swelling/Shrinkage Constant (ton/SCF) & $3.0 \times 10^{-5}$ \\
\hline $\mathrm{CO}_{2}$ Swelling/Shrinkage Constant (ton/SCF) & $1.2 \times 10^{-5}$ \\
\hline Initial Reservoir Temperature $\left({ }^{0} \mathbf{F}\right)$ & 126 \\
\hline Initial Reservoir Pressure (psi) & 1,700 \\
\hline Initial Water Saturation (\%) & 95 \\
\hline Water Viscosity (cp) & 0.7 \\
\hline Water Density (pcf) & 62.4 \\
\hline Gas Composition, $\%\left(\mathrm{CH}_{4}, \mathrm{CO}_{2}\right)$ & $(100,0)$ \\
\hline Sorption Volume Constant for $\mathrm{CH}_{4}$ (SCF/ton) & 490 (Weighted Average) \\
\hline Sorption Pressure Constant for $\mathrm{CH}_{4}$ (psig) & 548 (Weighted Average) \\
\hline Sorption Volume Constant for $\mathrm{CO}_{2}$ (SCF/ton) & 909 (Weighted Average) \\
\hline Sorption Pressure Constant for $\mathrm{CO}_{2}$ (psig) & 329 (Weighted Average) \\
\hline Initial Gas Composition - $\mathrm{CH}_{4}, \mathrm{CO}_{2}(\%, \%)$ & $(90,10)$ \\
\hline Minimum Bottomhole Pressure (psig) & 15 \\
\hline Coal Desorption Time (days) & 1 \\
\hline
\end{tabular}


(a) Reservoir Porosity

Porosity in the reservoir is unknown and was estimated, however a value of less than $2 \%$ has been reported (Oudinot, 2008). Estimates for porosity are based on an index of production rates. It was assumed that producers with higher production rates lie in areas with higher porosity. Porosity estimates for each well were developed and the results were interpolated to cover the extents of the study area. Porosity values were assumed to range from a minimum of $1 \%$ to a maximum of $2 \%$. Porosity of the block containing well "i" was determined based on an index of production wells. The production for index for any well " $i$ " is shown in Equation 5.1 below. Figure 5.4 shows the porosity map of the study area with a maximum porosity of $2 \%$ and a minimum porosity of $1 \%$.

$$
Q_{i}=\frac{\varphi_{M A X}-\varphi_{M I N}}{R_{M A X}-R_{M I N}}\left(R_{M A X}-R_{M I N}\right)+\varphi_{M I N}
$$

where;

$$
\begin{aligned}
& \mathrm{R}_{\mathrm{i}}=\text { The relative production of each well compared to maximum production } \\
& \mathrm{R}_{\mathrm{MIN}}=\text { Minimum relative production ratio among all producers } \\
& \mathrm{Q}_{\mathrm{i}}=\text { Production rate of well " } \mathrm{i} \text { ". } \\
& \varphi_{\mathrm{MIN}}=\text { Specified minimum porosity } \\
& \varphi_{\mathrm{MAX}}=\text { Specified maximum porosity }
\end{aligned}
$$




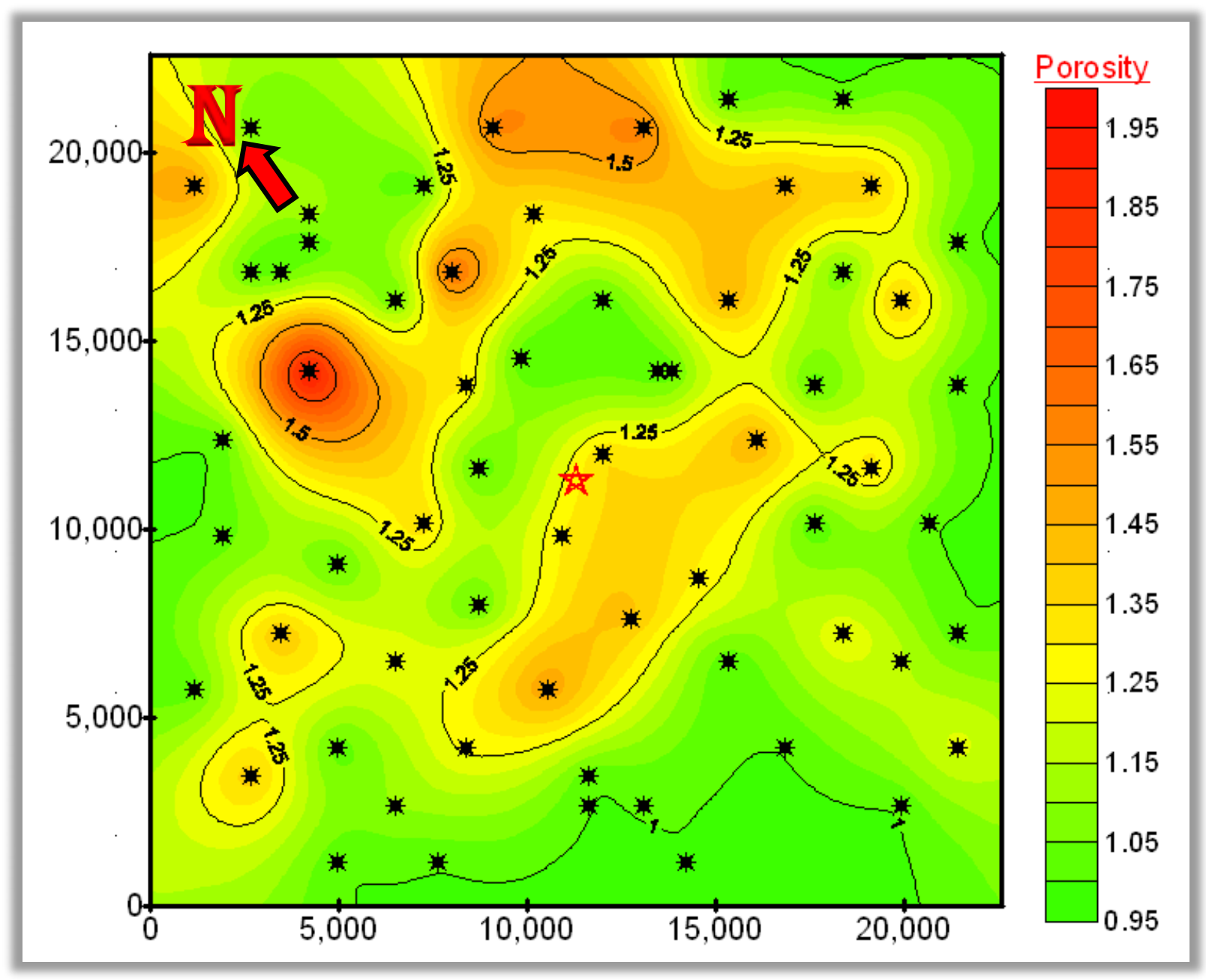

Figure 5.4: Estimated Initial Coal Porosity of the Pump Canyon Reservoir

(b) Reservoir Permeability

A relationship between porosity and permeability of coals has been developed by Schwerer and Pavone and is shown below in Equation 5.2 (Schwerer and Pavone, 1984). The porosity of the coal was calculated as explained in the previous section and used in the calculations for permeability. The exponent " $\mathrm{n}$ " is typically 3.0 for coals. The variable porosity factor "a" was taken to be 0.0022 as found through a trial and error procedure. The permeability map created using the aforementioned porosity map is presented is Figure 5.5. 


$$
\varphi=a k^{n}
$$

where;

$\varphi=$ Porosity of the coal

$\mathrm{k}=$ Intrinsic permeability of the coal

$\mathrm{a}=$ Variable Porosity Factor

$\varphi_{\mathrm{MIN}}=$ Specified minimum porosity

$\varphi_{\mathrm{MAX}}=$ Specified maximum porosity

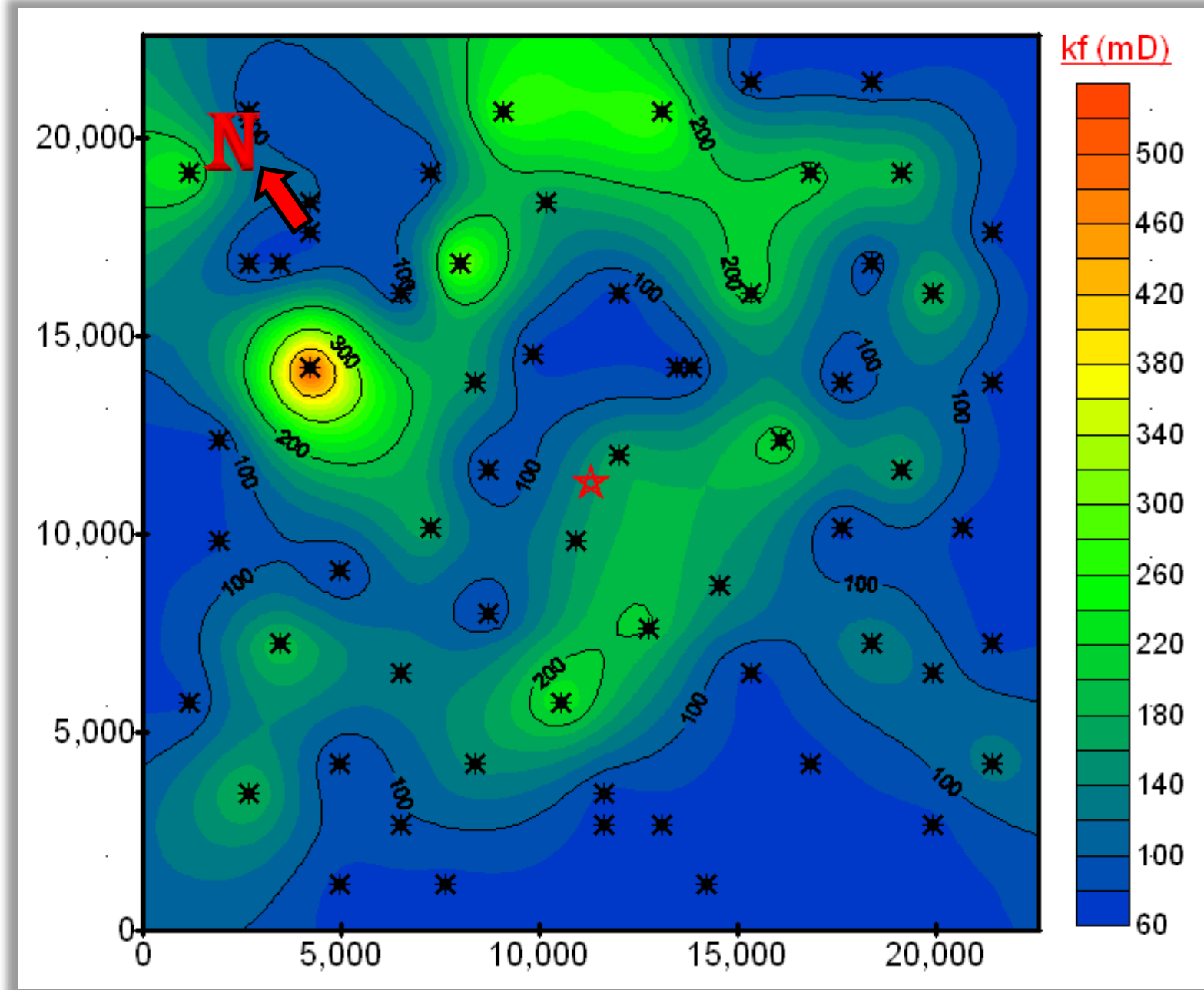

Figure 5.5: Estimated Initial Face Cleat Coal Permeability of the Pump Canyon Reservoir 
(c) Reservoir Pressure

Reservoir pressure data from 9 wells was available (Data provided by Ryan Frost of Conoco Phillips, and Grant Bromhal, 2009). Figure 5.6 shows the field measured bottomhole pressure data. This graph suggests that the Pump Canyon reservoir had an initial reservoir pressure of approximately 1700 psi. No additional information regarding the initial pressure distribution in the reservoir was available, and thus a uniform reservoir pressure of 1700 psia was assigned to the reservoir.

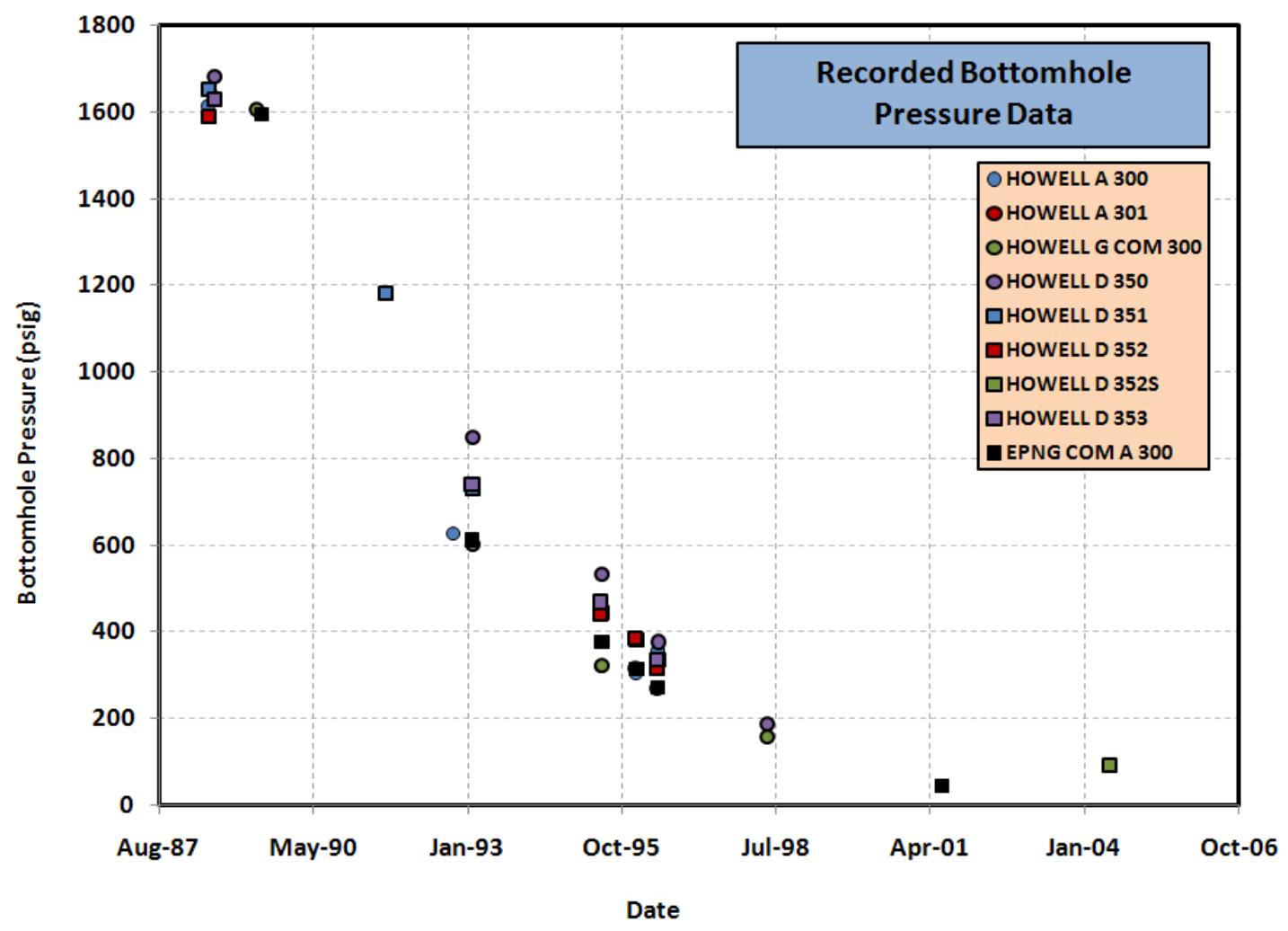

Figure 5.6: Bottomhole Pressure Data from Wells in the Study Area 
(d) Reservoir Temperature

The reservoir temperature was taken to be $126^{\circ} \mathrm{F}$ and is based on previously published studies (Oudinot et al, 2008).

\section{(e) Formation Depth}

The three individual coal seams in the study area were idealized as one larger coal seam with composite properties. A uniform depth of 3012 feet was given to the idealized coal seam based on published data (Oudinot et al 2008).

(f) Water Saturation

Initial water saturation of the reservoir was unknown. However, it is typical for undisturbed coal formations to be completely saturated or near full saturation. Hence, an initial water saturation of $95 \%$ was estimated for simulation purposes. This estimate compares well with initial water saturation levels reported in other studies (Oudinot et al 2008).

(g) Langmuir Parameters, Thickness Data, and Coal Density

Gas content, coal density, and formation thickness data for the study area has been reported and is shown in Table 5.3. Composite values for seam thickness, coal density, and Langmuir parameters for the idealized coal seam were computed as shown below: 
Table 5.3: Gas Content, Thickness, and Density Data for the Fruitland Coals

\begin{tabular}{|c|c|c|c|c|c|c|}
\hline \multirow{2}{*}{$\begin{array}{c}\text { Coal } \\
\text { Formation }\end{array}$} & \multirow{2}{*}{$\begin{array}{l}\text { Thickness } \\
\text { (ft) }\end{array}$} & \multirow{2}{*}{$\begin{array}{c}\text { Density } \\
\text { (g/cc) }\end{array}$} & \multicolumn{2}{|c|}{ Methane } & \multicolumn{2}{|c|}{ Carbon Dioxide } \\
\hline & & & $\begin{array}{c}\mathrm{V}_{\mathrm{L}} \\
\text { (SCF/ton) }\end{array}$ & $\begin{array}{c}P_{L} \\
\text { (psia) }\end{array}$ & $\begin{array}{c}\mathrm{V}_{\mathrm{L}} \\
\text { (SCF/ton) }\end{array}$ & $\begin{array}{c}P_{\mathrm{L}} \\
\text { (psia) }\end{array}$ \\
\hline Upper Seam & 26 & 1.51 & 446.5 & 546 & 809 & 317 \\
\hline Middle Seam & 15 & 1.54 & 435.5 & 605.5 & 766 & 260 \\
\hline Lower Seam & 29 & 1.44 & 541.5 & 519.5 & 1038 & 371.5 \\
\hline Average & 60 & 1.48 & 490 & 548 & 909 & 329 \\
\hline
\end{tabular}

-Total Thickness $=\mathrm{T}_{1}+\mathrm{T}_{2}+\mathrm{T}_{3}=60$ feet,

where; $\quad T_{i}=$ Thickness of Layer "i"

-Average Langmuir Pressure $=\frac{T_{1} P_{1}+T_{2} P_{2}+T_{3} P_{3}}{T_{1}+T_{2}+T_{3}}$

where; $\mathrm{P}_{\mathrm{i}}=$ Langmuir Pressure in Layer "i"

-Average Langmuir Volume $=\frac{T_{1} V_{1}+T_{2} V_{2}+T_{3} V_{3}}{T_{1}+T_{2}+T_{3}}$

where; $\mathrm{V}_{\mathrm{i}}=$ Langmuir Volume in Layer "i"

-Average Coal Density $=\frac{T_{1} D_{1}+T_{2} D_{2}+T_{3} D_{3}}{T_{1}+T_{2}+T_{3}}$

where; $D_{i}=$ Coal Density of Layer "i" 
(h) Sorption Time Constant

The sorption time constant used in this study was assumed to be 1 day as reported in a previous study (Oudinot et al, 2008).

\section{(i) Initial Gas Composition}

The initial gas composition in the reservoir was assumed to be $90 \%$ methane and $10 \%$ carbon dioxide.

\section{(j) Gas Properties}

Several gas properties were required for both carbon dioxide and methane. Molecular weight, critical point parameters, and Pitzers's accentric factors are among input parameters used. A summary of gas properties is shown in Table 5.4.

Table 5.4: Gas Properties of Carbon Dioxide and Methane

\begin{tabular}{||l|c|c||}
\hline Gas Property & Methane & Carbon Dioxide \\
\hline Molecular Weight (Ib/lb-mol) & 16.043 & 44.01 \\
\hline Critical Pressure (psia) & 666.4 & 1071.33 \\
\hline Critical Temperature ( $\left.{ }^{\circ} \mathrm{F}\right)$ & -116.67 & 87.8783 \\
\hline Pitzer's Accentric Factor & 0.0104 & 0.02667 \\
\hline
\end{tabular}

(k) Production Data

Production data was provided by Gotech (www.octane.nmt.edu) and was incorporated into the model. Production rates were used in the estimation of porosity and permeability values. In 
addition, production data shows activation times and any shut in periods for production wells. Production data was also used for comparisons with simulated results.

\section{(1) Reservoir Anisotropy}

Reservoir anisotropy is a ratio of coal permeability in the face cleats to that in the butt cleats and is described below in Equation 5.3:

$$
\mathrm{Ar}=\frac{k_{f}}{k_{b}}
$$

where;

$$
\begin{aligned}
& \mathrm{A}_{\mathrm{r}}=\text { Anisotropic Ratio of the Reservoir } \\
& \mathrm{k}_{\mathrm{f}}=\text { Face Cleat Permeability } \\
& \mathrm{k}_{\mathrm{b}}=\text { Butt Cleat Permeability }
\end{aligned}
$$




\section{CHAPTER 6: MODELING CARBON DIOXIDE INJECTION}

\section{1 - Refined Injection Grid}

The goal of injection modeling is very different from that of history matching. In the history matching process described in Chapter 5, the primary goal was to estimate unknown properties for the study area. For that application a larger grid was assumed and the calculations were somewhat coarse. The goal of injection modeling is to determine the reservoir response to carbon dioxide injection. For this application the area immediately around the injection well is of greatest interest because that is where the interface is. As a result, a refined injection grid was created for greater accuracy in modeling injection into the reservoir. The refined injection grid is centered around the injection well just like the history matching grid. However the refined grid covers a much smaller area at just over 2 square miles, approximately $12 \%$ of the area of the larger grid. Figure 6.1 shows the boundary of the refined grid relative to history matching study area.

As stated above, the area right around the injection well is of particular interest during injection modeling. In this area, it is imperative to be able to look at the reservoir response in a higher resolution than was available in the previous history matching model. Therefore it was necessary to have relatively small grid block dimensions in the injection region. Since the need for high resolution is not so great on the outskirts of the model, a variable size grid spacing was implemented. The refined grid is a 63 x 63 block finite difference grid and is shown in Figure 6.2. The grid block dimensions range in size from 30 feet per side around the injection well to 275 feet per side on the model boundary. There are 9 production wells and one injection well included in the refined grid.

In this region, the cleat orientation has been reported as N 35 $\mathrm{E}$ (Mavor and Close, 1989; Koperna et al, 2009; Oudinot et al, 2008). As previously discussed, the cleat network is the primary transport mechanism in a coal formation; therefore this orientation must be taken into consideration during modeling. The refined grid was rotated in order to account for cleat orientation as shown in Figure 6.3. This aligns the $\mathrm{X}$ and $\mathrm{Y}$ axes defined by the model with the reported cleat orientation. 
The refined finite difference grid used for simulations is shown in Figure 6.4. A value of "1" in a cell represents an active cell not containing a well and a value of "-n" indicates a cell containing well number $\mathrm{n}$. An index of wells for the refined grid is shown in Table 6.1.

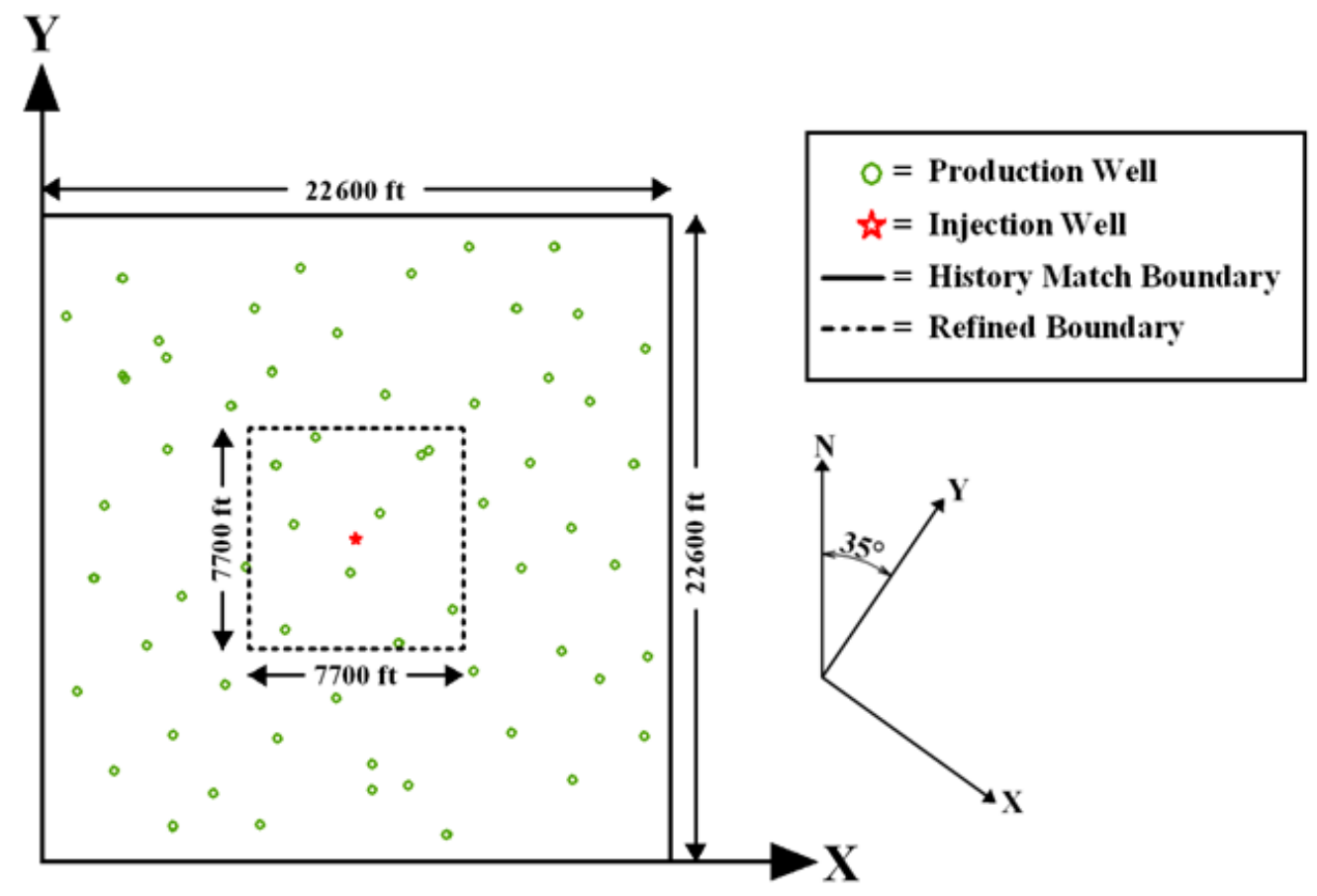

Figure 6.1: Location of the Refined Grid Relative to the History Matching Grid

\section{2 - Overview of Field Injection}

The injection well at the Pump Canyon site was drilled in July of 2008 and its exact location is T $31 \mathrm{~N}, \mathrm{R} 8 \mathrm{~W}$, Section 32 (Oudinot et al, 2008; Koperna et al, 2009). Injection of carbon dioxide at the site began on July 23, 2008 and continued until August 27, 2009. During this time period, a total of 18,000 tons of carbon dioxide was injected into the Pump Canyon reservoir. Injection rates and pressures were determined in the field and are shown in Figure 6.5. As shown in the Figure, the injection pressure used, although not truly constant, stay roughly around 1100 psia for most of the injection period (Koperna et al, 2009). 


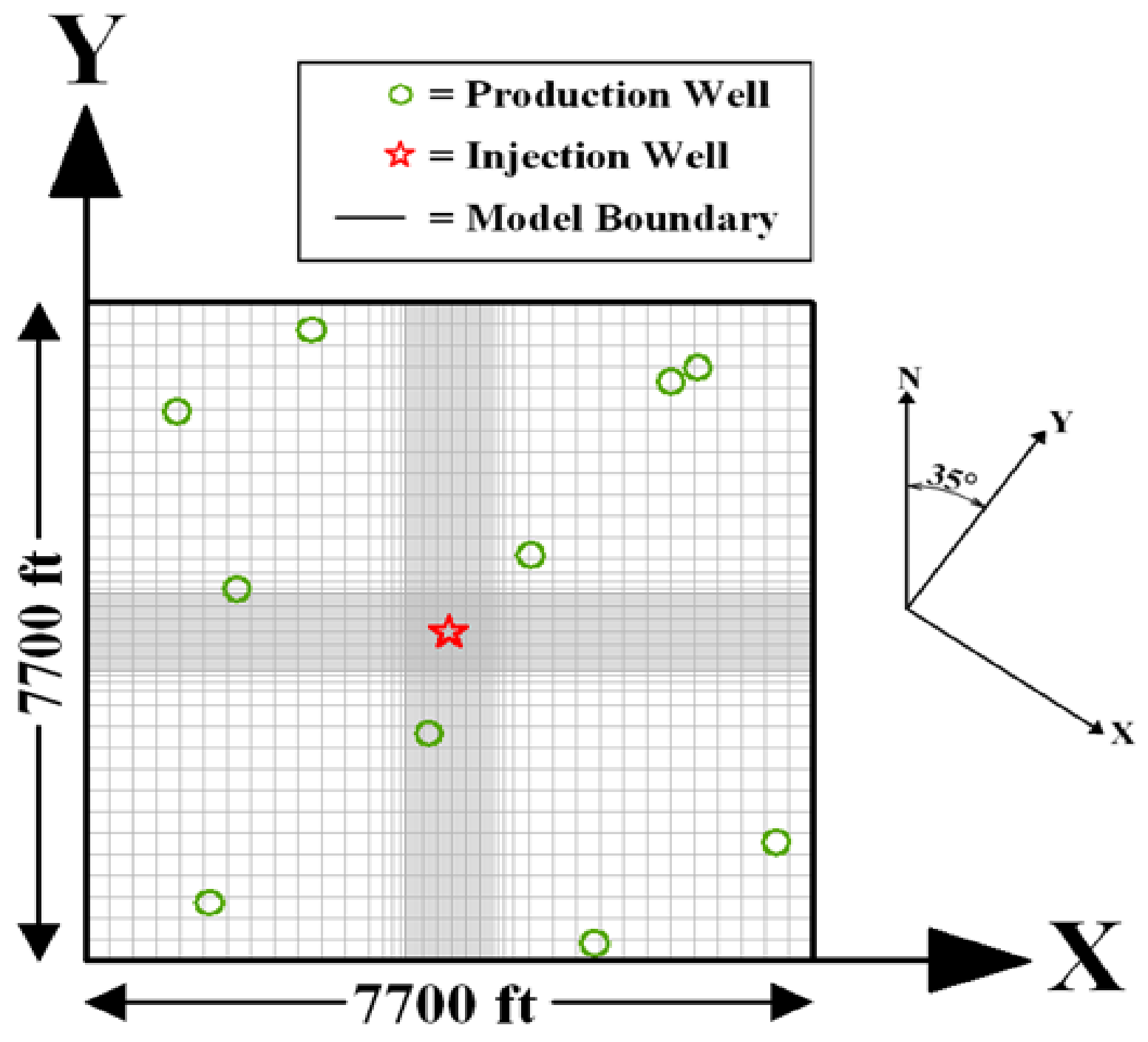

Figure 6.2: Refined Grid used for Injection Modeling 


$$
\begin{aligned}
0 & =\text { Production Well } \\
\llcorner & =\text { Injection Well } \\
- & =\text { History Match Boundary } \\
\cdots-- & =\text { Refined Boundary }
\end{aligned}
$$

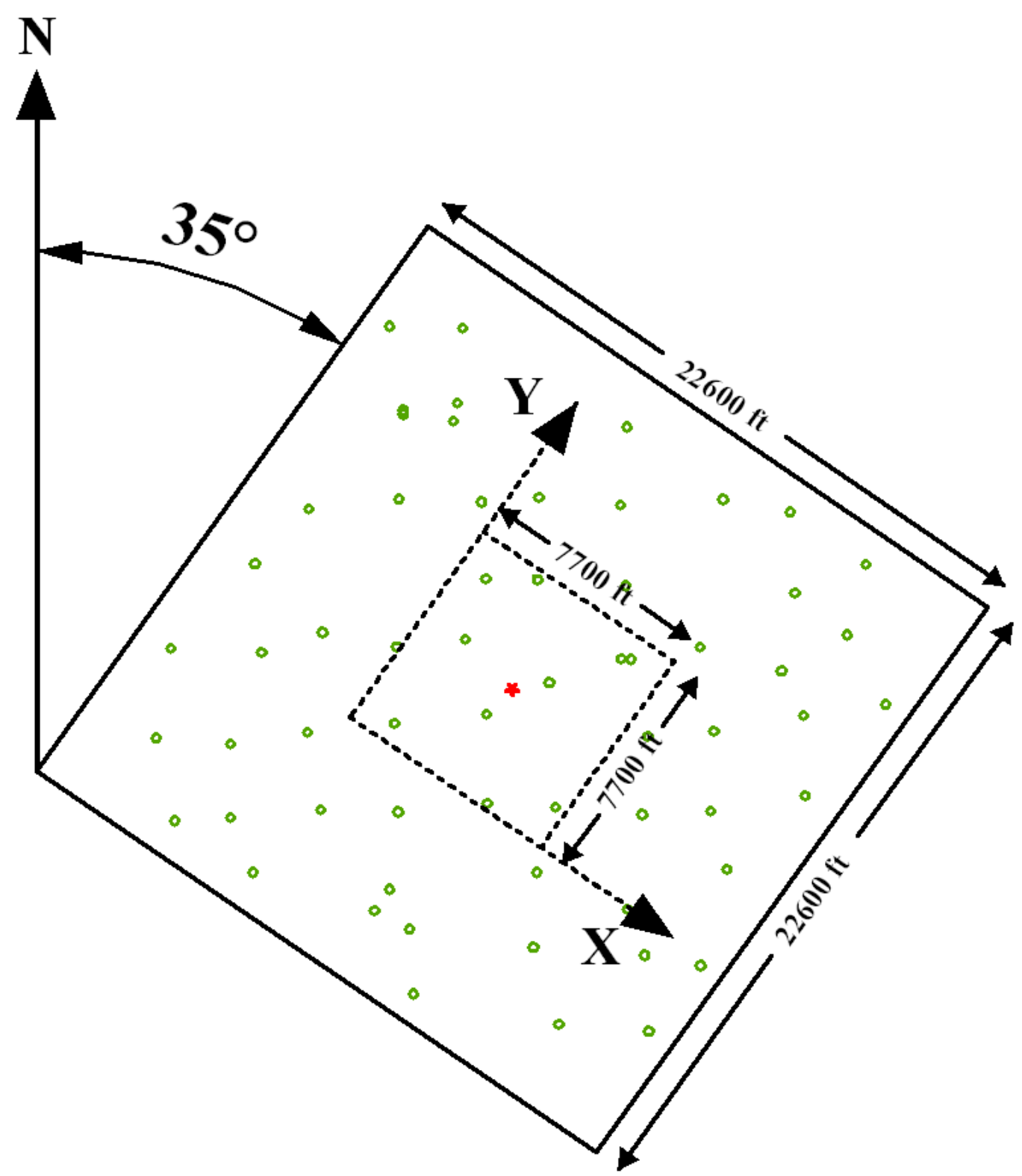

Figure 6.3: Refined Grid Rotated to Account for Cleat Orientation 


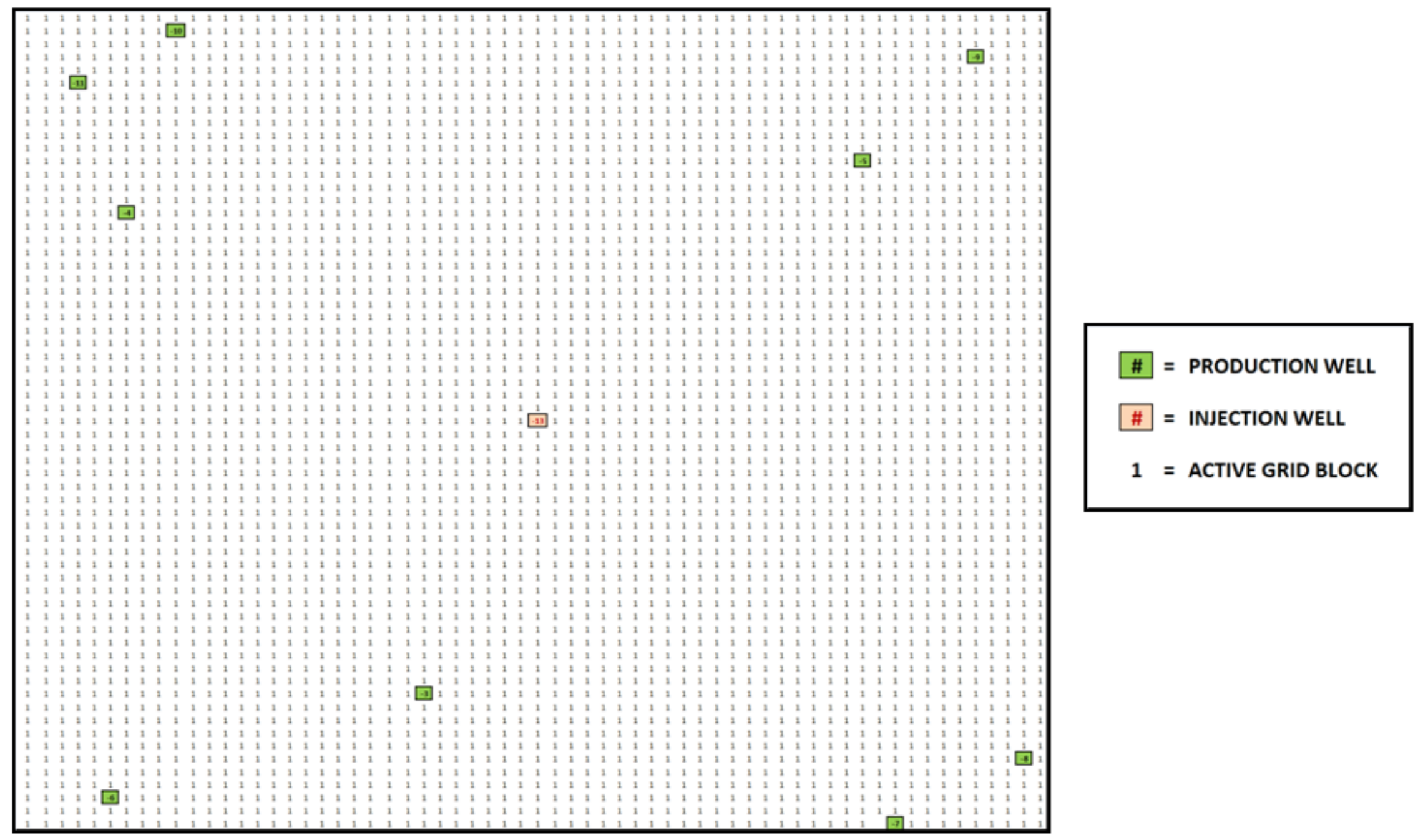

Figure 6.4: Refined Finite Difference Grids for Injection Modeling 
Table 6.1: Index of Wells in the Refined Injection Grid

\section{Index of Wells}

$\begin{array}{cl}\text { Well \# } & \text { Well Name } \\ 3 & \text { EPNG COM A } 300 \\ 4 & \text { EPNG COM A 300S } \\ 5 & \text { FC STATE COM 1 } \\ 6 & \text { HOWELL D 352S } \\ 7 & \text { HOWELL A 300 } \\ 8 & \text { MOORE B 3 } \\ 9 & \text { KERNAGHAN B 8S } \\ 10 & \text { FLETCHER 2 } \\ 11 & \text { HOWELL D 351 } \\ 13 & \text { INJECTION WELL }\end{array}$

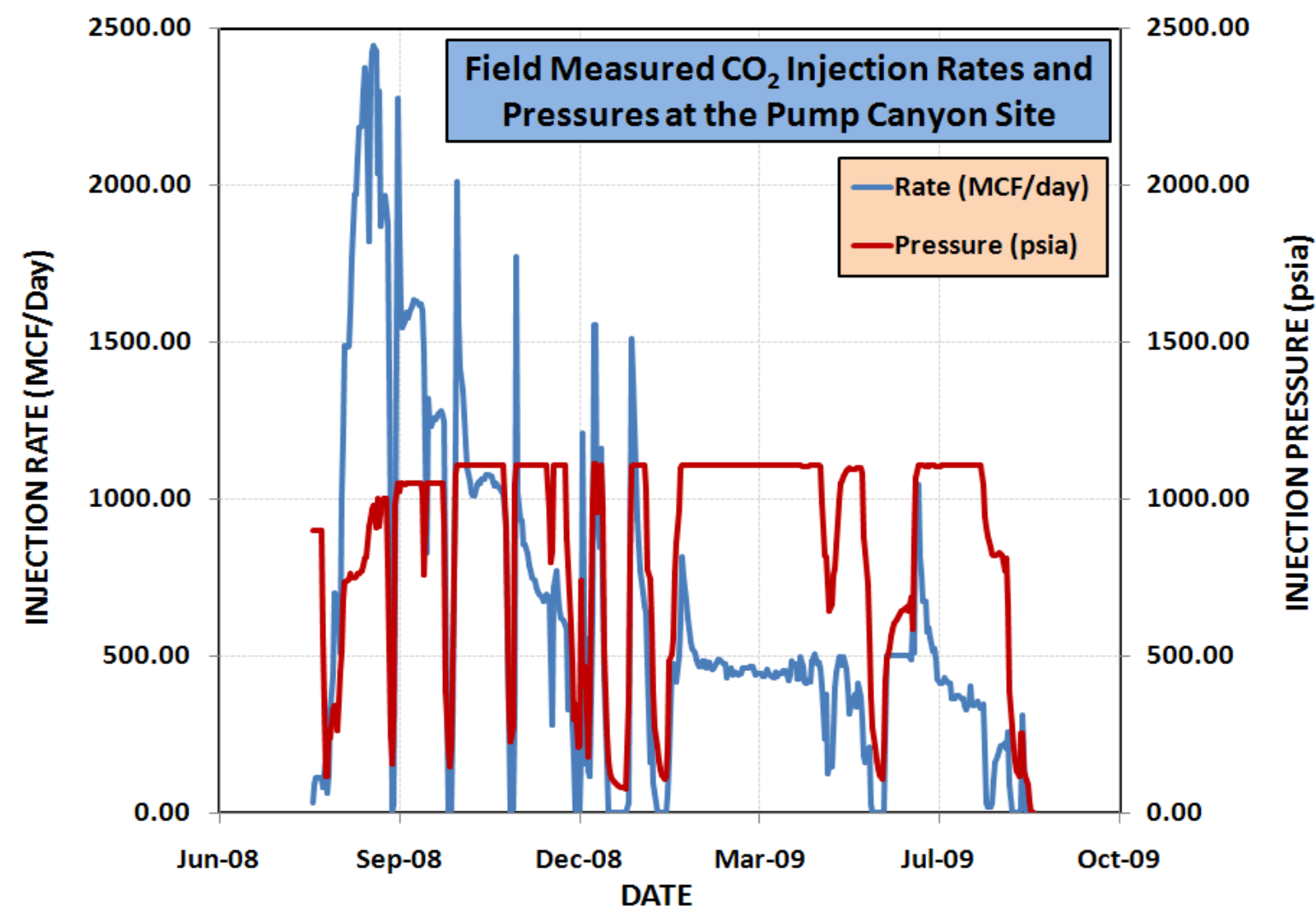

Figure 6.5: Field Measured Injection Pressures and Rates 


\section{3 - Simulating Injection of Carbon Dioxide}

Input parameters for injection modeling were extracted from the larger history matching grid and interpolated to fit the refined injection modeling grid. Reservoir porosity, reservoir permeability, reservoir pressure and water saturation values were among the parameters extracted from the history matching simulations and are shown in Figures 6.6, 6.7, 6.8, and 6.9, respectively. Several input parameters were material properties of the coal and remained constant across both the history matching an injection modeling grids. Table 6.2 shows a list of input parameters. The field measured daily injection rates displayed in Figure 6.5 were used as input for the model.

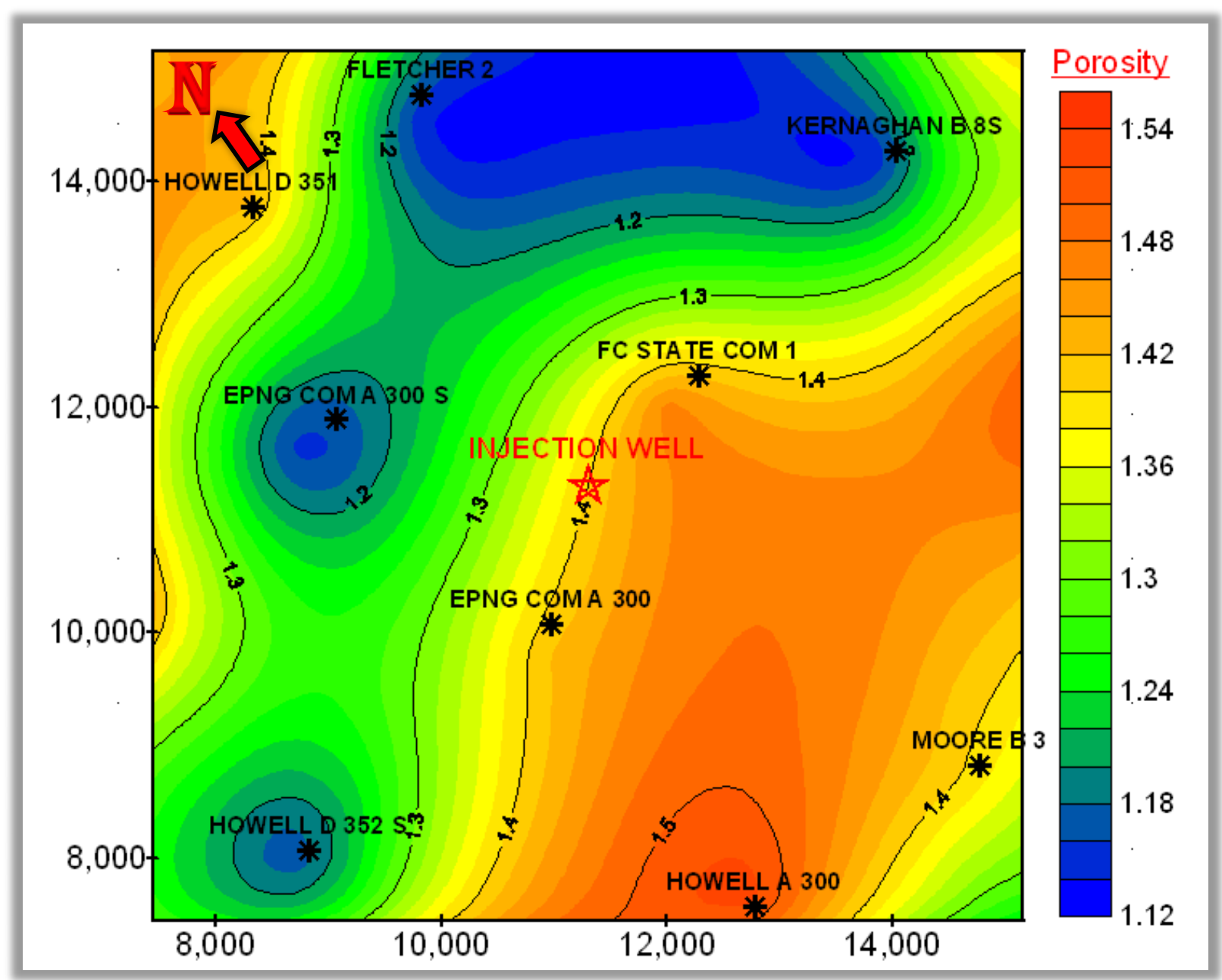

Figure 6.6: Initial Reservoir Porosity for the Refined Grid 


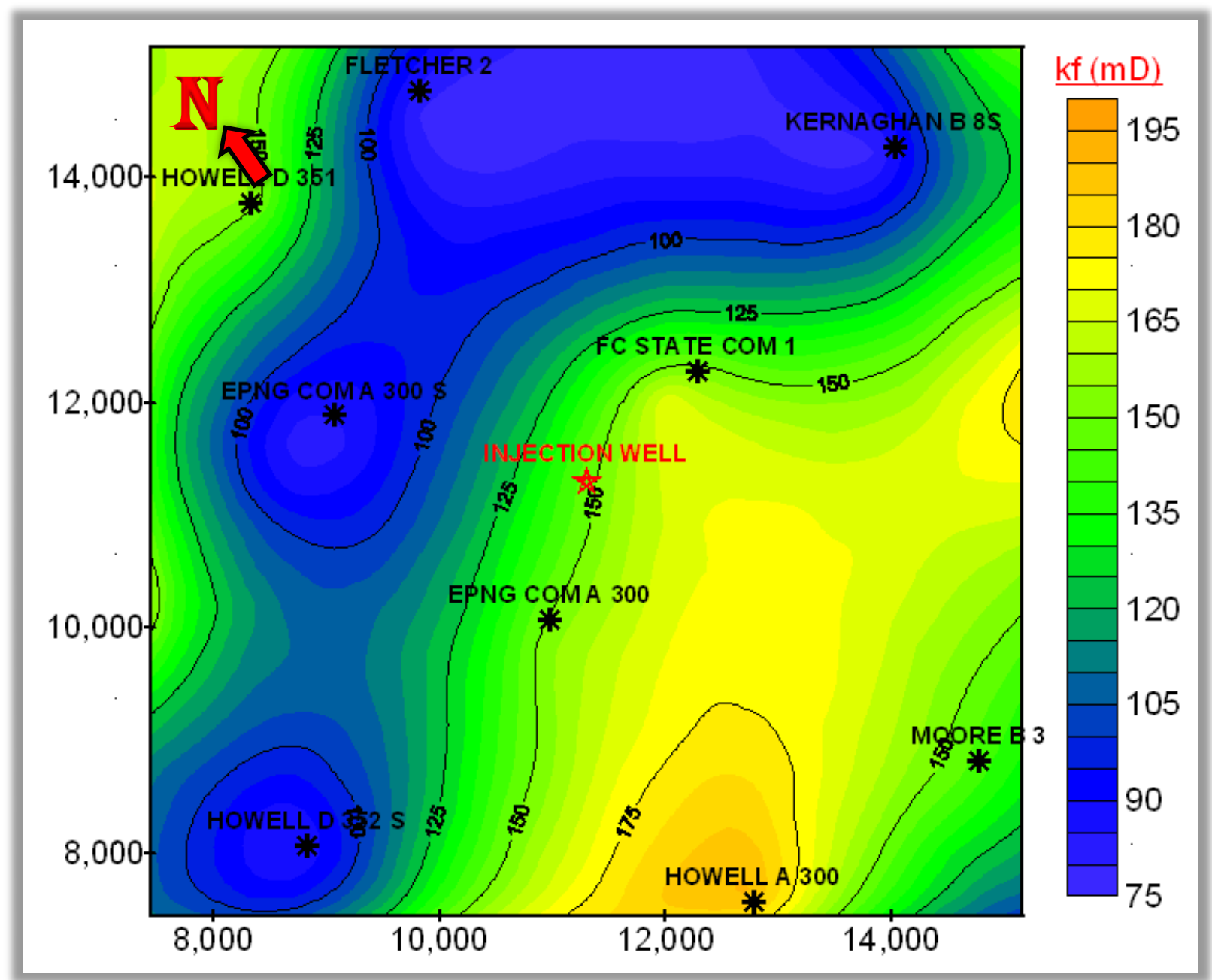

Figure 6.7: Initial Reservoir Face Cleat Permeability for the Refined Grid 


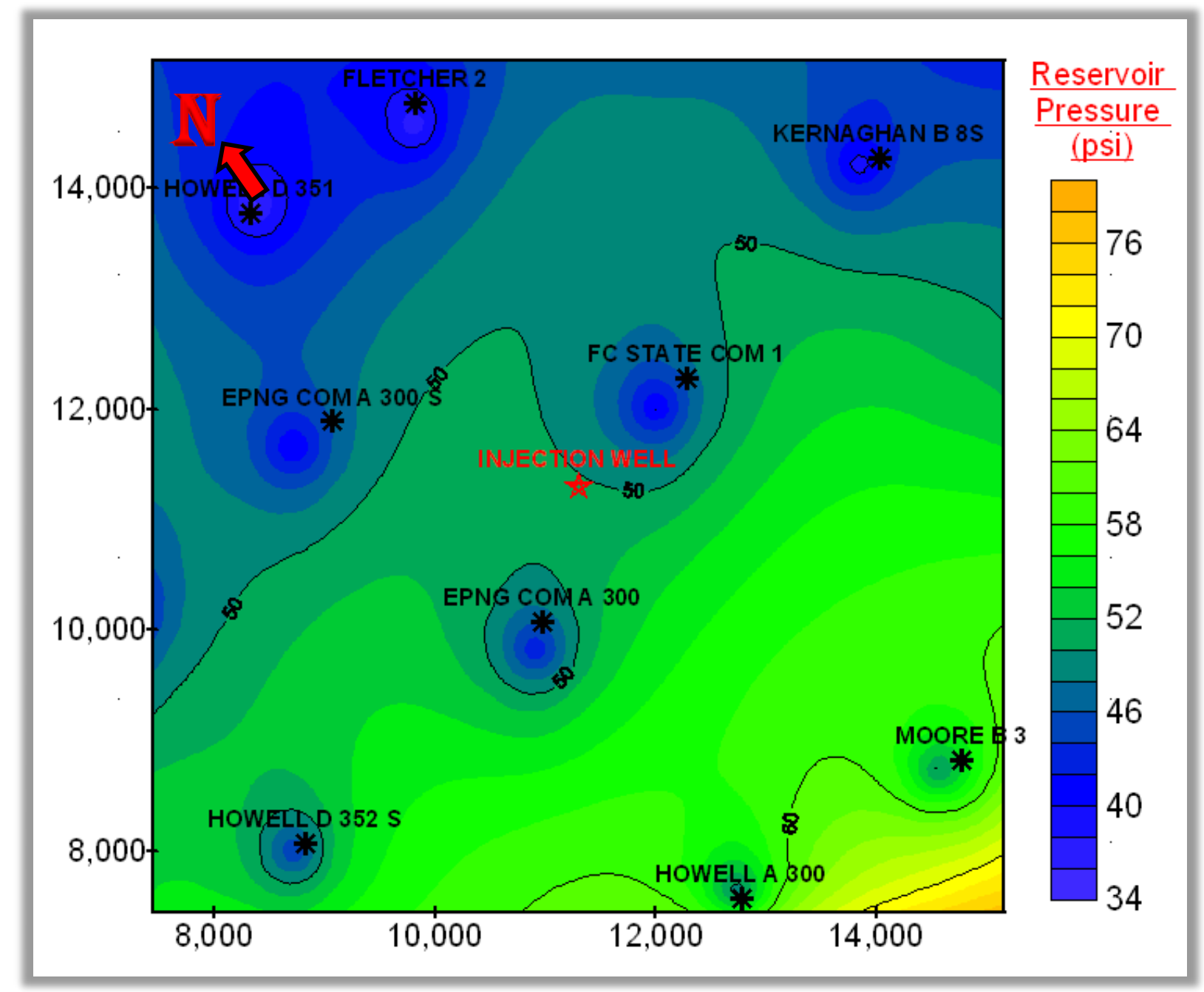

Figure 6.8: Initial Reservoir Pressure for the Refined Grid 


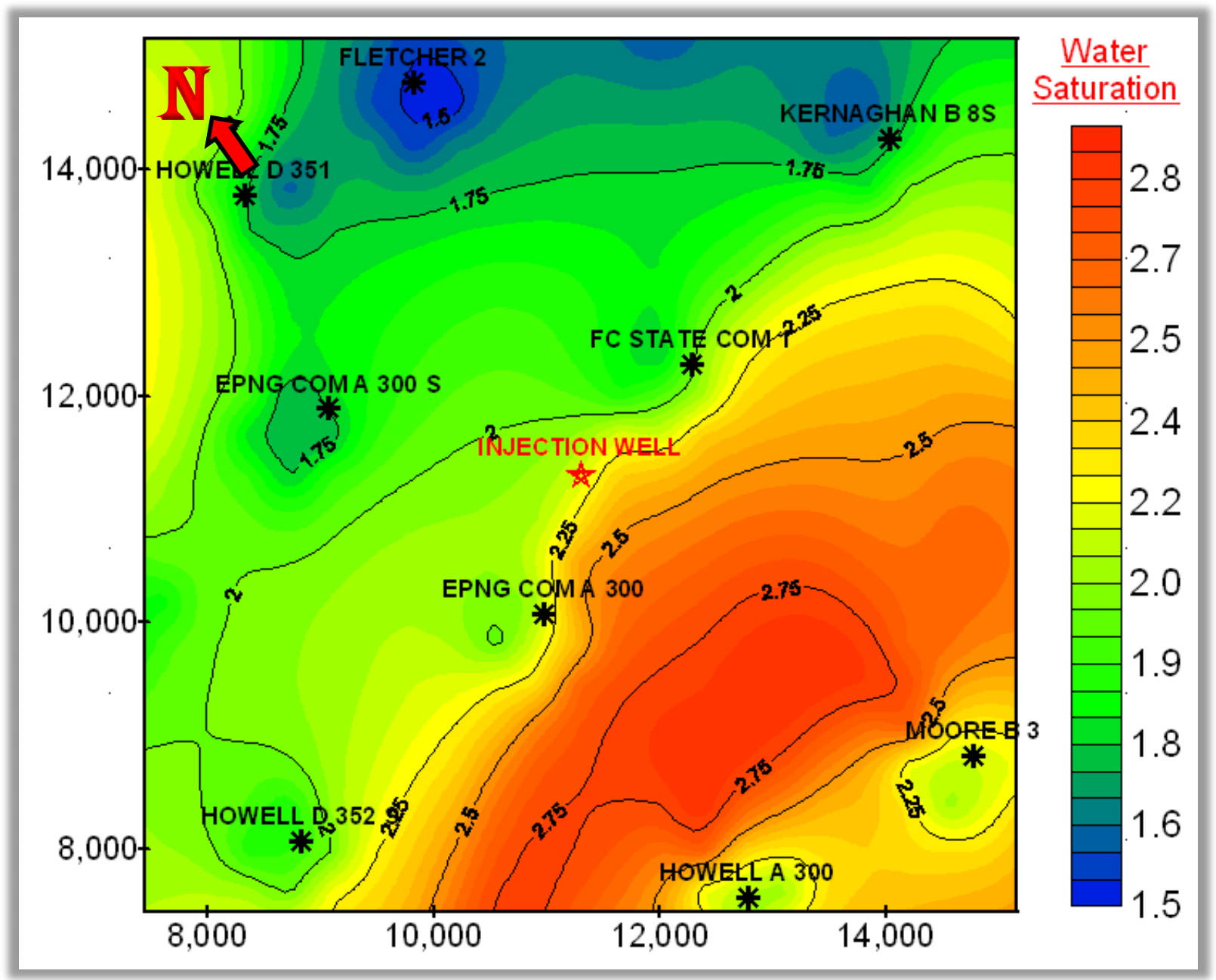

Figure 6.9: Initial Reservoir Water Saturation for the Refined Grid 
Table 6.2: Input Parameters used for Injection Modeling

\begin{tabular}{|c|c|}
\hline Reservoir Property & Input \\
\hline Reservoir Grid (I, J, K) & $63,63,1$ \\
\hline Individual Grid Block Size, I -Direction (feet) & $\begin{array}{c}12 \times 250,1 \times 155,1 \times 100,1 \times 80,1 \times 50,31 \times 30,1 \times 50, \\
1 \times 80,1 \times 100,1 \times 155,12 \times 250\end{array}$ \\
\hline Individual Grid Block Size, J -Direction (feet) & $\begin{array}{c}12 \times 250,1 \times 155,1 \times 100,1 \times 80,1 \times 50,31 \times 30,1 \times 50, \\
1 \times 80,1 \times 100,1 \times 155,12 \times 250\end{array}$ \\
\hline Reservoir Depth (feet) & 3,012 \\
\hline Reservoir Thickness (feet) & 60 (Average) \\
\hline Cleat Permeability $(\mathrm{mD})$ & Figure 6.7 \\
\hline Cleat Porosity (\%) & Figure 6.6 \\
\hline Permeability Anisotropy & $1.5-2.0$ \\
\hline Coal Density (pcf) & 99.88 \\
\hline Poisson's Ratio & 0.32 \\
\hline Elastic Modulus (psi) & 521,000 \\
\hline Palmer and Mansoori exponent & 3 \\
\hline $\mathrm{CH}_{4}$ Swelling/Shrinkage Constant (ton/SCF) & $3.0 \times 10^{-5}$ \\
\hline $\mathrm{CO}_{2}$ Swelling/Shrinkage Constant (ton/SCF) & $1.2 \times 10^{-5}$ \\
\hline Initial Reservoir Temperature $\left({ }^{0} \mathrm{~F}\right)$ & 126 \\
\hline Initial Reservoir Pressure (psi) & 1,700 \\
\hline Initial Water Saturation (\%) & 95 \\
\hline Water Viscosity (cp) & 0.7 \\
\hline Water Density (pcf) & 62.4 \\
\hline Gas Composition, $\%\left(\mathrm{CH}_{4}, \mathrm{CO}_{2}\right)$ & $(100,0)$ \\
\hline Sorption Volume Constant for $\mathrm{CH}_{4}(\mathrm{SCF} /$ ton $)$ & 490 (Weighted Average) \\
\hline Sorption Pressure Constant for $\mathrm{CH}_{4}$ (psig) & 548 (Weighted Average) \\
\hline Sorption Volume Constant for $\mathrm{CO}_{2}$ (SCF/ton) & 909 (Weighted Average) \\
\hline Sorption Pressure Constant for $\mathrm{CO}_{2}$ (psig) & 329 (Weighted Average) \\
\hline Initial Gas Composition - $\mathrm{CH}_{4}, \mathrm{CO}_{2}(\%, \%)$ & $(90,10)$ \\
\hline Minimum Bottomhole Pressure (psig) & 15 \\
\hline Coal Desorption Time (days) & 1 \\
\hline
\end{tabular}




\section{CHAPTER 7: TRACER MODELING}

\section{1 - Introduction to Tracers}

At the Pump Canyon site, perflourocarbon tracers (PFT's) were used to monitor reservoir behavior during sequestration operations. PFT's are an ideal choice for use in enhanced coalbed methane and carbon sequestration projects. These tracers are completely soluble in carbon dioxide allowing for a smooth and uniform mixture which increases the reliability of field results. In addition, PFT's are free of all toxins and radioactive materials making them environmentally friendly. PFT's are also non-reactive, giving them uninhibited movement through the coal seam for an accurate representation of fluid movement.

Produced gases are analyzed for tracer content and every month tracer data was recorded. Tracer movement through a reservoir can give valuable insight to the coal formation. Such monitoring techniques can hopefully be the first indication of any unknown heterogeneity in the reservoir. PFT tracers are capable of being detected in very small concentrations therefore injection volumes are small allowing minimal obtrusion to the reservoir.

\section{2 - Field Tracer Data}

Two tracers were dissolved in carbon dioxide and injected into the reservoir at the Pump Canyon Site. The first tracer consisted of 90\% $\mathrm{PMCH}$ and $10 \% \mathrm{PTCH}$, and was injected from September 18, 2008 through October 8, 2008. The second tracer consisted of 100\% PDCH and was injected from October 18, 2008 through November 12, 2008. Each tracer injection period lasted three weeks and consisted of a twenty liter injection volume. The daily volume of tracer injected into the reservoir is unknown, however it is a very small portion of total injection volume.

Tracer signal at production wells were measured every two months after injection of the tracers. Figure 7.1 shows field measured tracer data. This is a coarse measurement, and although the results accurately portray the timing of tracer arrival at production wells, the rise and fall of tracer signals is measured roughly. Only the two production wells closest to the 
injection well saw tracer signals, FC State Com 1 and EPNG Com A 300. These two wells are approximately the same distance away from the injection well with EPNG Com A 300 being to the southwest and FC State Com 1 to the east. Tracers reach the east offset well about 90 days after injection. The southwest offset well saw tracer production after about 240 days.

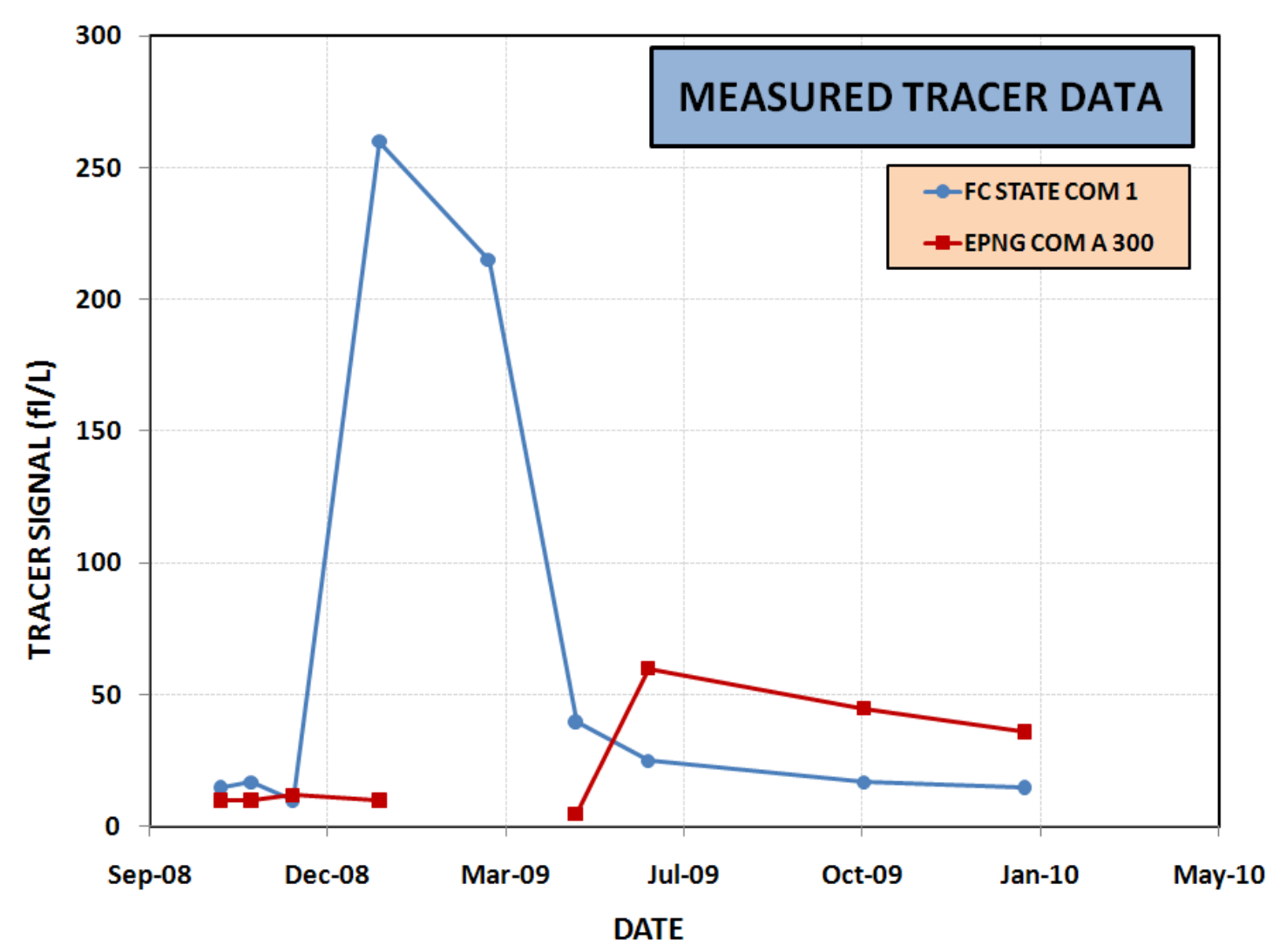

Figure 7.1: Measured Tracer Signal Data 


\section{3 - Modeling Tracer Injection}

For simulation purposes, only one tracer was introduced to the reservoir. The exact properties of the tracers are unknown, however tracers are known to be conservative. The injected tracer was assumed to be a percentage of the daily injection volume during the injection period. The tracer injection period was assumed to be continuous from September 18, 2008 through November 12, 2008. Tracers were introduced into the reservoir along with carbon dioxide and their movement through the coal matrix was simulated. Tracer production at nearby production wells may give information on reservoir anisotropy and any reservoir heterogeneity that may exist. 


\section{CHAPTER 8: MODELING RESULTS}

\section{1 - History Matching Results}

The primary goal of history matching is to generate reasonable estimates of unknown reservoir properties. In order to obtain accurate estimates for the Pump Canyon reservoir system, the entire study region was taken into account during this phase of modeling. An error analysis was performed on the wells closest to the injector to quantify the comparison of computed and measured values. While an emphasis was placed on correctly estimating geologic properties near the injection well, the entire study region was taken into account during the history matching process. Wells on the boundary were not investigated on a well by well basis like those on the interior of the grid; however the computed cumulative CBM production from the reservoir was compared with its measured counterpart to ensure that the model is consistent with historical data. Figure 8.1 shows the Finite difference modeling grid. An index of those wells represented on the grid can be found in Chapter 5.

A parametric analysis was used to generate an estimate of the anisotropy of the reservoir. Reservoir anisotropy is the ratio and reservoir anisotropies of 1.5 and 2 were investigated. Assumed reservoir anisotropy was determined by the best fit of two criteria: 1) a comparison of computed and measured cumulative CBM production in the reservoir, and 2) the normalized error between simulated and measured CBM production at each of the wells of interest. Figure 8.2 shows the influence of reservoir anisotropy on cumulative CBM production in the reservoir. The process used to determine normalized error of each well is shown in Equations 8.1 and 8.2. The results of the comparison are shown in Tables 8.1 and 8.2. A comparison of measured and simulated values for the wells of interest is shown is Figures 8.3 - 8.15. Figure 8.16 shows a comparison of simulated total CBM production and field production data. A comparison of simulated and measured bottomhole pressures is presented in Figure 8.17. Using this approach, an anisotropic factor of 1.5 is assumed for the reservoir. 
The normalized error $\left(\psi_{\text {Cumulative }}\right)$ for cumulative gas production was defined as:

$$
\psi_{\text {CUMULATIVE }}=\sum \frac{Q_{\text {MEASURED }}-Q_{\text {SIMULATED }}}{Q_{\text {MEASURED-MAX }}}
$$

where;

$\psi_{\text {Cumulative }}=$ normalized error for cumulative gas production

$\mathrm{Q}_{\text {Measured }}=$ measured cumulative gas production at any period of time

$\mathrm{Q}_{\text {Simulated }}=$ simulated cumulative gas production rate at any period of time

$\mathrm{Q}_{\text {Measured-Max }}=$ Maximum measured gas production

$\psi_{\text {WELL }}=\sum \frac{q_{\text {MEASURED }}-q_{\text {SIMULATED }}}{q_{\text {MEASURED-MAX }}}$

where;

$\psi_{\text {Well }}=$ normalized error for gas production rate of individual production well

$\mathrm{q}_{\text {Measured }}=$ measured gas production rate at any period of time

$\mathrm{q}_{\text {Simulated }}=$ simulated gas production rate at any period of time

$\mathrm{q}$ Measured-Max $=$ Maximum measured gas production rate

Reservoir pressure was also taken into account during history matching. Over the years reservoir pressure was measured at certain wells in the study area. Figure 8.19 shows a comparison between those measure values and their simulated counterparts. Overall the match between simulated reservoir pressures and measured values is good, especially in the later stages of production. Between an acceptable match of simulated and measured production rates and a good overall match of simulated reservoir pressure over time, it was determined that the assumed parameters used in the reservoir were acceptable estimates of reservoir properties. 


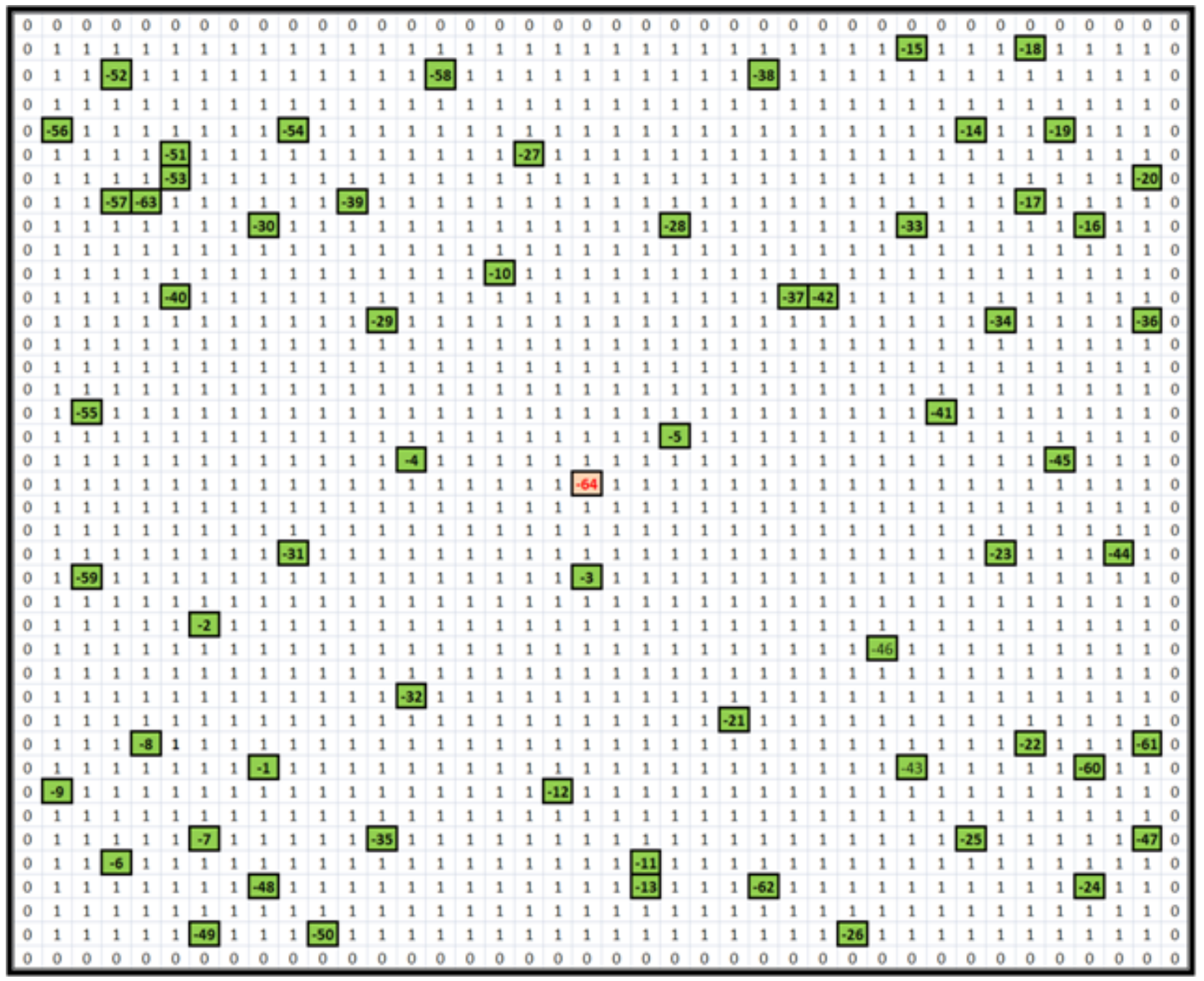

$\# \quad=$ PRODUCTION WELL

\# = INJECTION WELL

1 = ACTIVE GRID BLOCK

Figure 8.1: Finite Difference Grid Used for History Matching 


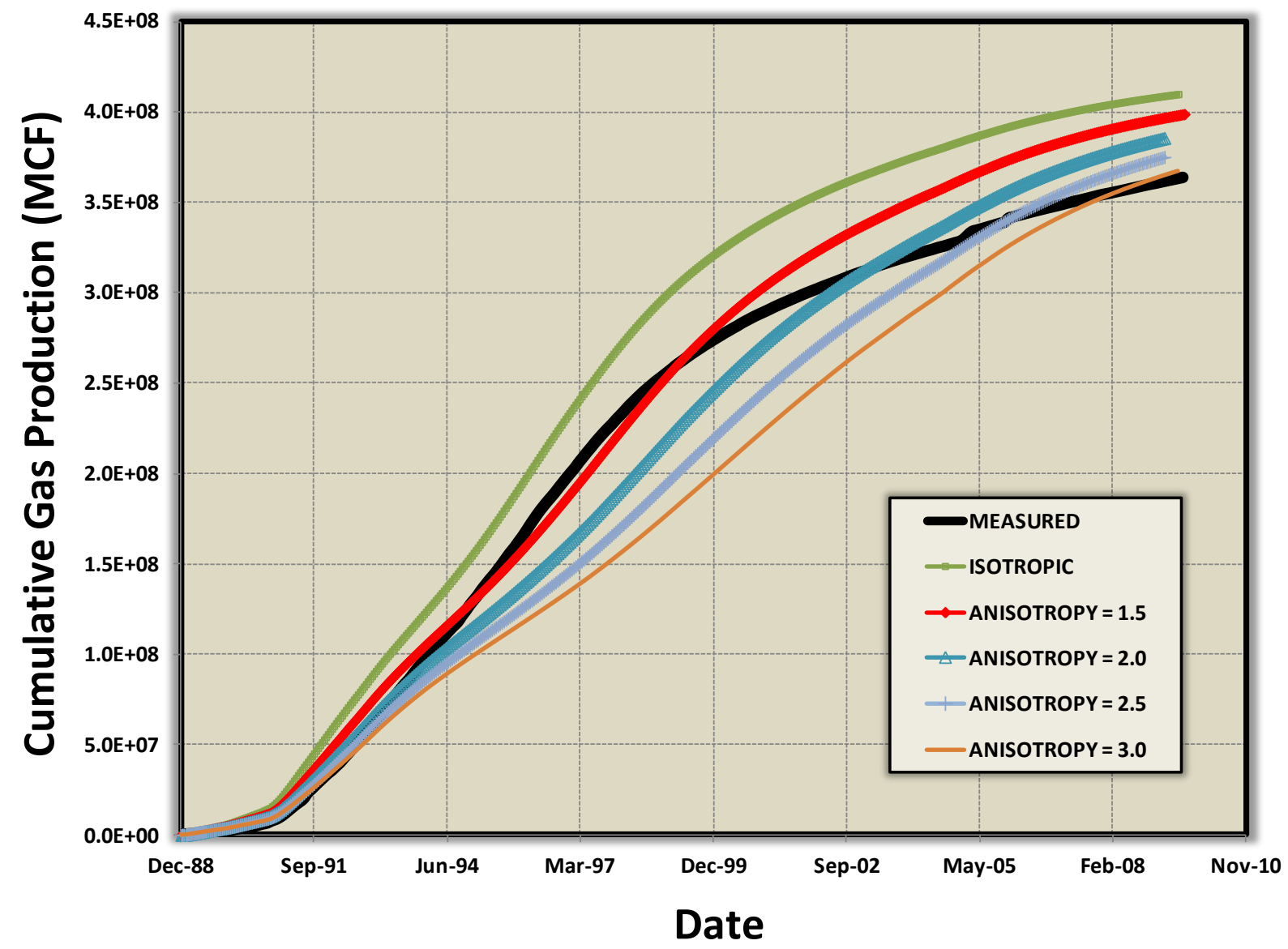

Figure 8.2: Influence of Reservoir Anisotropy on Cumulative CBM Production 


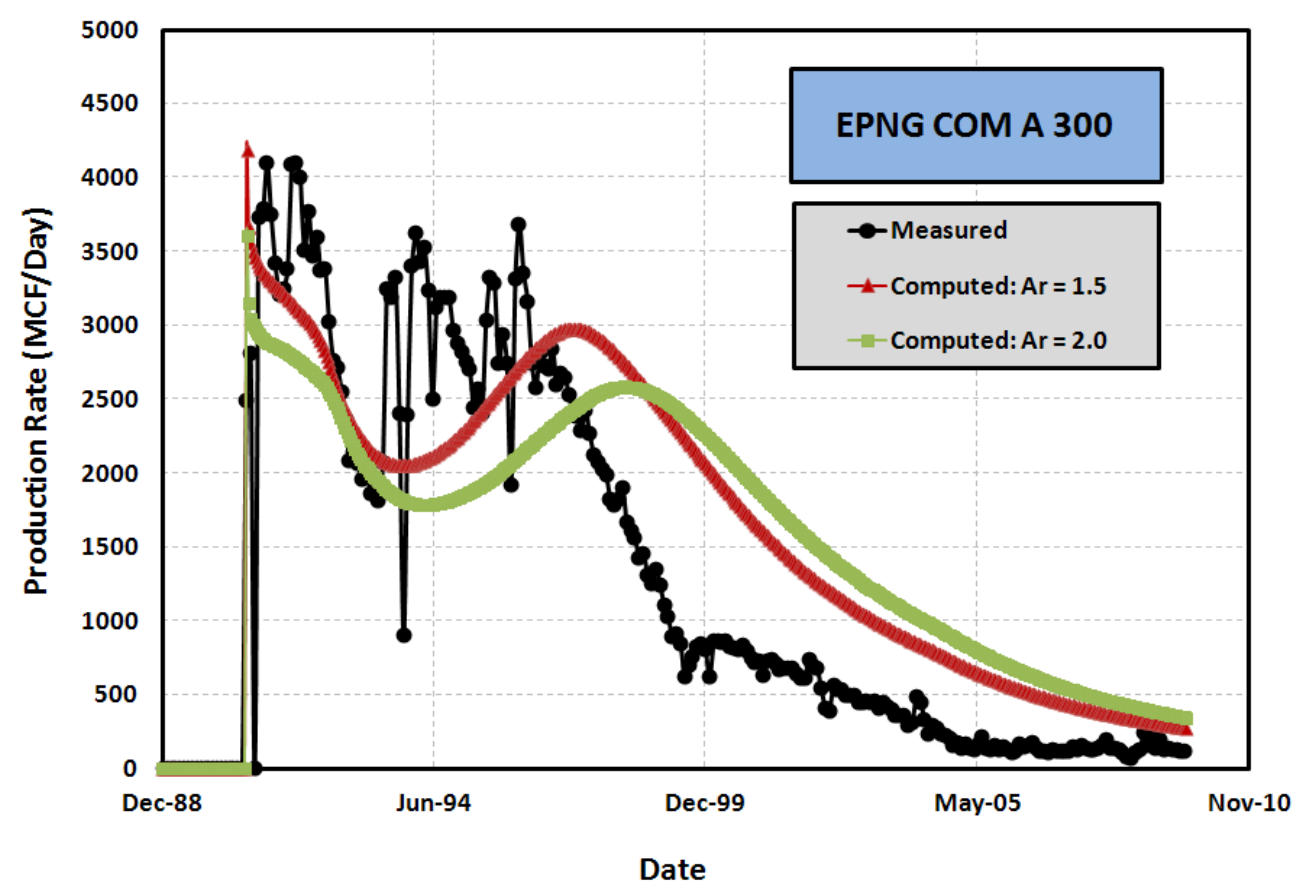

Figure 8.3: History Matching Results for EPNG Com A 300

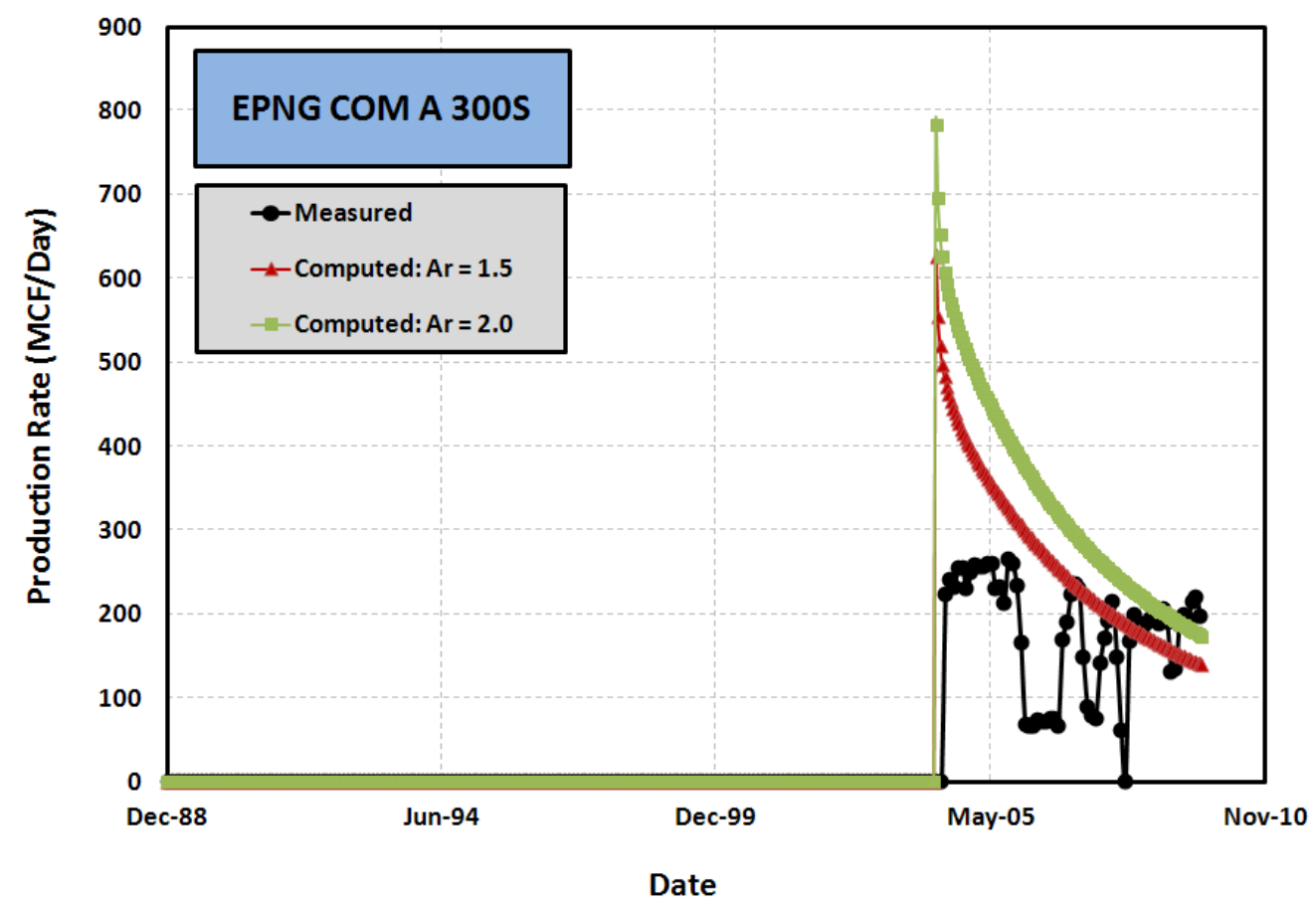

Figure 8.4: History Matching Results for EPNG Com A 300S 


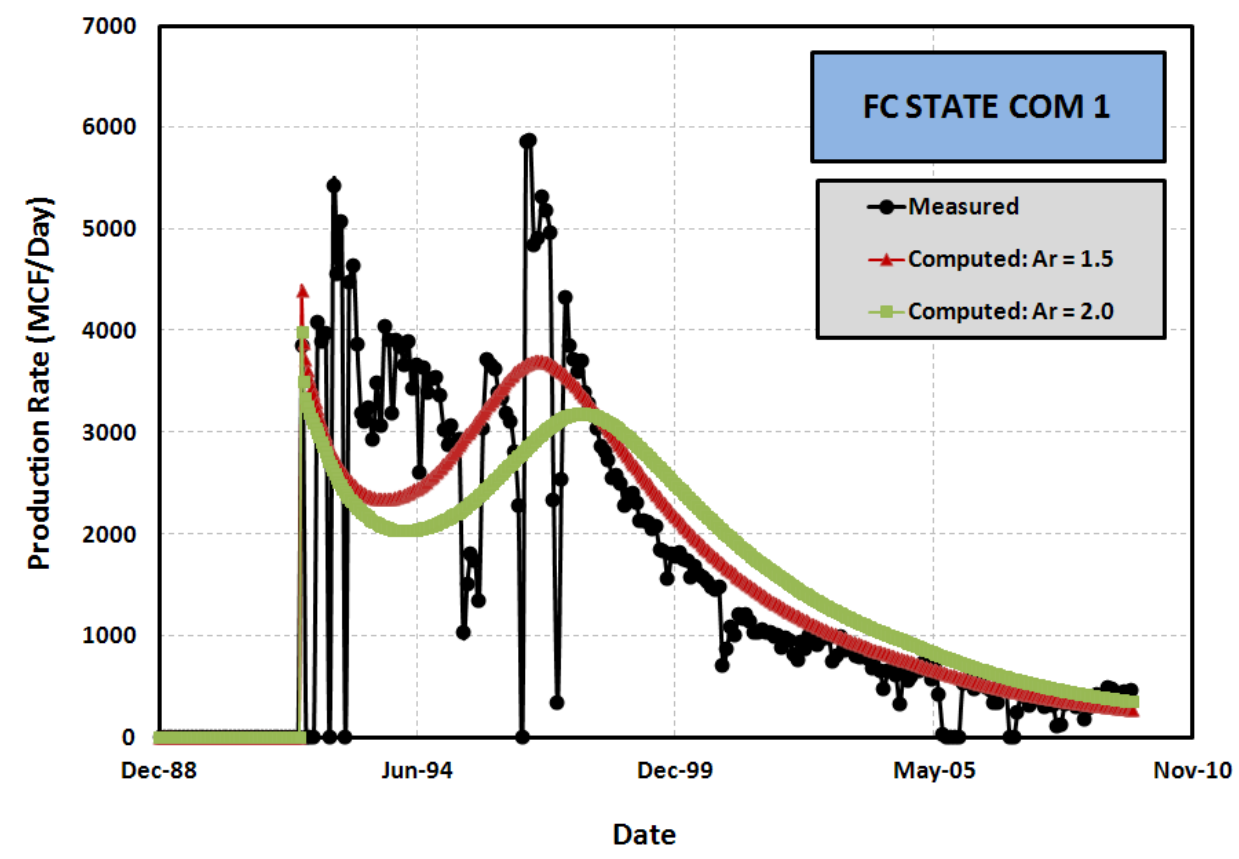

Figure 8.5: History Matching Results for FC State Com 1

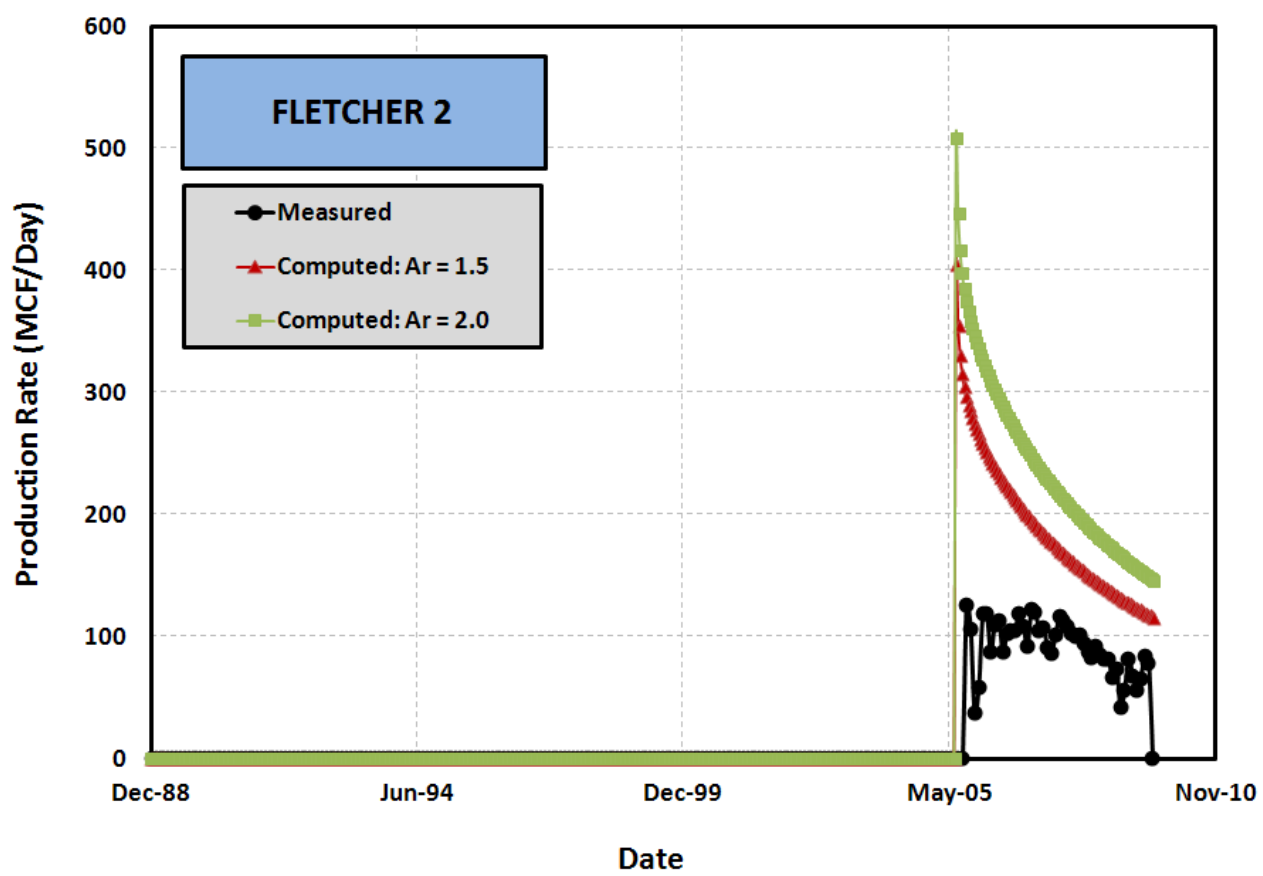

Figure 8.6: History Matching Results for FC State Com 4 


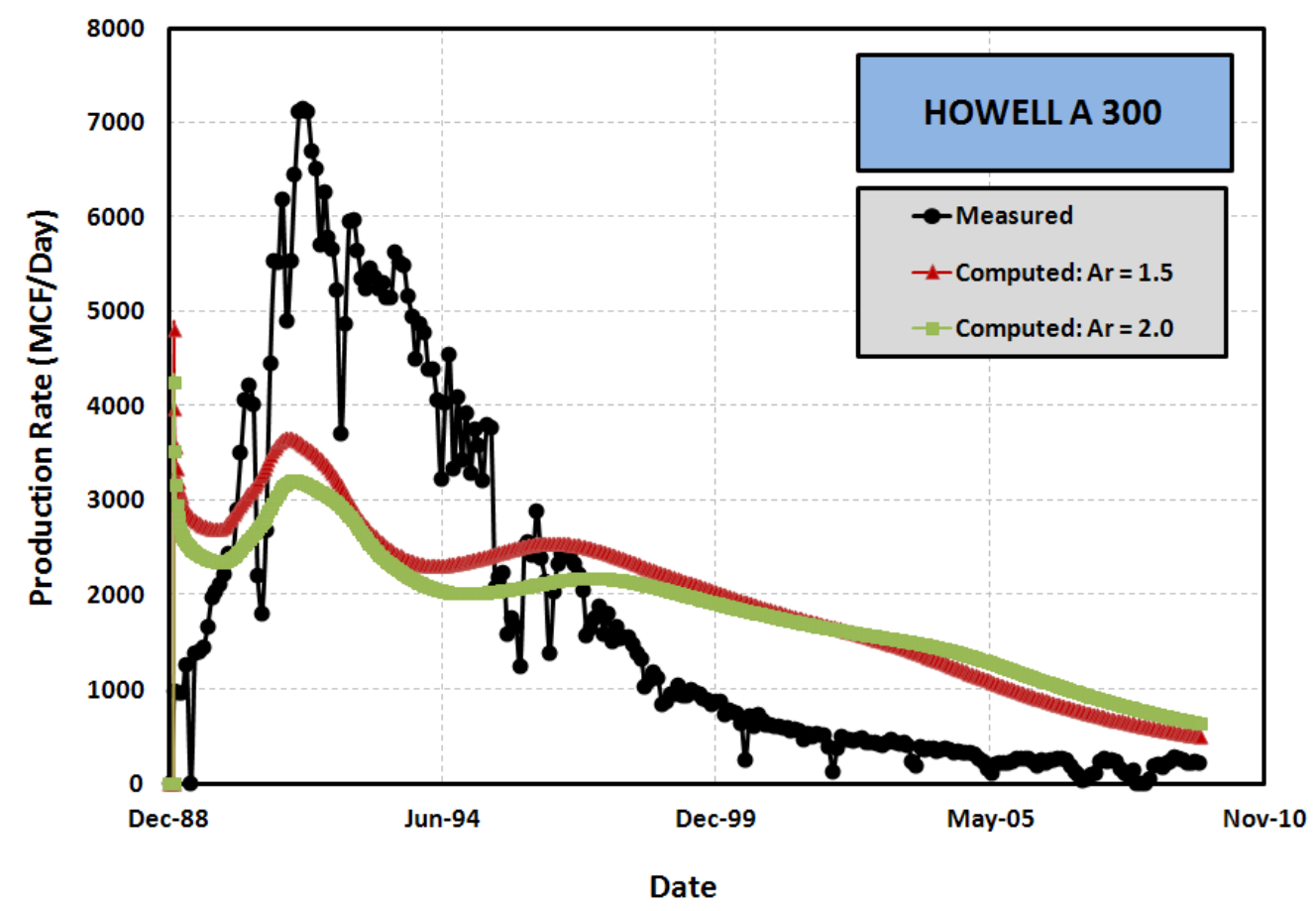

Figure 8.7: History Matching Results for Fletcher 2



Figure 8.8: History Matching Results for Hale 350 


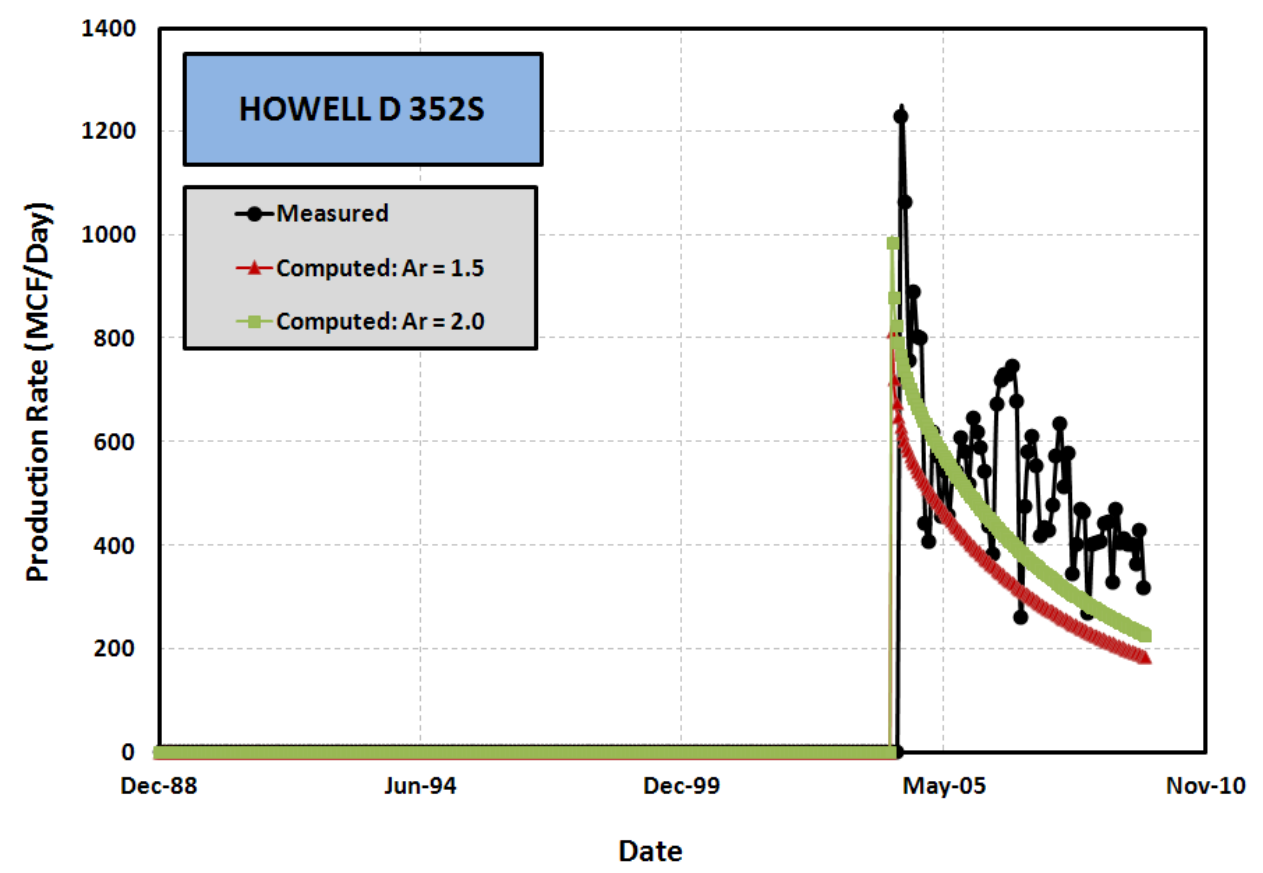

Figure 8.9: History Matching Results for Howell A 300

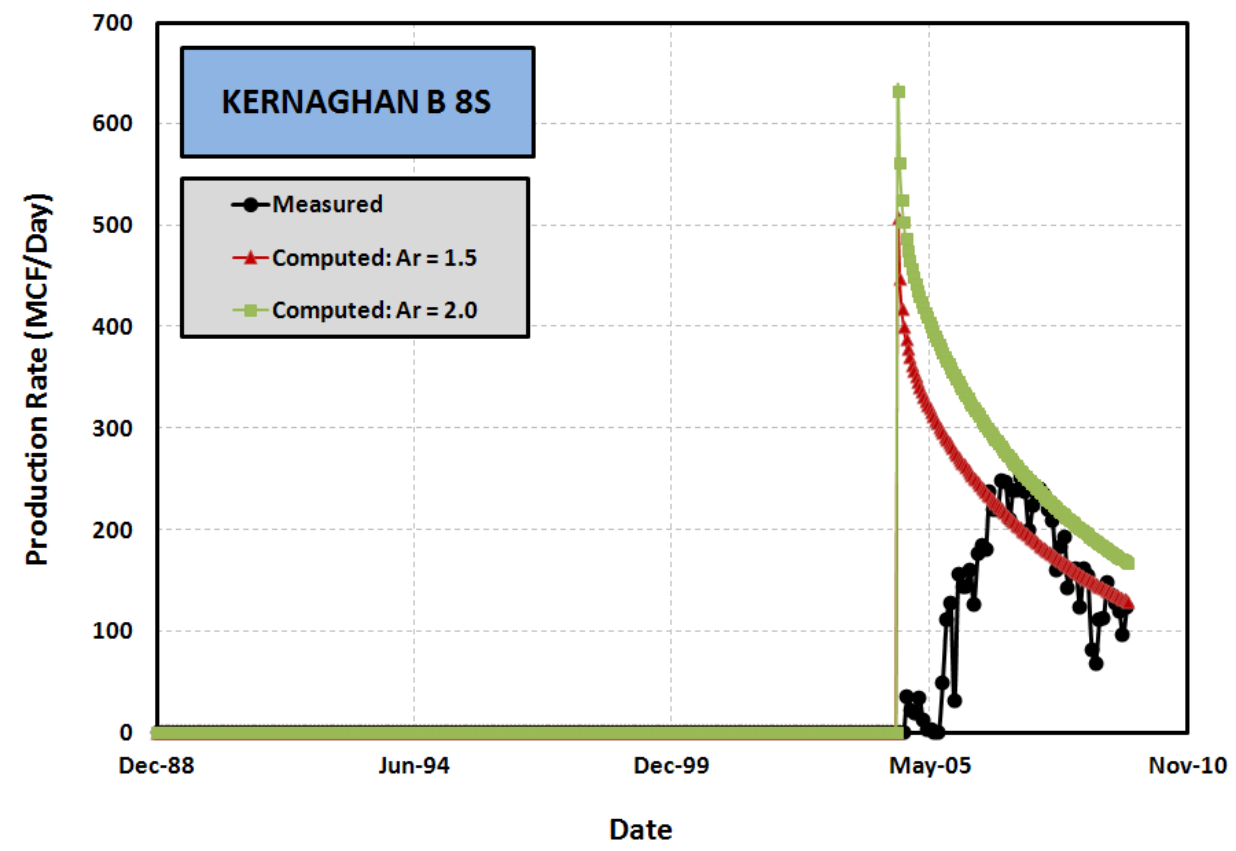

Figure 8.10: History Matching Results for Howell D 351 


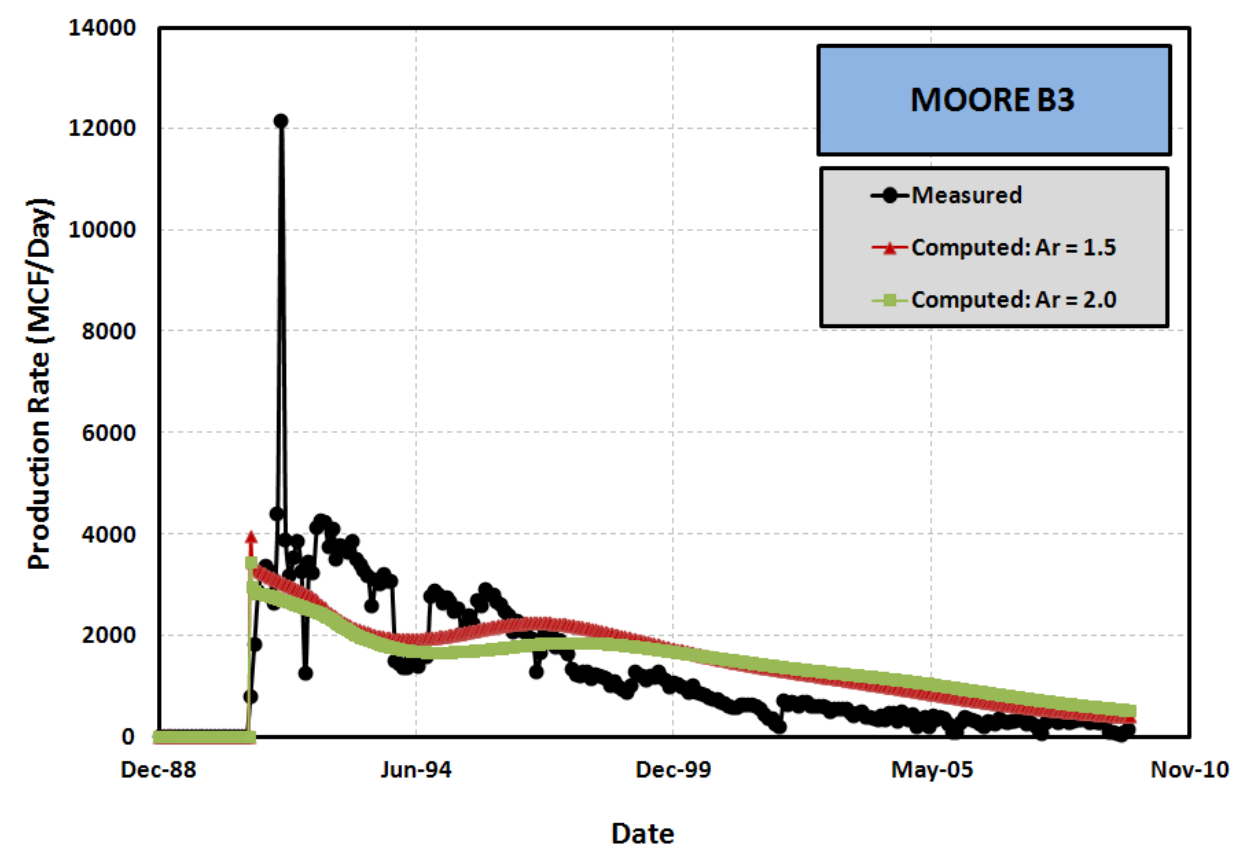

Figure 8.11: History Matching Results for Howell D 352 S



Figure 8.12: History Matching Results for Total CBM Production 
Table 8.1: Normalized Error of CBM Production

\begin{tabular}{|c|c|c|c|c|c|}
\hline & \multicolumn{5}{|c|}{$\psi_{\text {well }}$} \\
\cline { 2 - 6 } & $\mathrm{Ar}=1$ & $\mathrm{Ar}=1.5$ & $\mathrm{Ar}=2$ & $\mathrm{Ar}=2.5$ & $\mathrm{Ar}=3$ \\
\hline Well \# 3 & -22.16 & -18.42 & -14.85 & -11.24 & -8.23 \\
\hline Well \# 4 & -5.48 & -22.38 & -38.21 & -52.72 & -65.13 \\
\hline Well \# 5 & -2.40 & -2.26 & -1.18 & 0.02 & 1.49 \\
\hline Well \# 10 & -17.42 & -36.51 & -54.52 & -72.52 & -89.35 \\
\hline Well \# 21 & -12.02 & -6.19 & -1.94 & 1.38 & 4.41 \\
\hline Well \# 29 & -24.64 & -18.63 & -14.04 & -9.98 & -6.59 \\
\hline Well \# 32 & 12.97 & 8.43 & 4.40 & 0.97 & -2.45 \\
\hline Well \# 42 & -4.41 & -19.06 & -33.15 & -46.91 & -59.83 \\
\hline Well \# 46 & -19.16 & -14.64 & -10.71 & -7.31 & -4.15 \\
\hline Cumulative & -24.17 & -7.90 & 4.49 & 14.44 & 22.75 \\
\hline
\end{tabular}

Table 8.2: Square of the Normalized Error of CBM Production

\begin{tabular}{|c|c|c|c|c|c|}
\hline & \multicolumn{5}{|c|}{$\left(\psi_{\text {well }}\right)^{2}$} \\
\cline { 2 - 6 } & $\mathrm{Ar}=1$ & $\mathrm{Ar}=1.5$ & $\mathrm{Ar}=2$ & $\mathrm{Ar}=2.5$ & $\mathrm{Ar}=3$ \\
\hline Well \# 3 & 4.43 & 7.40 & 10.75 & 13.27 & 15.13 \\
\hline Well \# 4 & 5.94 & 16.61 & 36.34 & 62.63 & 91.07 \\
\hline Well \# 5 & 3.68 & 3.30 & 4.86 & 6.60 & 8.11 \\
\hline Well \# 10 & 11.11 & 38.02 & 79.74 & 137.16 & 204.90 \\
\hline Well \# 21 & 8.06 & 9.40 & 10.60 & 11.59 & 12.41 \\
\hline Well \# 29 & 8.90 & 7.86 & 8.42 & 9.20 & 9.96 \\
\hline Well \# 32 & 3.29 & 1.73 & 0.98 & 0.80 & 1.05 \\
\hline Well \# 42 & 11.74 & 21.56 & 38.52 & 62.18 & 90.76 \\
\hline Well \# 46 & 6.17 & 6.77 & 7.87 & 8.82 & 9.57 \\
\hline Cumulative & 2.80 & 0.71 & 0.86 & 2.02 & 3.71 \\
\hline
\end{tabular}


Table 8.3: Coefficient of Correlation of CBM Production

\begin{tabular}{|c|c|c|c|c|c|}
\hline & \multicolumn{5}{|c|}{$\mathrm{R}^{2}$} \\
\cline { 2 - 6 } & $\mathrm{Ar}=1$ & $\mathrm{Ar}=1.5$ & $\mathrm{Ar}=2$ & $\mathrm{Ar}=2.5$ & $\mathrm{Ar}=3$ \\
\hline Well \# 3 & 0.90 & 0.73 & 0.55 & 0.42 & 0.32 \\
\hline Well \# 4 & 0.14 & 0.13 & 0.13 & 0.13 & 0.13 \\
\hline Well \# 5 & 0.71 & 0.72 & 0.59 & 0.44 & 0.30 \\
\hline Well \# 10 & 0.09 & 0.09 & 0.09 & 0.09 & 0.10 \\
\hline Well \# 21 & 0.62 & 0.61 & 0.64 & 0.68 & 0.72 \\
\hline Well \# 29 & 0.66 & 0.56 & 0.45 & 0.37 & 0.30 \\
\hline Well \# 32 & 0.44 & 0.44 & 0.44 & 0.44 & 0.43 \\
\hline Well \# 42 & 0.27 & 0.27 & 0.26 & 0.26 & 0.26 \\
\hline Well \# 46 & 0.74 & 0.69 & 0.67 & 0.67 & 0.68 \\
\hline Cumulative & 0.9990 & 0.9906 & 0.9753 & 0.9595 & 0.9451 \\
\hline
\end{tabular}

Table 8.4: Summary of Statistics of CBM Production

\begin{tabular}{|c|c|c|c|}
\hline $\mathrm{A}_{\mathrm{r}}$ & $\mathrm{R}^{2}$ & $\psi_{\text {cumulative }}$ & $\left(\psi_{\text {cumulative }}\right)^{2}$ \\
\hline 1.0 & 0.999 & -24.17 & 2.80 \\
\hline 1.5 & 0.9906 & -7.90 & 0.71 \\
\hline 2.0 & 0.9753 & 4.49 & 0.86 \\
\hline 2.5 & 0.9595 & 14.44 & 2.02 \\
\hline 3.0 & 0.9451 & 22.75 & 3.71 \\
\hline
\end{tabular}




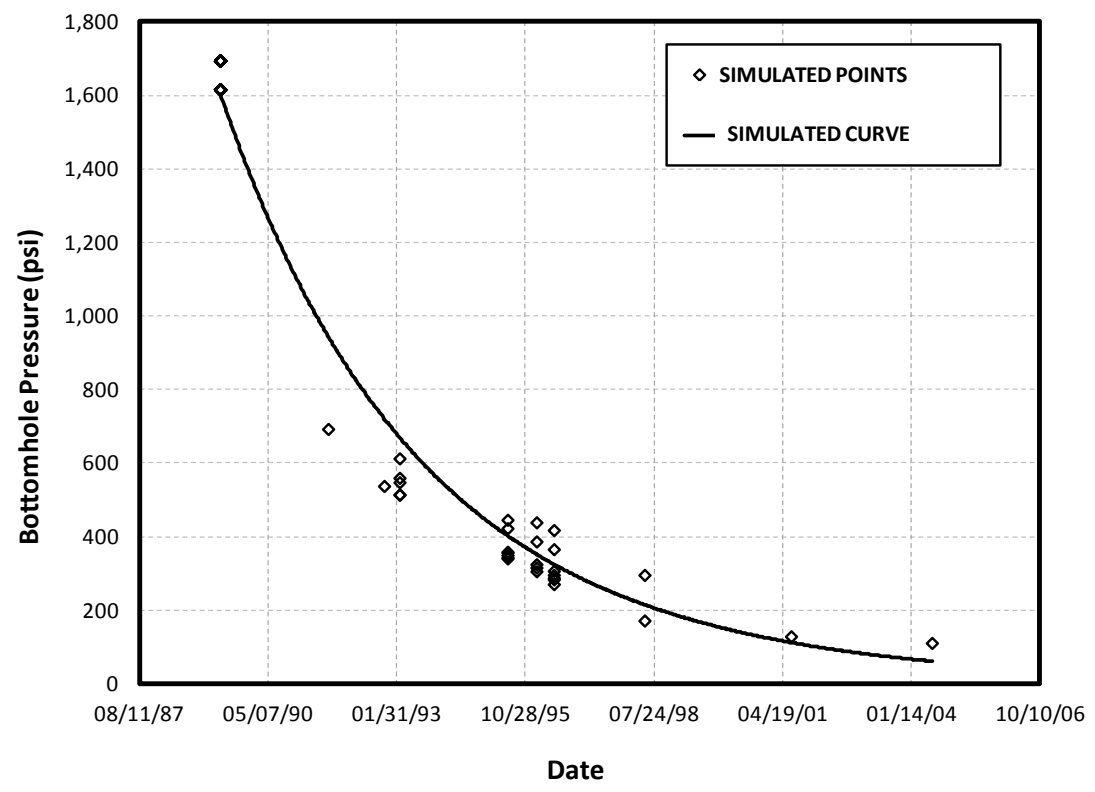

Figure 8.13: Comparison of Measured and Simulated Reservoir Pressures

\section{2 - Injection Modeling Results}

Injection pressures were simulated during injection modeling. Figure 8.18 shows a comparison between the simulated injection pressure and field measured values. Injection pressure matches are good in the early stages of injection, however with ongoing sequestration the simulated pressures fell well below field measured values.

Of particular interest during injection modeling is the pressure distribution around the injection well. Resolution around the injector was the reason for creating the refined grid. A sample pressure contour from January 23, 2009 is shown in Figure 8.19. 


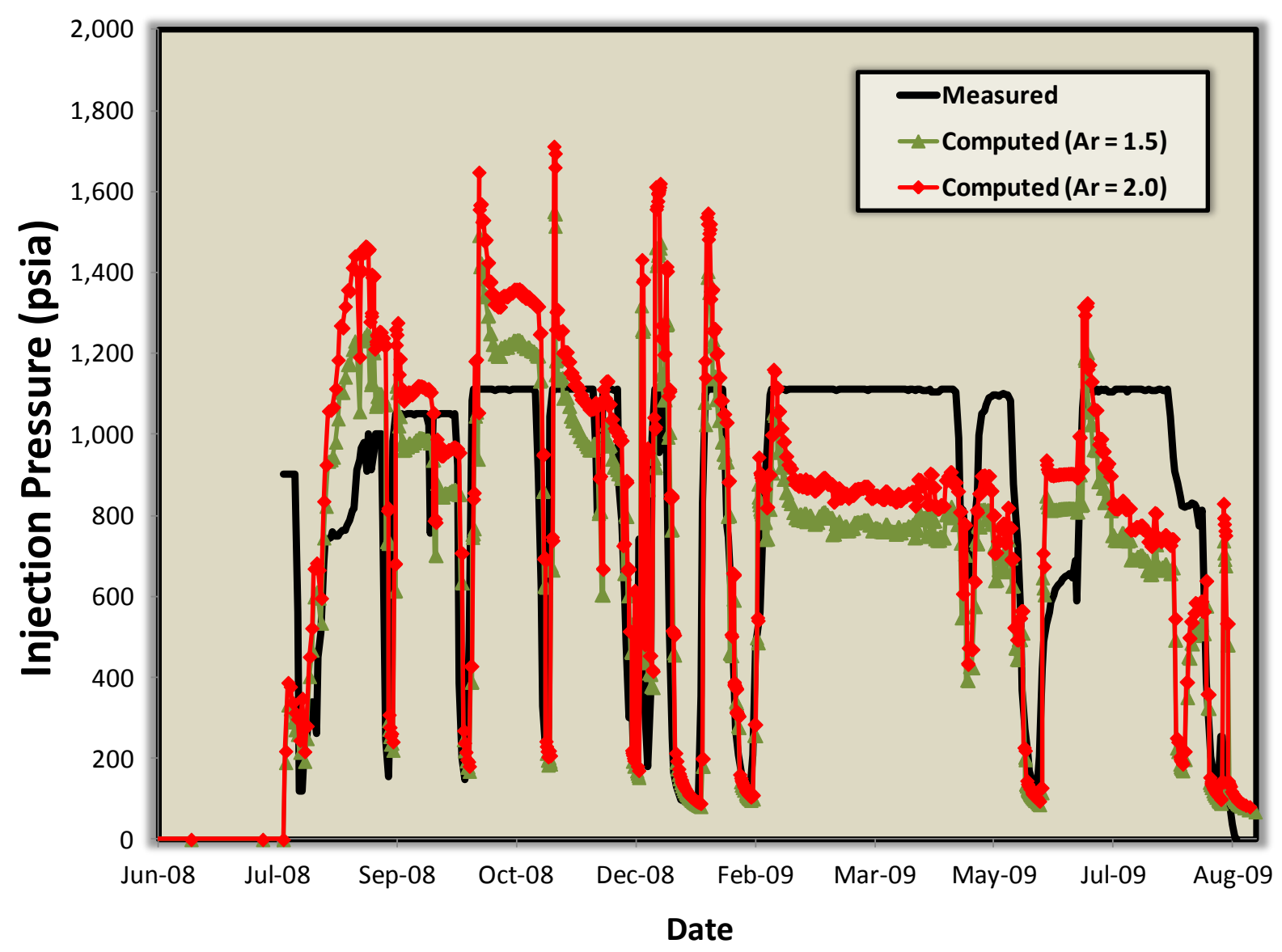

Figure 8.14: Comparison of Measured and Simulated Injection Pressures 


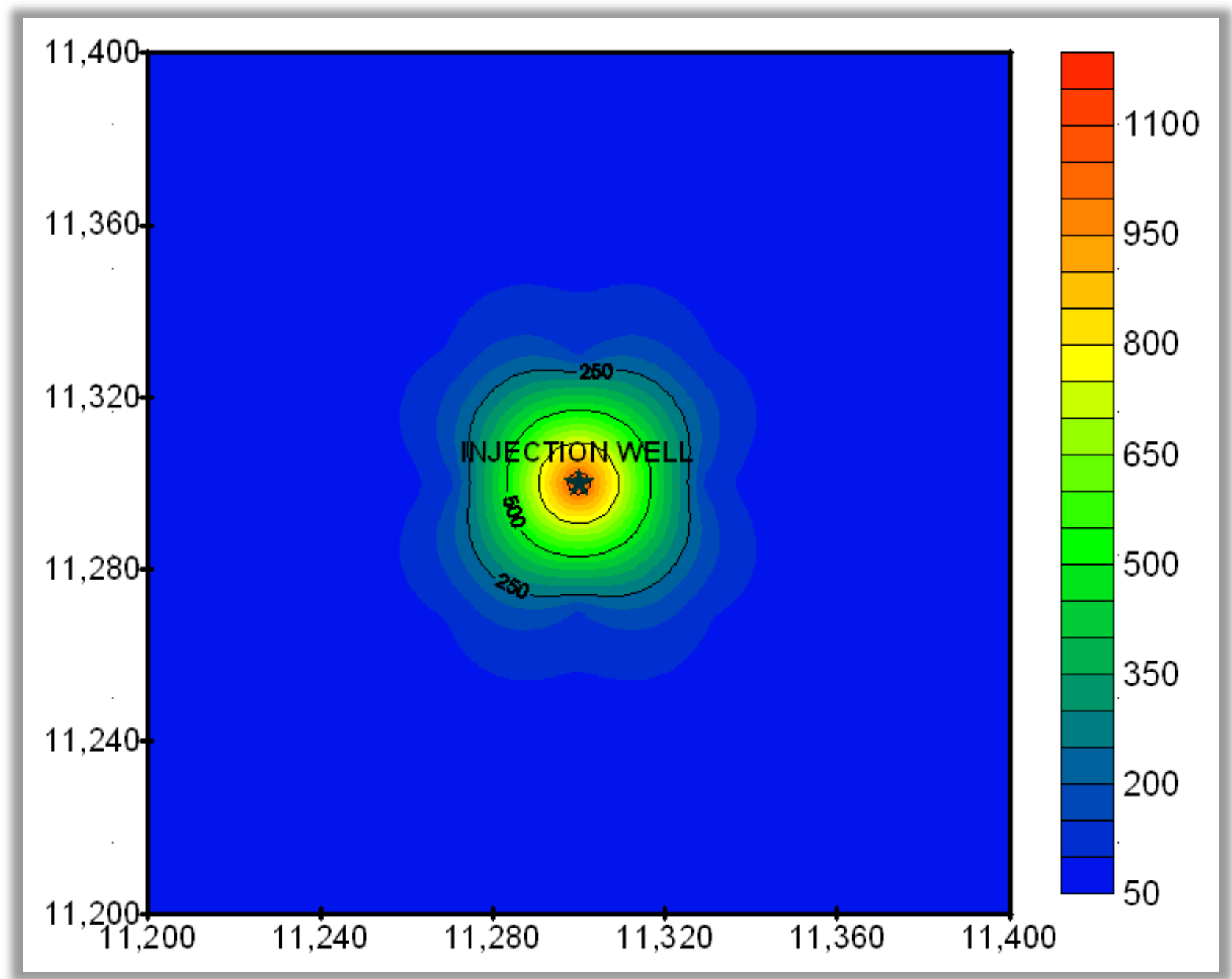

Figure 8.15: Pressure Distribution During Injection of Carbon Dioxide

\section{3 - Tracer Modeling Results}

Tracer injection and production was simulated while production in the study area was continued. During tracer modeling, measurable amounts of injected tracer were only seen at the two wells closest to the injection well. Comparisons of field measured tracer data and simulated tracer production are shown for those two wells, FC State Com1 and EPNG Com A 300, in Figures 8.20 and 8.21 , respectively. 


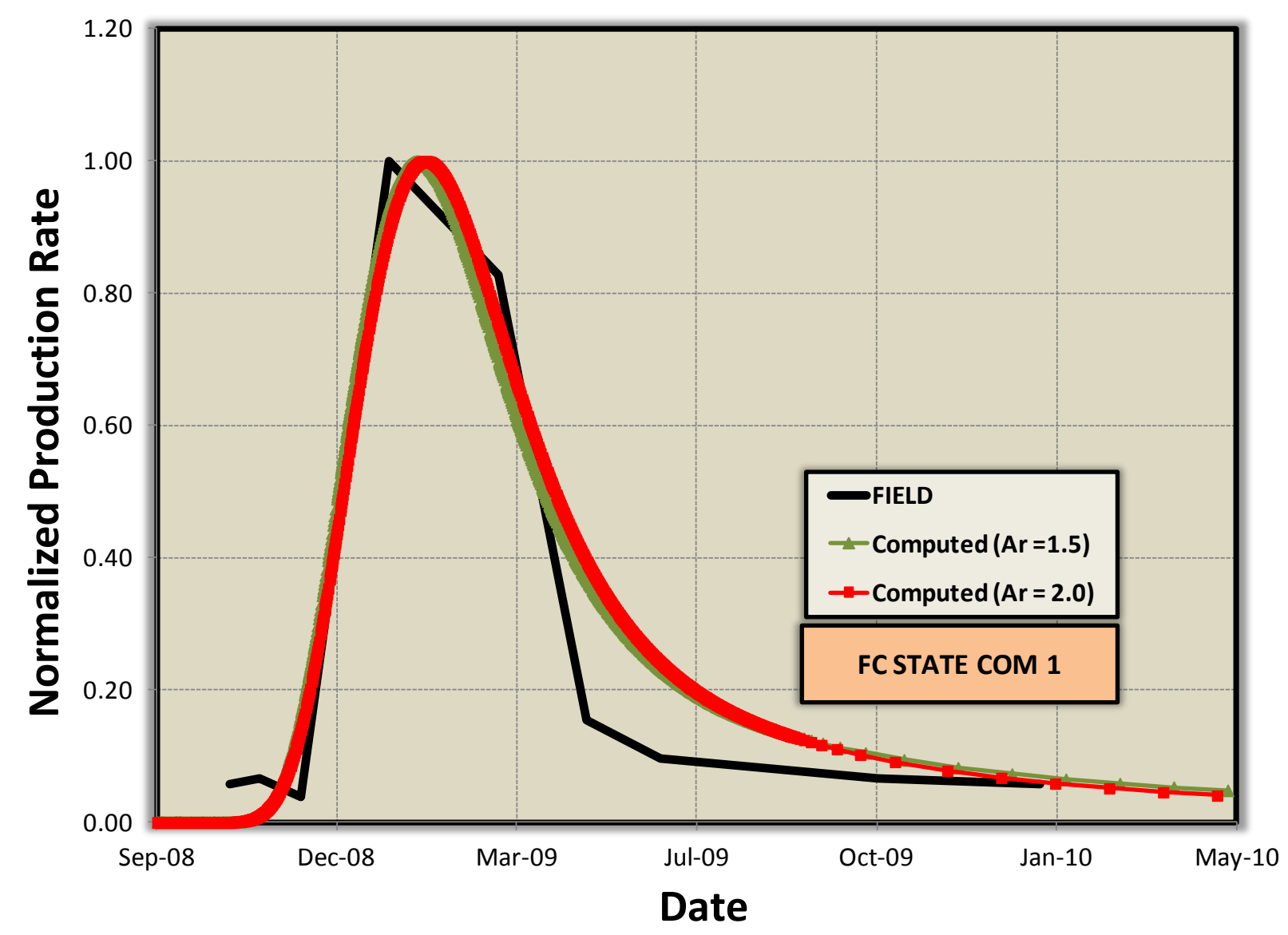

Figure 8.16: Simulated and Measured Tracer Production at FC State Com 1 


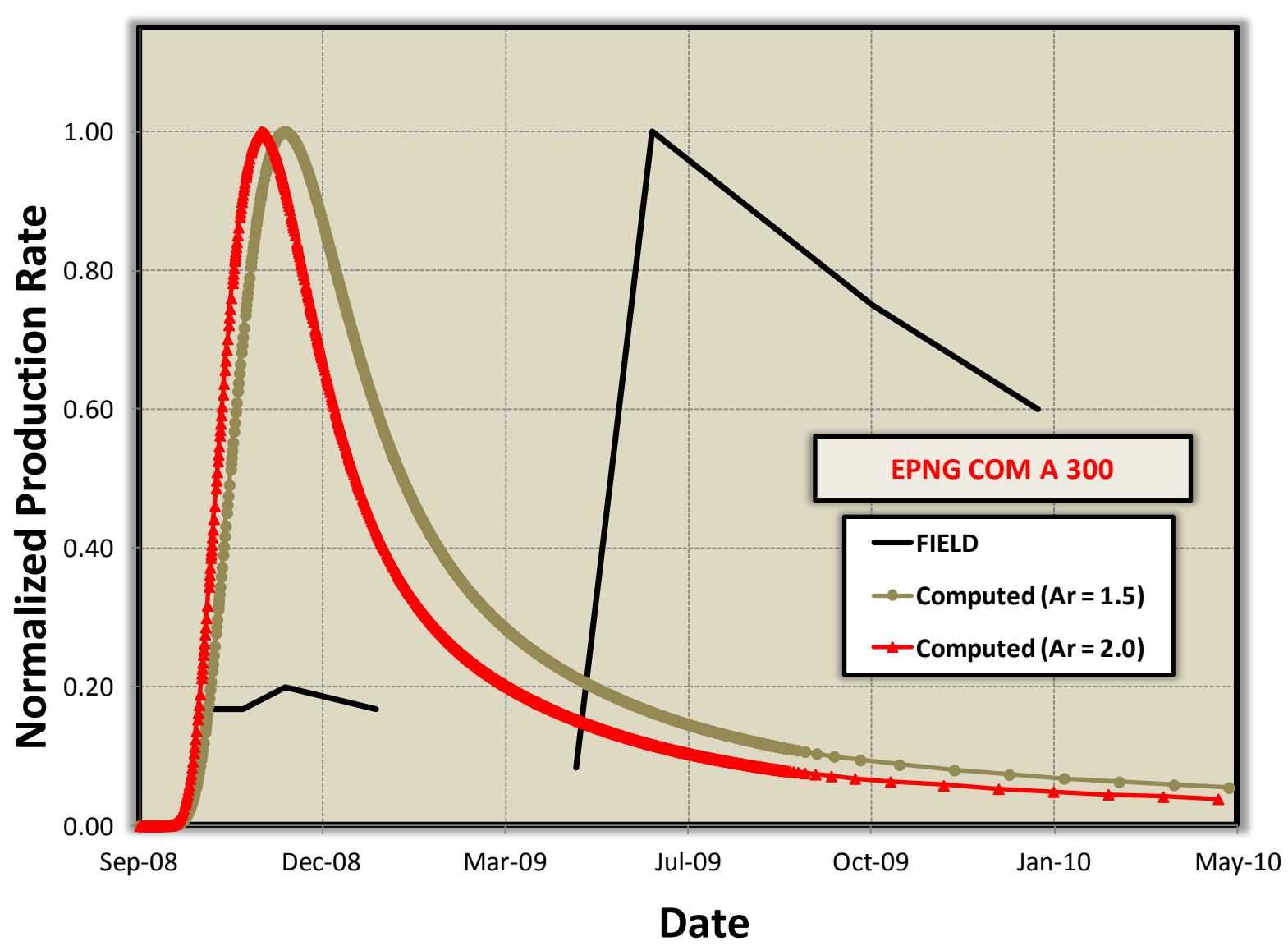

Figure 8.17: Simulated and Measured Tracer Production at EPNG Com A 300

The exact volume of tracer injected into the Pump Canyon reservoir is unknown. It is known that the volume of injected tracer is quite small in comparison to the carbon dioxide it is dissolved in. Since the volume of tracer in unknown, it was necessary to investigate the effects of injected tracer volume on tracer production at nearby wells. Figure 8.22 shows the results of this investigation and the influence of tracer injection volume. 




Figure 8.18: Influence of Volume of Injected Tracer on Relative Tracer Production at FC State Com 1 


\section{CHAPTER 9: SUMMARY AND CONCLUSIONS}

\section{1 - General Summary}

The Pump Canyon coalbed methane reservoir in the San Juan Basin in northern New Mexico was selected by the U.S. Department of Energy as a demonstration site for carbon sequestration into unmineable coal seams. The Pump Canyon demonstration site was designed to assess the suitability of such reservoirs for potential large scale injection projects. Over a period of 13 months starting in July 2009, roughly 18,000 tons of carbon dioxide was injected into the Pump Canyon reservoir. A wide variety of monitoring technologies were employed to monitor the reservoir response to injection. One part of the puzzle in understanding any reservoir is numerical modeling. Supplementing field operations with reservoir modeling adds up to a more detailed and informed view of a complicated geologic system.

Numerical modeling of the Pump Canyon coalbed methane reservoir was performed using a generalized swelling and shrinkage model integrated with an existing reservoir simulator, PSU-COALCOMP. This modifies reservoir simulator accounts for the effects of swelling and shrinkage of the coal matrix as discussed in Chapter 4. Objectives of the reservoir modeling study were to:

- Study the history of coalbed methane production in the study area

- Construct an appropriate reservoir model based on available geologic data

- Perform history matching to obtain estimates of unknown properties

- Model the injection of carbon dioxide into the reservoir to and the behavior of the reservoir system

- Monitor the movement of tracers injected into the reservoir to better understand the response of the reservoir system

- Investigate the swelling and shrinkage of coals and the impact of swelling and shrinkage on sequestration practices 


\section{2 - Conclusions of History Matching}

Overall the reservoir model created based on data from the Pump Canyon site compares fairly well with historical data. Reservoir production rates are comparable to field values for wells located all over the grid. Reservoir pressures produce a good match in comparison with field values. Similar pressure behavior in the reservoir suggests that the model is an accurate representation of the reservoir system.

Coal porosity and permeability are of great interest in determining the storage and injectivity of a reservoir. The history matching process is complicated and involves a variety of variables as discussed in Chapter 5, however a lot of the process boils down to determining porosity and permeability values. Getting a solid and realistic estimate for these values is critical. Estimated porosity values agree with reported values of less than $2 \%$ quite well and produce acceptable matches with historical data.

Modeling results suggest that the Pump Canyon reservoir is ready for carbon dioxide injection. Coalbed methane production from the reservoir has dropped off significantly from its peak period, and constantly lowering reservoir pressures ensure that the rates will continue to fall as the reservoir depletes over time. Water saturation levels in the reservoir are low enough to allow fluid movement through the cleat network of the coal, therefore injected fluids should be able to migrate through the same space. In combination with the existing high permeability of the region, the conditions of the Pump Canyon coalbed methane reservoir the potential for sequestration of carbon dioxide with the potential of long term injection.

\section{3 - Conclusions of Injection Modeling}

Injection modeling indicates that coal swelling around the injection point has a very large effect on the performance of the sequestration operation. The permeability of the coal in the area immediately around the injection point, as obtained through the history matching process is roughly $100 \mathrm{md}$. During injection of carbon dioxide, the coal permeability immediately around the injection point drops to approximately $1 \mathrm{md}$. The permeability of the coal is reduced to almost nothing due to the effects of sequestration induced swelling. This swelling is highly 
localized, however. Within roughly 100 feet on either side of the injection well, reservoir pressure drop to their pre-injection values and remain constant. All of the pressure applied to the fluid during injection is distributed in the area right around the injection well.

\section{4 - Conclusions of Tracer Modeling}

Field results and reservoir modeling both agree that tracers reach only the two production wells closest to the injection well. Simulated tracer production for the eastern well, FC State Com 1, matches up very well with field measured results. Both breakthrough time and relative tracer production are virtually identical for this well. The southwestern well, EPNG Com A 300, did not match up as well. Simulated breakthrough for this well occurred before it was measured in the field. This may be caused by some significant heterogeneity or geologic feature in that region of the study area that impedes fluid movement in comparison with the computed case.

While history matching and injection modeling both indicated that reservoir anisotropy was a factor in reservoir performance, it is tracer modeling that provides the most insight into the level of reservoir anisotropy. In this case, reservoir anisotropy alone does not account for the difference in production between simulations and field measured values. This may indicate that the cleat orientation in the coal seam isn't quite the same as that reported from nearby wells. This may also indicate heterogeneity within the coal seam.

\section{5 - Recommendations}

The Pump Canyon reservoir has promise for large scale sequestration and long term storage of carbon dioxide. This reservoir offers a large storage volume that could significantly reduce carbon dioxide emissions. Recommendations for future work on the Pump Canyon carbon sequestration site are:

- Convert several production wells to injection wells to help offset the effects of coal swelling by spreading out the injection volume over a larger area. 
- Investigate the influence of injection pressure on coal swelling at the field site. Perhaps a lower injection rate could cause less swelling and produce a higher injection volume in the long run.

- Develop a field test that can help determine the swelling and shrinkage parameters of a coal formation. There is little data available on this subject, yet is has a significant influence on reservoir behavior during injection. Being able to get a rough value for these parameters from core samples would be a great help in the reservoir modeling process.

- Continue injection of carbon dioxide at the Pump Canyon site. While the effects of coal swelling have reduced the injectivity of the reservoir, the long term benefits of the project outweigh any setbacks. There is a very large volume of potential storage space in this reservoir that can be feasibly utilized at present time with plenty of room for future expansion. 


\section{REFERENCES}

Bachu S., Bonijoly D., Bradshaw J., Burruss R., Holloway S., Christensen N. and Mathiassen O. (2007). $\mathrm{CO}_{2}$ storage capacity estimation: methodology and gaps. International Journal of Greenhouse Gas Control 1 (4), 403-443.

Bromhal, G.S., Sams, W.N., Jikich, S., Ertekin, T. and Smith, D.H. (2005). Simulation of $\mathrm{CO}_{2}$ sequestration in coal beds: The effects of sorption isotherms. Chemical Geology 217, 201-211.

Burruss, R. C. (2003). $\mathrm{CO}_{2}$ adsorption in coal seams as a function of rank and composition: a new task in USGS research on geologic sequestration of $\mathrm{CO}_{2}$. Coal-Seq II, Washington, D.C., U.S.A.

Cervik, J. (1969). Behavior of coal-gas reservoirs. Bureau of Mines Technical Progress Report10, Methane Control Program, U.S. Department of the Interior, April.

Chikatamarla L. Cui, X. and Bustin, R.M. (2004). Implications of volumetric swelling/shrinkage of coal in sequestration of acid gases. Proceedings of International Coalbed Symosium, Alabama, U.S.A.

Clarkson, C.R., Pan, Z., Palmer, I. and Harpalani, S. (2008). Predicting sorption-induced strain and permeability depletion for CBM reservoirs. SPE paper 114778. SPE Annual Technical Conference and Exhibition, Denver, Colorado, U.S.A., 21-24 September.

Gale, J. and Freund, P. (2001). Coal bed methane enhancement with $\mathrm{CO}_{2}$ sequestration: worldwide potential. Environmental Geoscience 8(3), 210.

IPCC. (2007). Intergovernmental Panel on Climate Change, www.ipcc.ch.

Karacan, C. O. (2007). Swelling induced volumetric strains internal to a stressed coal associated with $\mathrm{CO}_{2}$ sorption. International Journal of Coal Geology 72, 209-220.

Koperna, G., Oudinot, A. Y., McColpin, G.R., Liu, N., Heath, J.E., Wells, A. and Young, G.B. (2009). $\mathrm{CO}_{2}$-ECBM/storage activities at the San Juan basin's Pump Canyon test site. SPE paper 124002, Proceedings of the SPE Annual Technical Conference and Exhibition, New Orleans, Louisiana, U.S.A., October 4-7.

Langmuir, I. (1918). The adsorption of gases on plane surface of glass, mica, and platinum. Journal of American Chemical Society 40(9), 1361-1403.

Mazumder, S., Siemons, N. and Wolf, K. H. $\left(2006^{c}\right)$. Differential swelling and permeability changes of coal in response to $\mathrm{CO}_{2}$ injection for enhanced coalbed methane. Proceedings of the International Coalbed Methane Symposium, Tuscaloosa, Alabama, U.S.A.

McElhiney, J.E., Koenig, R.A., and Sccraufnagel, R.A. (1989). Evaluation of coalbed-methane reserves involves different techniques. Oil and Gas Journal, 63-72. 
Mitra, A. and Harpalani, S. (2007). Modeling incremental swelling of coal matrix with $\mathrm{CO}_{2}$ injection in coalbed methane reservoirs. Proceedings of the SPE Eastern Regional Meeting, Lexington, Kentucky, U.S.A.

Oudinot, A. Y., Schepers, K.C., Gonzalez R.J. and Reeves, S.R. (2008). An integrated reservoir characterization, geostatistical analysis, optimized history-matching and performance forecasting study of the 9-section, 30-well Pump Canyon $\mathrm{CO}_{2}$-ECBM/sequestration demonstration site, San Juan Basin, New Mexico. Paper 0804. Proceedings of International Coalbed and Shale Gas Symposium.

Palmer, I. and Manosoori, J. (1996). How permeability depends on stress and pore pressure in coalbeds: A new model. SPE paper 36737. Proceedings of the SPE Annual Technical Conference and Exhibition, Denver, Colorado, U.S.A., October, 6-9.

Rogers, R. E. (1994). Coalbed Methane: Principles and Practice. PTR Prentice Hall, New Jersey.

Shi, J.Q. and Durucan, S. (2003). Modelling of enhanced methane recovery and $\mathrm{CO}_{2}$ sequestration in deep coal seams: The impact of coal matrix shrinkage/swelling on cleat permeability. Paper 0343, Proceedings of the International Coalbed Symposium.

Siriwardane, H. J., Bowes, B.D., Bromhal, G.S., Gondle, R.K., Wells, A.W. and Strazisar, B.R. (2012). Modeling of $\mathrm{CBM}$ production, $\mathrm{CO}_{2}$ injection, and tracer movement at a field $\mathrm{CO}_{2}$ sequestration site. International Coalbed Journal of Coal Geology, Volume 96-97, 120-136.

Siriwardane, H. J., Smith, D. H. and Gorucu, F. (2006). Shrinkage and swelling of coal during coalbed methane production or geologic sequestration of carbon dioxide. Proceedings of the international Coalbed Methane Symposium, Tuscaloosa, Alabama, U.S.A.

Siriwardane, H.J., Gondle, R. and Smith, D.H. (2009). Shrinkage and swelling of coal induced by desorption and sorption of fluids: theoretical model and interpretation of a field project. International Coalbed Journal of Coal Geology, Volume 77 (1-2), 188-202, January.

Smith, D.H., Bromhal, G., Sams, W.N., Jikich, S. and Ertekin, T. (2004). Simulating carbon dioxide sequestration/ECBM production in coal seams: Effects of permeability anisotropies and the diffusion-time constant. SPE paper 84423. Proceedings for the SPE Annual Technical Conference and Exhibition, Denver, Colorado, U.S.A., October 5-8.

Schwerer, F.C. and Pavone, A.M. (1984). Effect pf Pressure-Dependant Permeability on WellTest Analyses and Long-Term Production of Methane from Coal Seams. Proceedings of the Unconventional Gas Recovery Symposium, Pittsburgh, Pennsylvania, U.S.A.

Stone, W.J., Lyford, F.P., Frenzel, P.F., Mizell, N.H. and Padgett, E.T. (1983). Hydrogeology and water resources of San Juan Basin, New Mexico. New Mexico, Bureau of Mines and Mineral Resources, Hydrologic Report 6, pp. 70. 
U.S. D.O.E. (2007). Carbon Sequestration Atlas of the United States and Canada. www.netl.doe.gov

Winschel, R.A. and Scandrol, R.O. (2007). Enhanced coal bed methane production and sequestration of $\mathrm{CO} 2$ in unmineable coal seams. Presentation at "Unconventional Plays and Research Needs for Appalachian Basin Small Producers" Meeting, NRCCE (WVU), Morgantown, February, 15.

www.CO2now.org

Www.octane.nmt.edu

www.pge.com

www.southwestcarbonpartnership.org

www.teachcoal.org 